\title{
REPORT OF THE TASK FORCE ON COLLISION HALL LIMITATIONS
}

\author{
SSC Central Design Group* \\ c/o Lawrence Berkeley Laboratory \\ Berkeley, California 94720
}

April 1987

\section{DISCLAIMER}

\begin{abstract}
This report was prepared as an account of work sponsored by an agency of the United States Government. Neither the United States Government nor any agency thereof, nor any of their employees, makes any warranty, express or implied, or assumes any legal liability or responsibility for the accuracy, completeness, or usefulness of any information, apparatus, product, or process disclosed, or represents that its use would not infringe privately owned rights. Reference herein to any specific commercial product, process, or service by trade name, trademark, manufacturer, or otherwise does not necessarily constitute or imply its endorsement, recommendation, or favoring by the United States Government or any agency thereof. The views and opinions of authors expressed herein do not necessarily state or reflect those of the United States Government or any agency thereof.
\end{abstract}

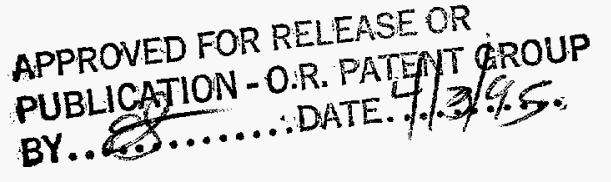

* Operated by Universities Research Association for the U.S. Department of Energy 



\section{DISCLAIMER}

Portions of this document may be illegible in electronic image products. Images are produced from the best available original document. 


\section{Executive Summary}

The Task Force on Collision Hall Limitations met March 23-26, 1987, to obtain a greater understanding of the civil construction requirements for a large scale model SSC detector and to identify limitations, if any, on overall detector scale and individual detector components that may result from civil construction limitations. To this purpose the Task Force studied civil construction techniques and limitations for both deep sites and surface or near surface sites, developed limits and criteria for model detector assembly and servicing, developed a model detector assembly scenario, and estimated an overall schedule from initiation of the design of the experimental hall complex to the completion of the assembly of the model detector. Our conclusions apply only to facilities required to house experiments of the scale of the model detector studied.

From our studies it is apparent that the experimental hall complex required for SSC-scale detectors can be constructed under a variety of assumptions regarding the eventual SSC site. There may be significant differences in the schedule and the cost of the experimental hall complex between surface and deep underground locations, with the deep underground, in general, being more expensive and requiring a longer time for construction. The difference in cost and schedule for the experimental facilities for housing the model detector between a surface site and a deep underground site may amount to $\$ 25 \mathrm{M}$ and two years.

For the very large experimental hall considered here two limitations emerged. In order to use prudent and cost effective civil construction techniques, a free span of $30 \mathrm{~m}$ or less should be used in planning underground caverns in rock. The maximum depth for near vertical open cut construction is $30-45 \mathrm{~m}$. If the open excavation can be sloped or benched without restrictions from the size of surface activities, an open cut may be considerably deeper. The minimum depth for the top of a $30 \mathrm{~m}$ span cavern excavated in rock is set by a requirement for $30 \mathrm{~m}$ or more of competent rock above the crown to support the overburden. Note that the ground surface and the top of competent rock may not necessarily coincide. These requirements may result in a range of depths which is undesirable for siting experimental halls. These requirements may also place constraints on the elevation of the SSC tunnel itself in the vicinity of the interaction regions.

Given the physical scale of the model detector considered by the Task Force, construction of the complete model detector in an assembly area with subsequent movement into an on-beam position is not desirable and not feasible in a cost effective manner. A major part of the model detector, the muon system, should be built in place on the beamline. The weight of the model detector will require a deep foundation for support. For 
detectors of more modest scale, these comments may not apply but such detectors were not examined by the Task Force.

From our study, the time required to design and construct the experimental hall complex and to assemble the model detector approaches and may even exceed the time required to complete the accelerator complex. One should therefore examine carefully if detectors of the scale of the model detector are optimal and, if they are, should encourage a "fast start" to the design and construction of the experimental facilities and of such detectors. 


\section{Table of Contents}

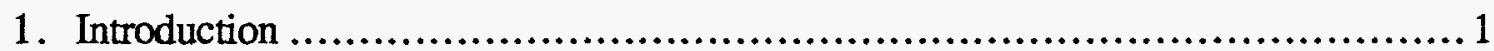

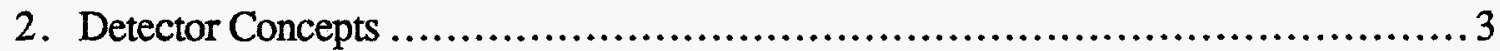

3. Civil Construction Techniques and Limitations..................................8

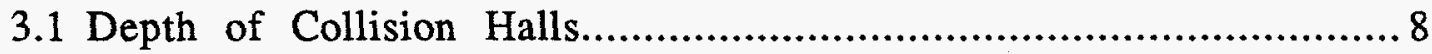

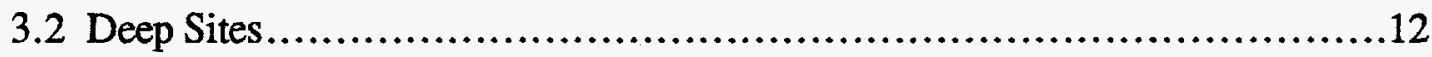

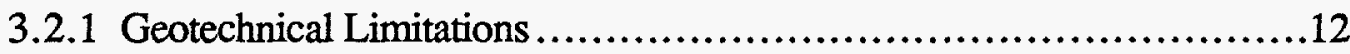

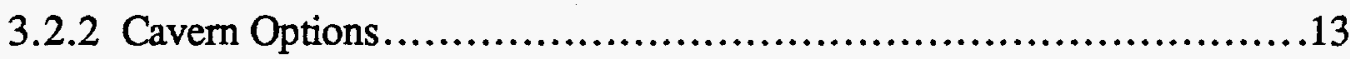

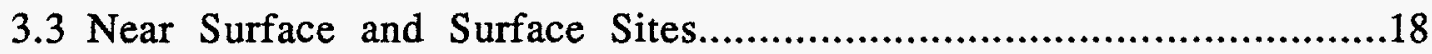

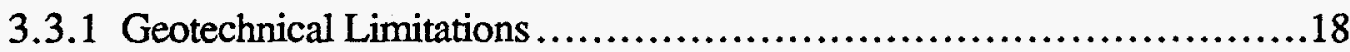

3.3.2 Hall Options ....................................................22

3.4 Collision Hall Dimensions, Costs, and Schedules...........................23

3.4.1 Typical Hall Dimensions ...........................................23

3.4.2 Typical Collision Hall Schedules..............................................24

3.4.3 Comparative Costs of Collision Halls ....................................25

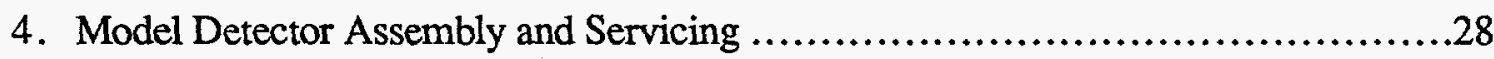

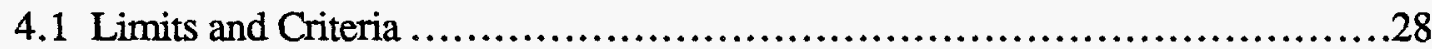

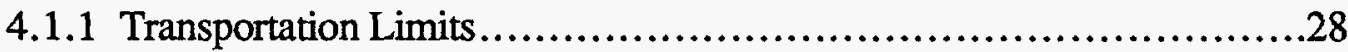

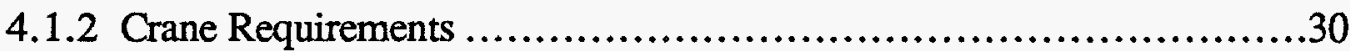

4.1.3 Access to Experimental Area......................................................31

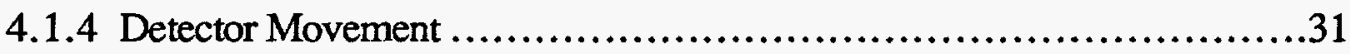

4.1.5 Preassembly Space for Experiments...............................34

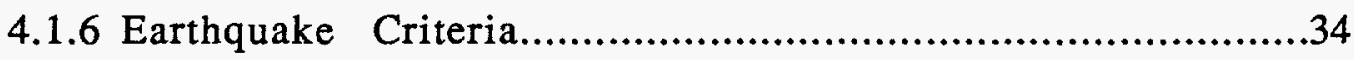

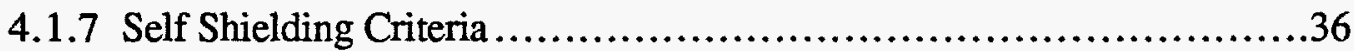

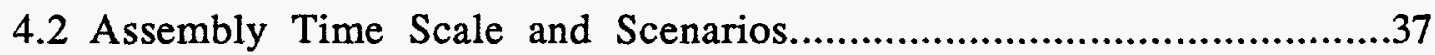

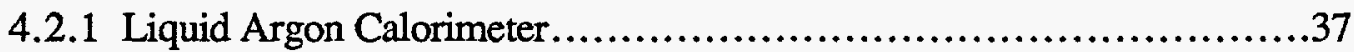

4.2.2 Superconducting Solenoid Magnet...........................................38

4.2.3 Muon Detection System .............................................39

4.3 Critical Path Analysis of Model Detector Assembly Scenario ..................42

4.3.1 Critical Path Analysis of the Liquid Argon Calorimeter Assembly........43

4.3.2 Critical Path Analysis of Magnet Assembly.................................44

4.3.3 Critical Path Analysis for the Muon Detection System ...................44

4.3.4 Critical Path Analysis for Electronics Installation and Testing..............45

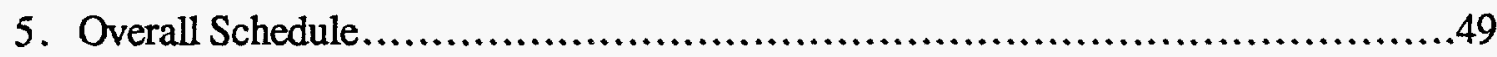

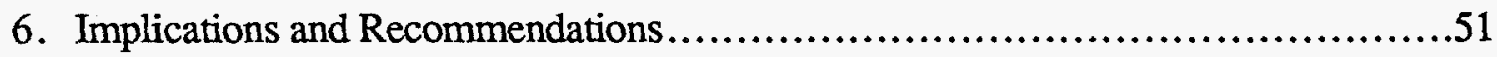

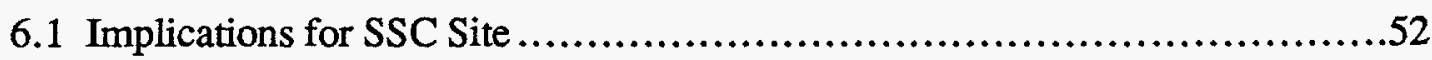

6.2 Implications for Experimental Halls .....................................53 


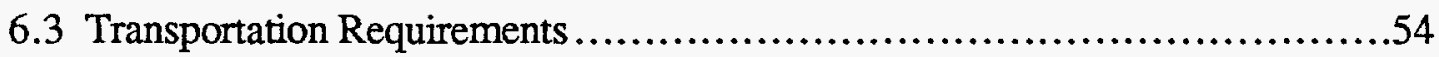

6.4 Civil Construction Schedule and Cost.......................................54

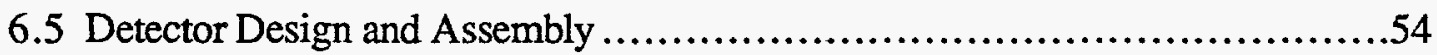

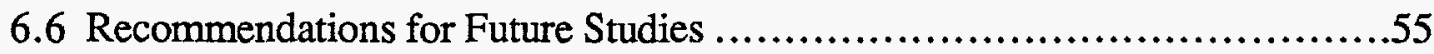

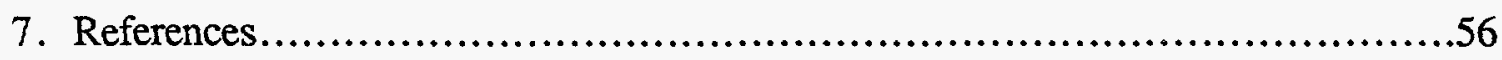

Appendix A - Task Force Participants......................................................57

Appendix B - Report of the Snowmass ' 86 IR Working Group......................59

Appendix C-Experience at LEP....................................................71

Appendix D - Radiation Levels in the Collision Hall ..............................75 


\section{Introduction}

Many of the large, $4 \pi$ detectors that have been suggested for the SSC are substantially larger and heavier than any similar detector now in operation or planned for operation in the near future. In order to assess the impact of such detectors on the civil construction requirements for the SSC, a model $4 \pi$ detector was devised based on previous efforts at the Snowmass Workshops ${ }^{1}$ and the efforts of the panel on a Cost Estimate of Initial SSC Experimental Equipment.$^{2}$ It should be emphasized that this model detector does not represent a complete design, but has been devised solely for studies related to exploring the limits of the facilities required to house and service such detectors.

The overall goal of the Task Force was to obtain a greater understanding of the civil construction requirements for detectors of the scale presented in the model detector and to identify limitations, if any, on overall detector scale (size or weight) and individual detector component (size or weight) that may result from civil construction limitations. It was obviously important to understand the dependence of such requirements and possible limitations on the characteristics of a potential SSC site.

\section{Charges to the Task Force}

Below we outline the charges presented to the Task Force members. Members of the Task Force are listed in Appendix A. The Task Force was requested to produce a written report on their conclusions by June 1, 1987.

Discuss and describe possible limitations arising from excavations of halls, caverns, shafts and tunnels to house the model $4 \pi$ detector for the SSC for both an underground location and a near surface location. Specific items to be addressed include:

(a) What are the restrictions on underground cavern size, particularly free span, as a function of depth and rock characteristics?

(b) What additional restrictions, if any, result from the combined construction of a collision hall and an adjacent assembly hall with connecting doorway in an underground location? What, if any, are the restrictions on the size of the doorway connecting the collision and assembly halls?

(c) What are the restrictions on vertical shaft size and location (with respect to the collision hall) for an underground location as a function of depth?

(d) What is the role of access ramps during construction of the hall and during operation?

(e) What are the restrictions on characteristics of the hall floor to support the detector and possible movement of significant detector components? What are the implications of detector movement for the alignment of interaction region magnets? 
(f) What is the nature of the hall construction for a near surface location?

(g) What are the cost implications of a near surface location compared to an underground location?

(h) Evaluate the relative merits of construction in place of the detector (collision hall only) and of construction of all or part of the detector in an assembly hall or area, with subsequent movement into the collision hall.

(i) Develop the appropriate schedule for the construction of the IR hall facilities. 


\section{Detector Concepts}

At the present time definitive, complete descriptions of potential large detectors for the SSC do not exist. We therefore must rely on "workshop level " studies to attempt to define the physical parameters of the large detectors for the SSC. A summary of extant large detector concepts from various workshops in the last 2-3 years is given in Table 2.1. Very crudely one may characterize the central portions of these detectors as having dimensions up to about $25 \mathrm{~m}$ in length (along the beam) and about $20 \mathrm{~m}$ in height and width. Additional forward/backward detectors may be present. Weights up to about 50,000 tons are possible. The dimensions and other characteristics of some of the detectors listed in Table 2.1 are given in Appendix B, the Report of the IR Working Group at the Snowmass 1986 meeting and in Reference 2.

For the purposes of this Task Force it was felt necessary to restrict the discussion to a representative model detector to focus the deliberations. We therefore devised a model detector based on the Model B $4 \pi$ detector discussed in Reference 2 .

This model detector is shown in Fig. 2.1, along with the weights of the indicated subsections. More detailed views of the model are given in Fig. 2.2. A more complete breakdown of the component weights of the model are given in Table 2.2. It serves no useful purpose to describe in detail the components of the model detector, since we are primarily interested in piece sizes, weights and dimensions rather than functionality. Additional description of comparable detectors is given in Reference 2.

We emphasize that this model does not represent an optimal or complete design and was devised solely for the purposes of the Task Force. It is also likely that this model represents an upper bound on weight and an approximate upper bound on size.

TABLE 2.1. Examples of detector concepts from workshops and reports.

\begin{tabular}{ll}
\hline \hline Solenoid based - Model A & SSC-SR-1023 + Snowmass 1986 Proceedings \\
Solenoid based - Model B & SSC-SR-1023 + Snowmass 1986 Proceedings \\
Solenoid based - LHC studies & Workshop on Future Accelerators, Jan. 1987 \\
Non-magnetic - Iron Muon & SSC-SR-1023 \\
Non-magnetic - D1 & Snowmass 1984 Proceedings \\
Precision muon spectrometer - L3+1 & SSC-SR-1023 + Snowmass 1986 Proceedings \\
Muon spectrometer - super solenoid & UM HE 86-32, 11/86 \\
Upgrade - CDF & SSC-SR-1023 \\
Upgrade-D0 & SSC-SR-1023 \\
Upgrade-UA1 & SSC-SR-1023 \\
\hline \hline
\end{tabular}




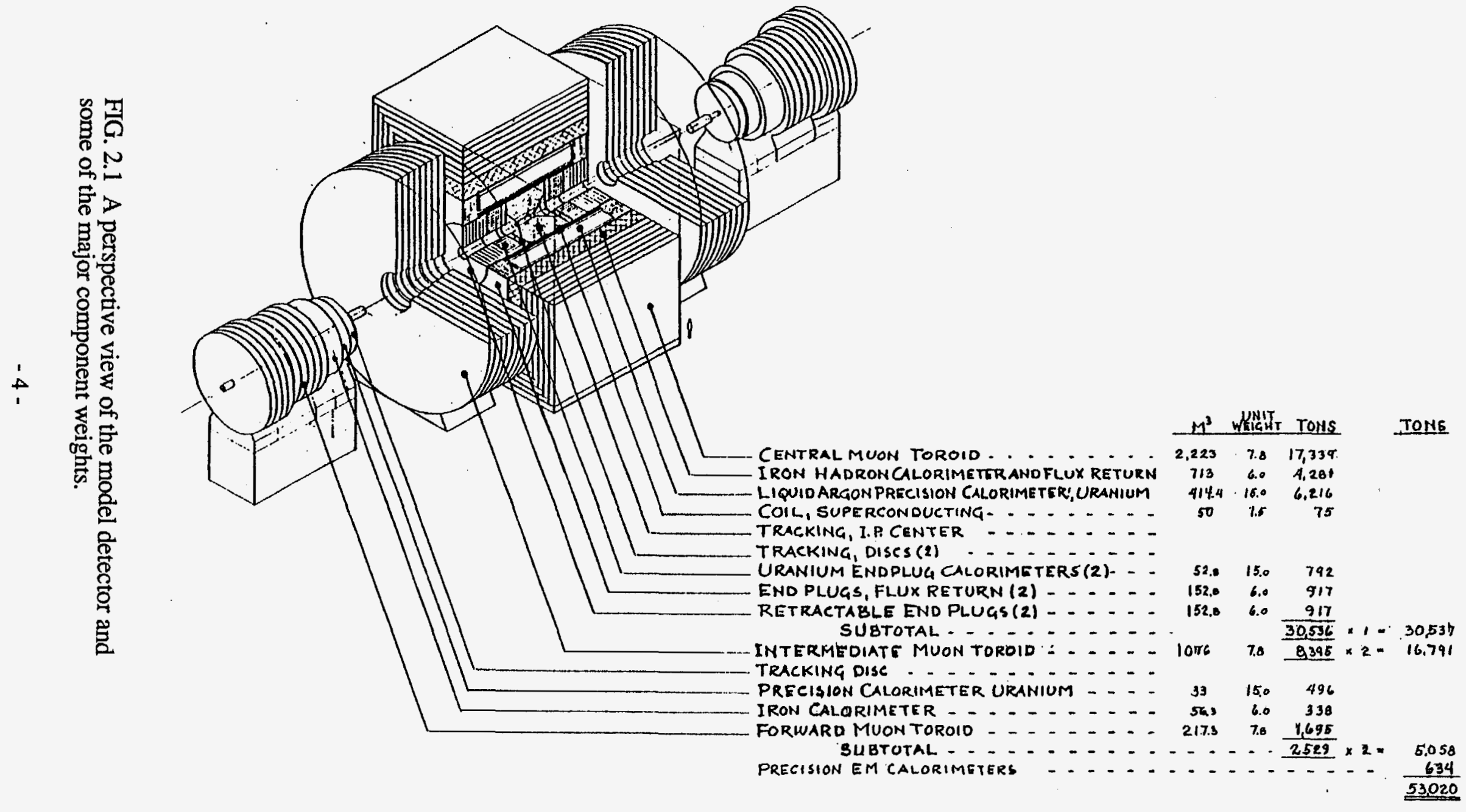



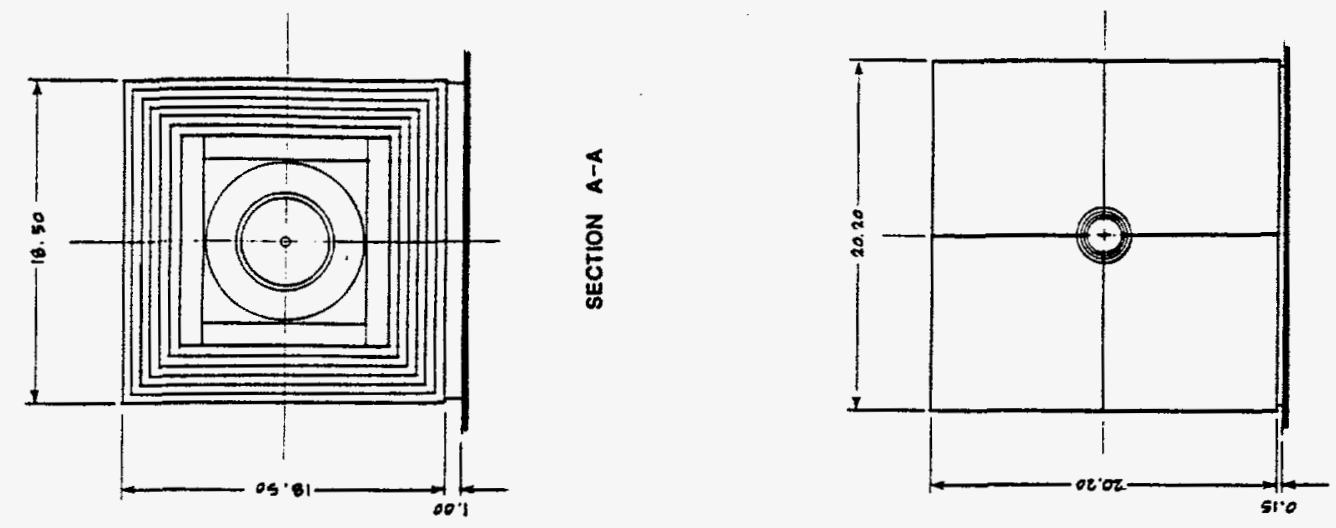

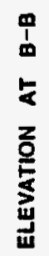
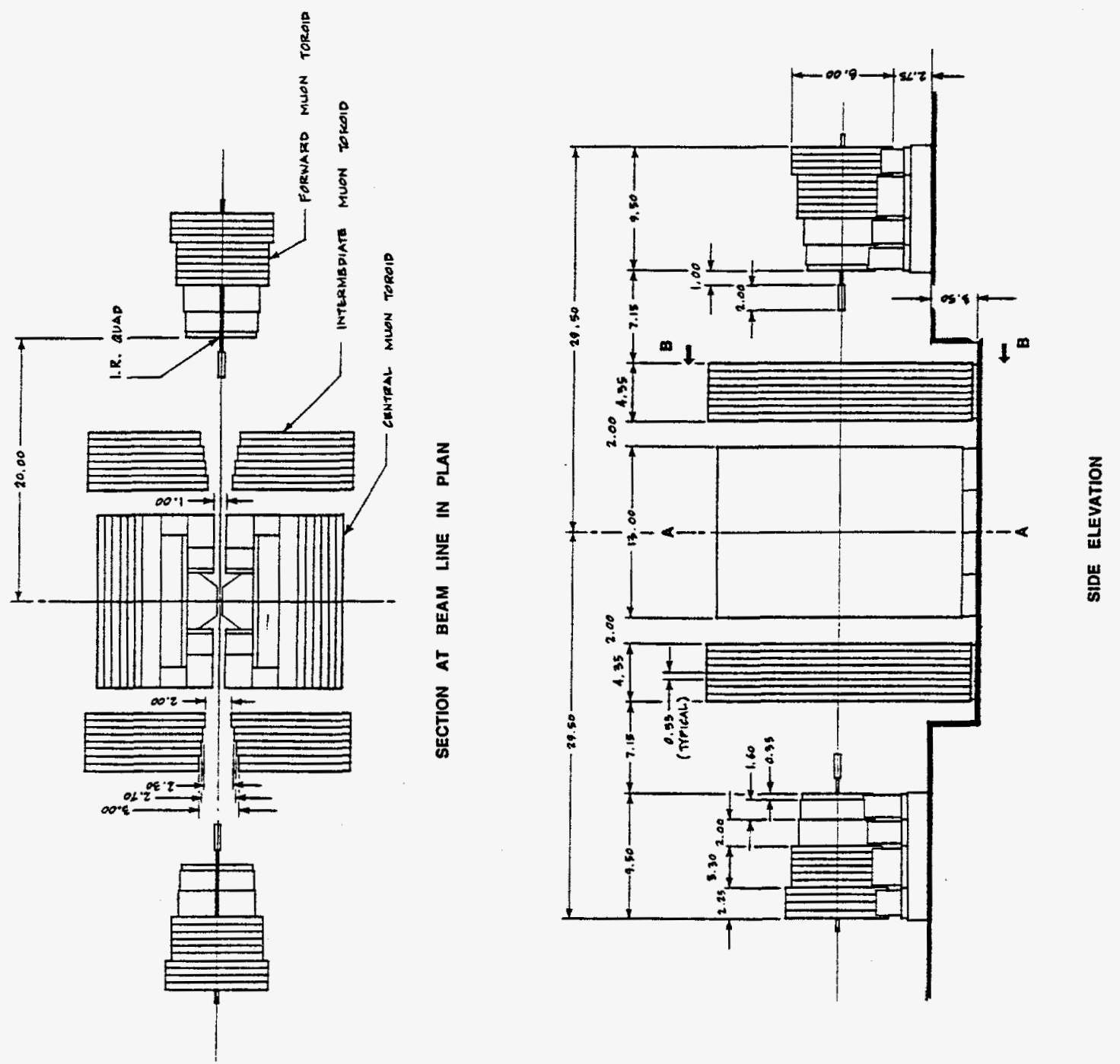

FIG. 2.2 Plan, elevation and section views of the model detector 
Table 2.2 Model Detector dimensions and weights.

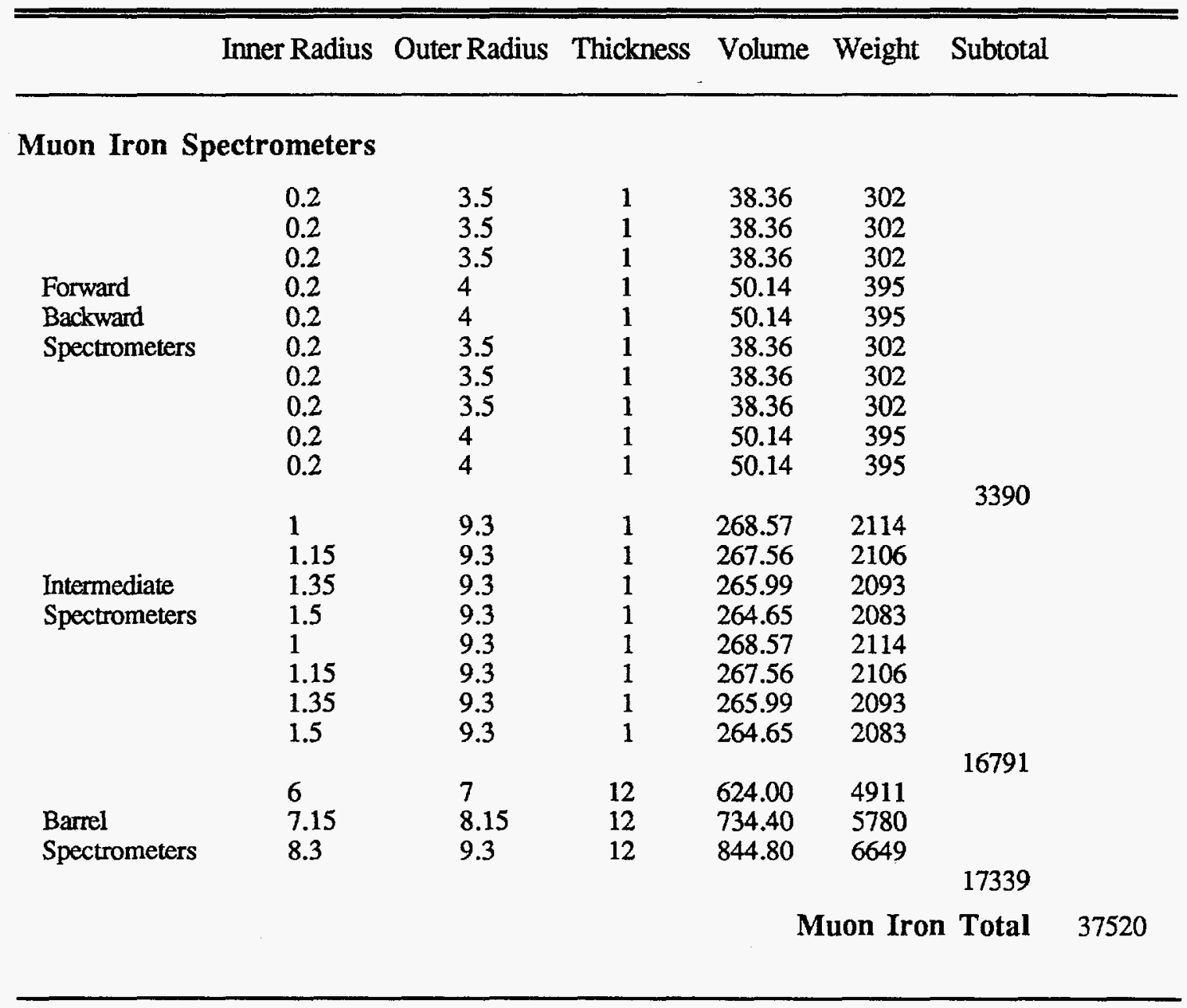

\section{Iron Hadron Calorimeter}

Average density is taken to be $\left(\mathrm{gm} / \mathrm{cm}^{3}\right) \quad 6$

$\begin{array}{lllrrrr}\text { Forward } & 0.2 & 3 & 2 & 56.30 & 338 & \\ & 0.2 & 3 & 2 & 56.30 & 338 & \\ \text { Endcap and } & 0.5 & 4.4 & 2 & 152.88 & 917 & 676 \\ \text { Flux Return } & 0.5 & 4.4 & 2 & 152.88 & 917 & \\ & & & & & & 1835 \\ \text { Barrel and } & 4.4 & 5.85 & 12 & 713.40 & 4280 & \\ \text { Flux Return } & & & & & & 4280\end{array}$

Iron Hadron Calorimeter Total 6791 


\section{Precision EM Calorimeters}

Average density assumed is $\left(\mathrm{gm} / \mathrm{cm}^{3}\right) \quad 10$

\begin{tabular}{|c|c|c|c|c|c|}
\hline Forward & $\begin{array}{l}0.2 \\
0.2\end{array}$ & $\begin{array}{l}2.75 \\
2.75\end{array}$ & $\begin{array}{l}0.2 \\
0.2\end{array}$ & $\begin{array}{l}4.73 \\
4.73\end{array}$ & $\begin{array}{l}47 \\
47\end{array}$ \\
\hline Endcap & $\begin{array}{l}0.5 \\
0.5\end{array}$ & $\begin{array}{l}2.5 \\
2.5\end{array}$ & $\begin{array}{l}0.2 \\
0.2\end{array}$ & $\begin{array}{l}3.77 \\
3.77\end{array}$ & $\begin{array}{l}38 \\
38\end{array}$ \\
\hline Barrel & 2.8 & 3 & 10 & 46.40 & 464 \\
\hline
\end{tabular}

Precision EM Total

Precision HAD Calorimeters

Average density assumed is $\left(\mathrm{gm} / \mathrm{cm}^{3}\right) \quad 15$

\begin{tabular}{|c|c|c|c|c|c|}
\hline Forward & $\begin{array}{l}0.2 \\
0.2\end{array}$ & $\begin{array}{l}2.75 \\
2.75\end{array}$ & $\begin{array}{l}1.4 \\
1.4\end{array}$ & $\begin{array}{l}33.09 \\
33.09\end{array}$ & $\begin{array}{l}496 \\
496\end{array}$ \\
\hline Endcap & $\begin{array}{l}0.5 \\
0.5\end{array}$ & $\begin{array}{l}2.5 \\
2.5\end{array}$ & $\begin{array}{l}1.4 \\
1.4\end{array}$ & $\begin{array}{l}26.39 \\
26.39\end{array}$ & $\begin{array}{l}396 \\
396\end{array}$ \\
\hline Barrel & 3 & 4.4 & 10 & 414.40 & 6216 \\
\hline
\end{tabular}

Precision HAD Total 8000

\section{Superconducting Coil}

Average density assumed is $\left(\mathrm{gm} / \mathrm{cm}^{3}\right) \quad 1.5$

$\begin{array}{lllclll}2.5 & 2.8 & 10 & 49.95 & 75 \\ & & & & \text { Superconducting } & \text { Coil } & \text { Total }\end{array}$

\section{Tracking Chambers}

Weight of tracking chambers is negligible 


\section{Civil Construction Techniques and Limitations}

\subsection{Depth of Collision Halls}

In the absence of a site, planning for the experimental areas at the SSC must assume that the collision halls may be at any depth, from the surface to several hundred meters below the surface. This is illustrated in Fig. 3.1. The specification of a minimum of $9 \mathrm{~m}$ of cover for shielding ${ }^{3}$ above the collider ring tunnel sets a minimum depth for the collision hall. The maximum depth is not well-defined, because of logistical, geological and construction considerations.

Practical limitations of construction techniques divide consideration of experimental halls between near surface sites, constructed by open cut techniques from the surface and deep sites excavated in rock. The sides of an open cut must be sloped at angles small enough to maintain stability, or otherwise reinforced against driving forces and earth pressures which occur in the surrounding ground because of the excavation. If vertical or near vertical (slope $\geq 60^{\circ}$ ) sides are required to comply with surface restrictions, then the practical limit for the depth of open cut construction in soil is approximately $30 \mathrm{~m} .^{\dagger}$ Approximately $15 \mathrm{~m}$ additional depth is achievable, if the excavation is into bedrock. This gives a maximum depth to the bottom of the cut of approximately $45 \mathrm{~m}$. For conceptual design, the maximum depth of a vertical or near vertical open cut entirely in rock may also be taken as $45 \mathrm{~m}$.

A minimum depth for a cavern excavated in rock is set by a requirement for sufficient competent rock above the crown of the excavation to support the overburden. The additional depth to invert is comprised of the height of the detector and its support structures, clearance between the top of the detector and the crane hook, the height of the crane bridge and trolley, and the height of the arch forming the crown.

For very large experimental halls, such as considered here, this quantization of depth between the near-surface and deep locations results in a range of depths in which it is not desirable to site the halls, or for which hall construction is only possible with a considerable penalty in cost and schedule. For a detector the size of the model detector, the height of the cavern to house it is $42 \mathrm{~m}$. For a $30 \mathrm{~m}$ span, an additional $30 \mathrm{~m}$ of competent rock is required above the crown, as discussed in Sec. 3.2.1.

The minimum depth to invert, then, assuming no soil cover over the rock, is $72 \mathrm{~m}$, or about $60 \mathrm{~m}$ to beam height. The corresponding maximum depth to beam for the near-surface site is about $33 \mathrm{~m}$. So, there is an undesirable zone for the beam height near the large hall of approximately $30 \mathrm{~m}$. This is illustrated in Fig. 3.2 .

$\dagger$ In soil, the total force required for horizontal equilibrium of vertical cuts increases roughly in proportion to the square of the depth. At depths exceeding 20 to $30 \mathrm{~m}$, support requirements add substantially to the cost of construction. 
It should be recognized that the foregoing observation applies to those conditions for which vertical or near vertical sides are required in open cuts. If an excavation can be sloped or benched without restrictions because of surface width, then an open cut may be considerably deeper than $45 \mathrm{~m}$ in both soil and rock. Under these conditions, the concept of an undesirable region will not apply, although the relative cost and environmental impact of a deep, sloped excavation will need careful evaluation.

The total weight of the model detector is estimated at approximately 50 kilotons. The bearing pressure resulting from distributing this weight over the projected area of the detector, approximately $20 \times 20 \mathrm{~m}^{2}$, is 125 tons $/ \mathrm{m}^{2}$ (23.3 ksf). This is within the limits of allowable pressure for most types of rock, but not for soils. For collision halls not bearing on rock, it is likely that this weight will require a deep foundation for support. This may place a restriction on the depth to rock below the collision hall.

The existence of undesirable region for the beam elevation in the vicinity of the large detector halls, plus the requirement that the model detector be supported on rock, implies that, in siting the SSC, the IRs be located first and then the tunnel orientation examined. 


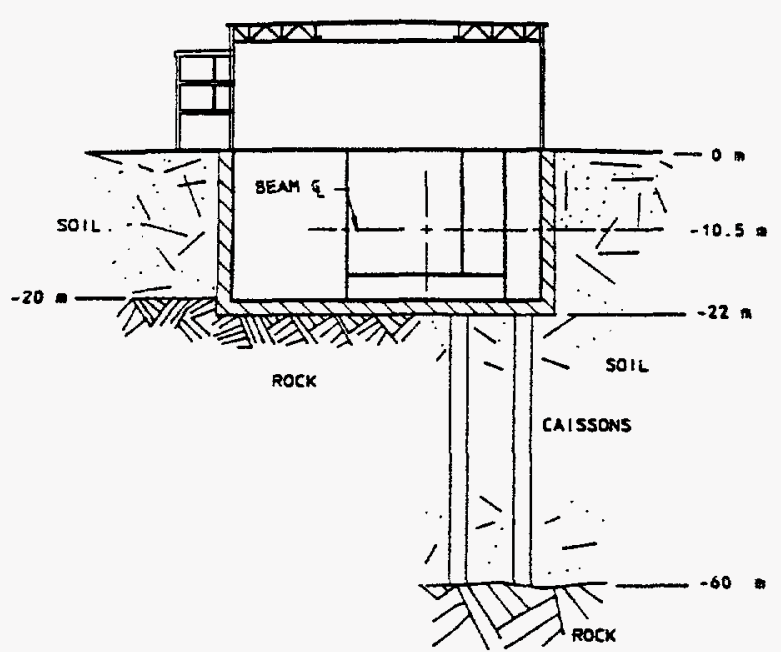

SURFACE - SELF-SHIELDED

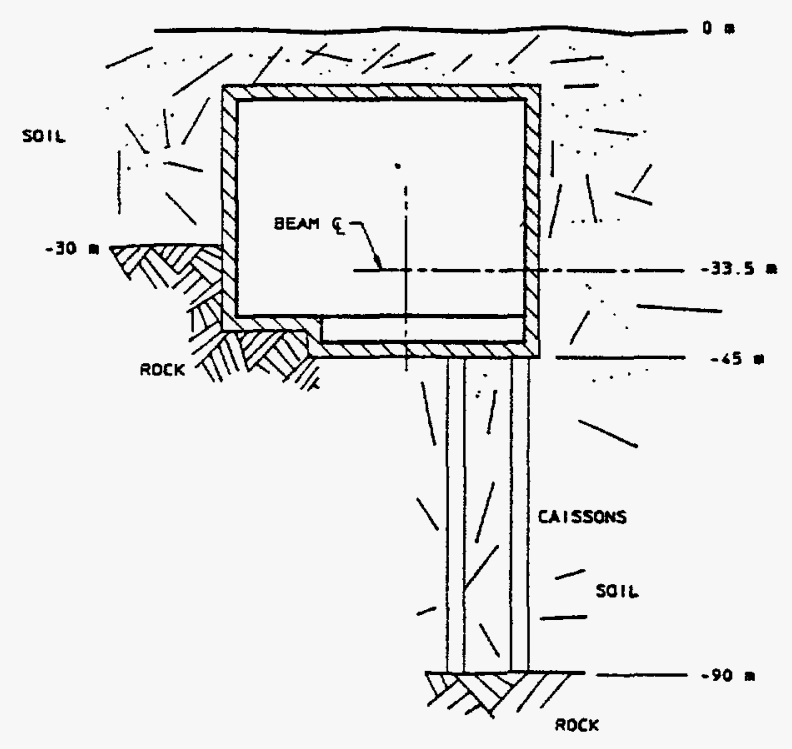

NEAR SURFACE - SHIELDED

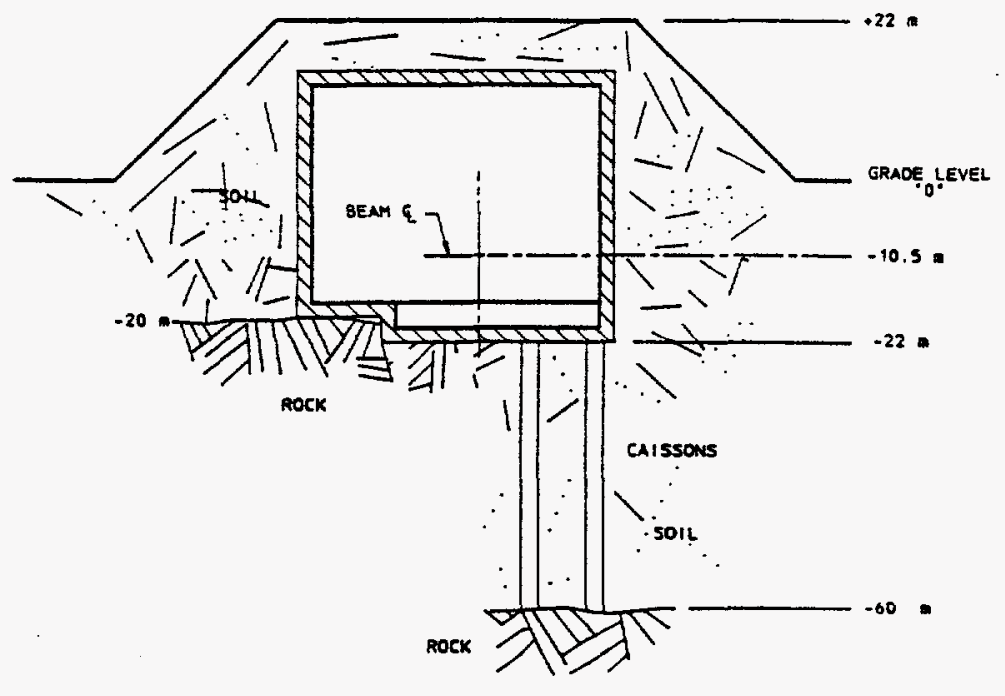

SURFACE - SHIELDED
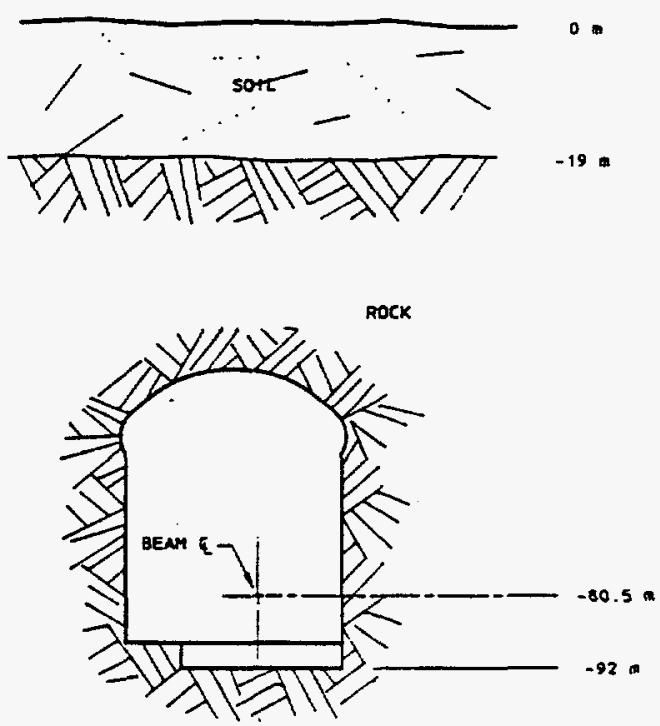

DEEP ROCK - SHIELDED

FIG. 3.1 The various options for depth of experimental halls. 


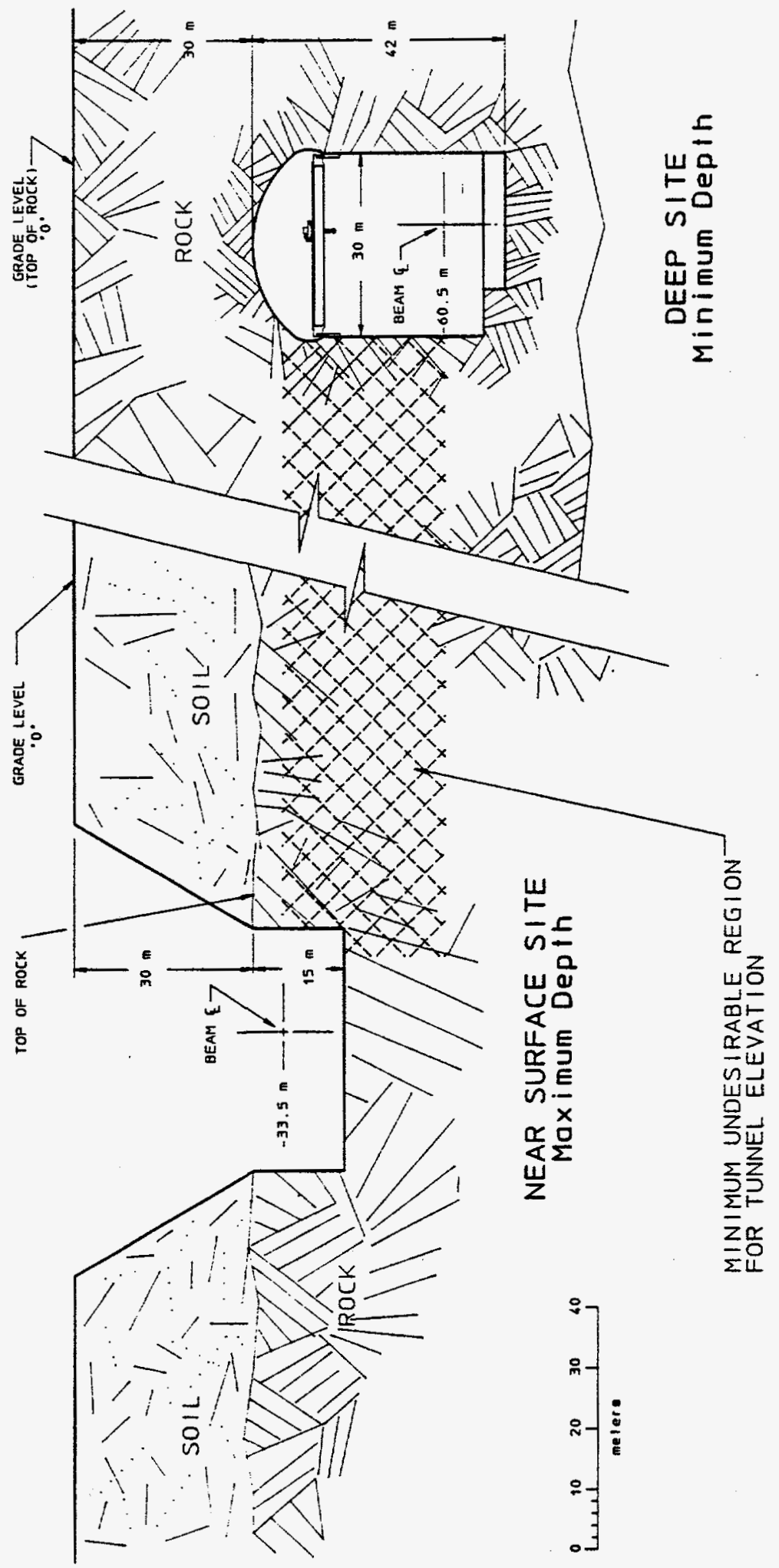

FIG. 3.2 An illustration of the undesirable region for location of the SSC tunnel resulting from the depth of the experimental halls, See the text for more explanation. 


\subsection{Deep Sites}

\subsubsection{Geotechnical Limitations}

Construction of a deep underground interaction region requires competent rock in which to build the required cavern or caverns, while maintaining an arch above the crown of sufficient strength to carry the weight of the overburden. The design of such underground caverns is based largely on precedent. Empirical data from prior construction experience helps greatly in planning the geometry, excavation, and support which will be compatible with the geological materials at depth. This prior experience provides a basis for identifying critical features of the rock mass and the geometry of the site, for choice of appropriate construction techniques, and for specifying support requirements consistent with the special characteristics of the site and the nature of the facility. During construction, field observations and measurements play a critical role in evaluating the performance of the rock mass, and in adjusting support requirements and construction techniques accordingly.

In the design of such caverns, analytical methods for assessing stresses and deformations in the rock can give valuable insights regarding the influence of geometrical and rock strength parameters on the behavior of the rock mass. However, the interpretation of these results must be tempered by practical considerations based on the structure of the rock and construction procedures to be employed. Of primary importance in the design of the underground enclosure is the span, i.e. the width of the opening. The span is the primary determinant of stresses and consequent deformations in the rock mass. These, in turn, determine the feasibility of the proposed cavern, the type and amount of support required, and the sequence for excavation and support.

A review of existing rock caverns constructed for civil engineering works reveals that spans of $25 \mathrm{~m}$ have been achieved in a variety of underground projects, and that a span of $30 \mathrm{~m}$ represents an approximate upper bound for normal practice under favorable conditions. ${ }^{4,5}$ A $30 \mathrm{~m}$ span should, then, be considered as a limit for planning and generic design work. Larger spans might be possible for special site conditions, or by use of specialized ground reinforcement and construction techniques. Specification of these larger spans could restrict the range of acceptable sites and require substantially increased costs above those considered here.

To achieve the suggested limiting span of $30 \mathrm{~m}$ requires a rock mass of good quality in which the rock mass structure and strength and the in situ stresses are suitably disposed to promote a stable opening. The cavern must also be shaped to develop a rock arch at its crown. For a span of $30 \mathrm{~m}$, experience suggests that the minimum depth of competent rock above the crown of the cavern should be $30 \mathrm{~m}$, i.e. equal to the span. ${ }^{4,5}$

The other two dimensions of the cavern, the height and the length, should provide no restriction on the size of the cavern. Cavern heights of $40-60 \mathrm{~m}$ are within the range 
of current construction practices, provided a suitable crown can be established as described above. The length of a cavern, transverse to the span, is unlimited, unless a limiting variation of geological conditions occurs.

\subsubsection{Cavern Options}

Three options for assembling and servicing the detector have been explored for their impact on the design of the underground space. Alternative 1 (Fig. 3.3), is to assemble and service the detector entirely in the collision hall, the cavern in which it will operate. This requires a cavern with sufficient space, suitably distributed, to accommodate all of the required operations. When the beam is present in the cavern, no work may be done on the detector, with the possible exception that some small shielded enclosure might be constructed within the enclosure for limited work. In Alternative 2 (Fig. 3.4) the bulk of the assembly would be carried out in the collision hall, but assembly of the inner components of the detector would be carried out in a second, adjacent cavern, the assembly hall. The assembly hall would be connected to the collision hall by a passage provided with the appropriate rails and facilities for moving the inner detector between the halls. A movable shield wall would seal off the assembly hall from the collision hall during beam operation to allow access in the assembly hall. Finally, in Alternative 3 (Fig. 3.5), a single, large cavern would be excavated with its axis transverse to the beam direction. The cavern would be divided into two areas by a thick shielding wall, with a movable section to allow passage of major elements of the detector. The bulk of the detector would be assembled on the beam line in a collision area at one end of the cavern. The inner portion of the detector would be assembled beyond the shielding wall in the assembly area. With the movable shield door in place, work could continue on the detector elements in the assembly area during beam operations.

For these large caverns, it would be very advantageous for cost and schedule, if a detailed evaluation of the rock mass were available before awarding the construction contract. In the present stage of design a tunnel of uniform cross-section, but of larger diameter than the arc tunnel, will be driven through the clusters. The collision halls constitute only a very small fraction of the length of the clusters, yet would constitute major obstacles to the traverse of a tunnel boring machine, if they were excavated prior to the tunnel boring. It is advantageous, then, from the point of view of evaluation of the rock mass for the caverns, and of driving of the cluster tunnel, to drive the tunnel prior to committing the excavation of the collision halls.

It should be emphasized that all of the alternatives discussed below can be seriously compromised, if the rock mass conditions, as encountered, deviate from the high quality that was assumed for deep siting of this facility. 


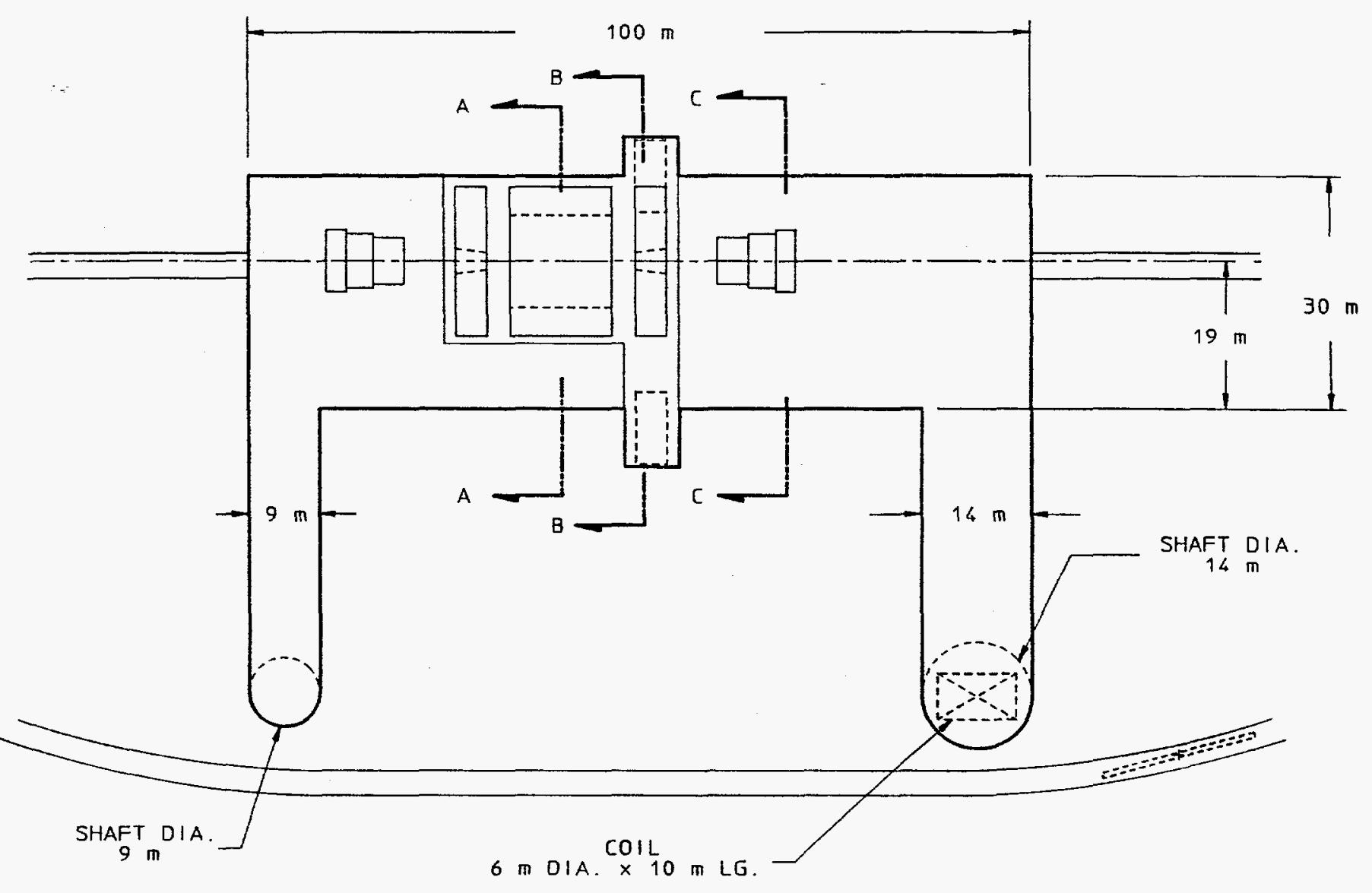

PLAN

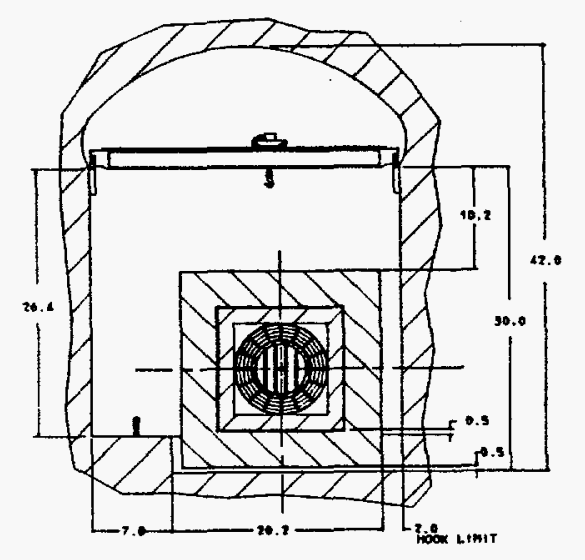

SEC A-A

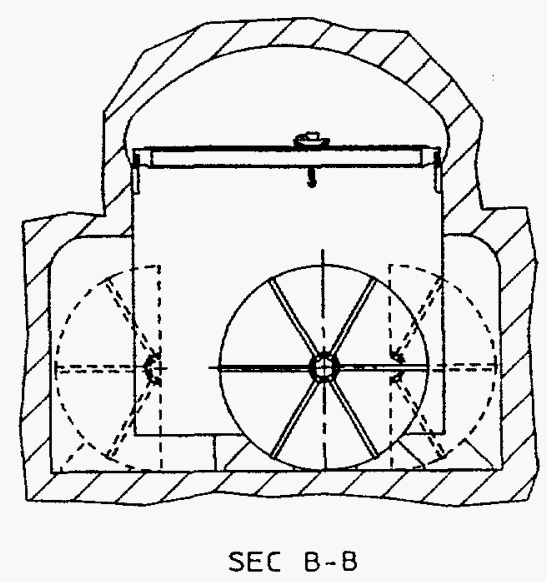

SEC B-B

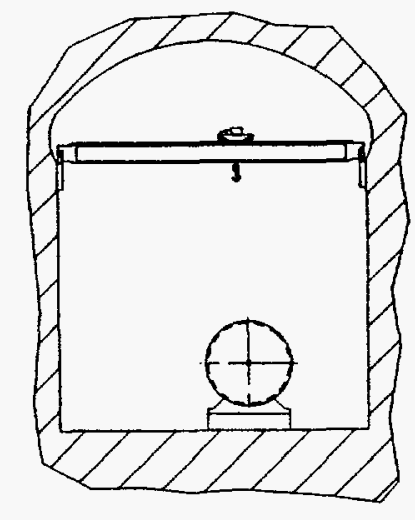

SEC $C-C$

FIG. 3.3 Deep Rock Location - Alternative 1. Only a collision hall exists in this option. All assembly will be done in the one hall. 

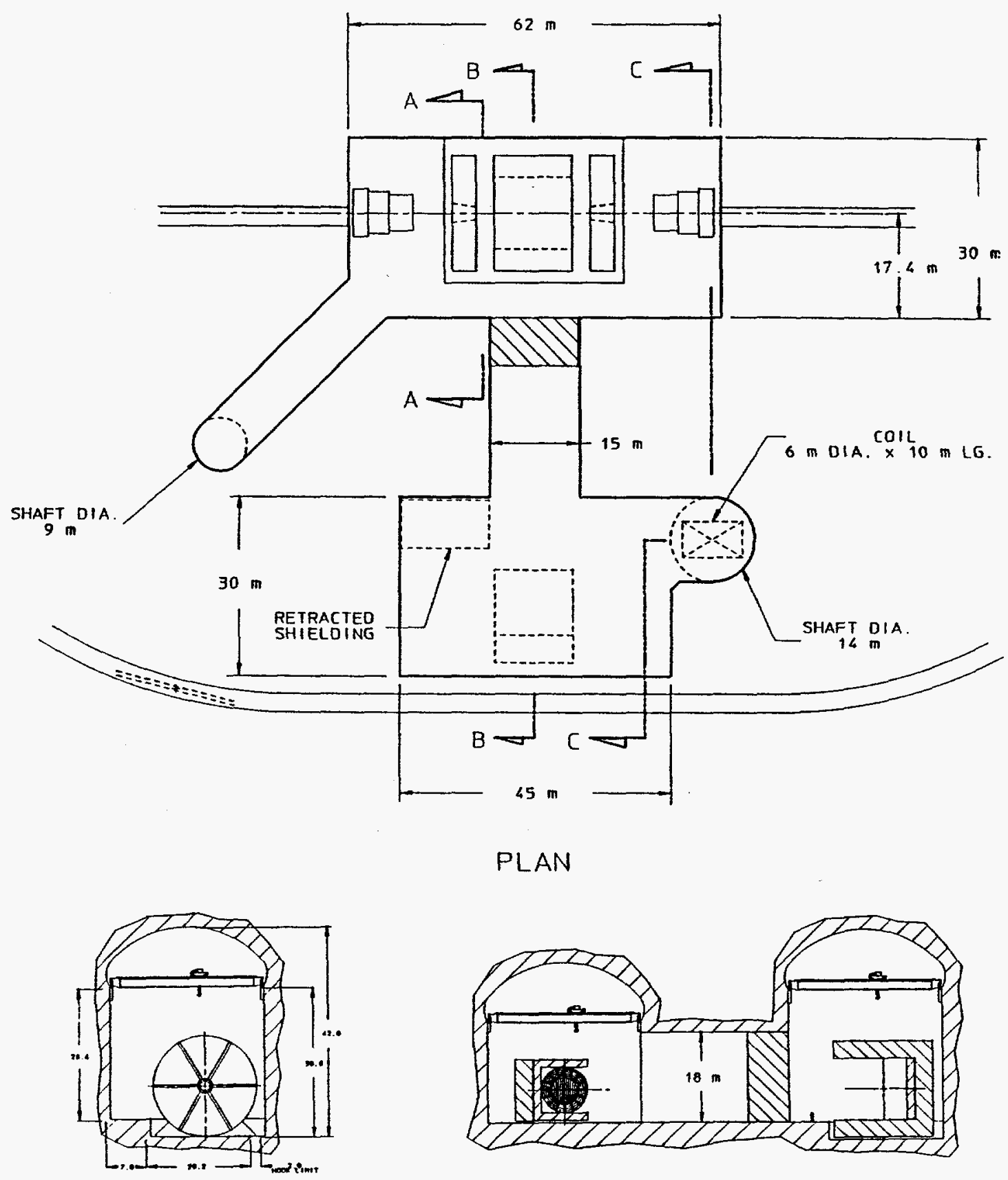

SEC A-A

SEC B-B

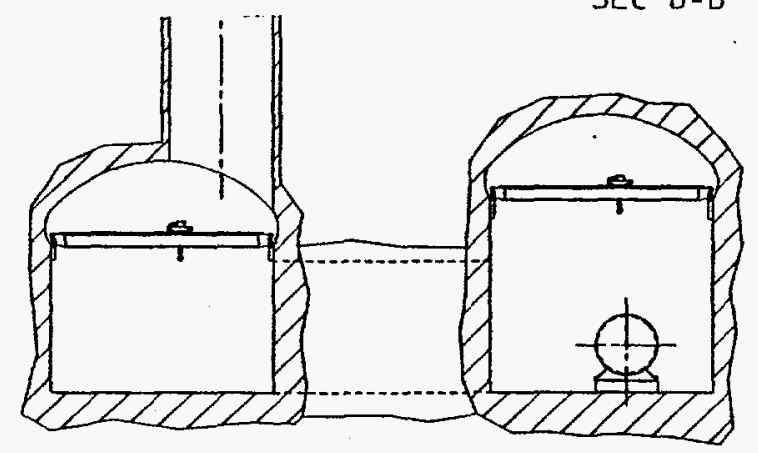

SEC $C-C$

FIG. 3.4 Deep Rock Location - Alternative 2. In this option both a collision hall and an assembly hall are constructed parallel to the beamline 

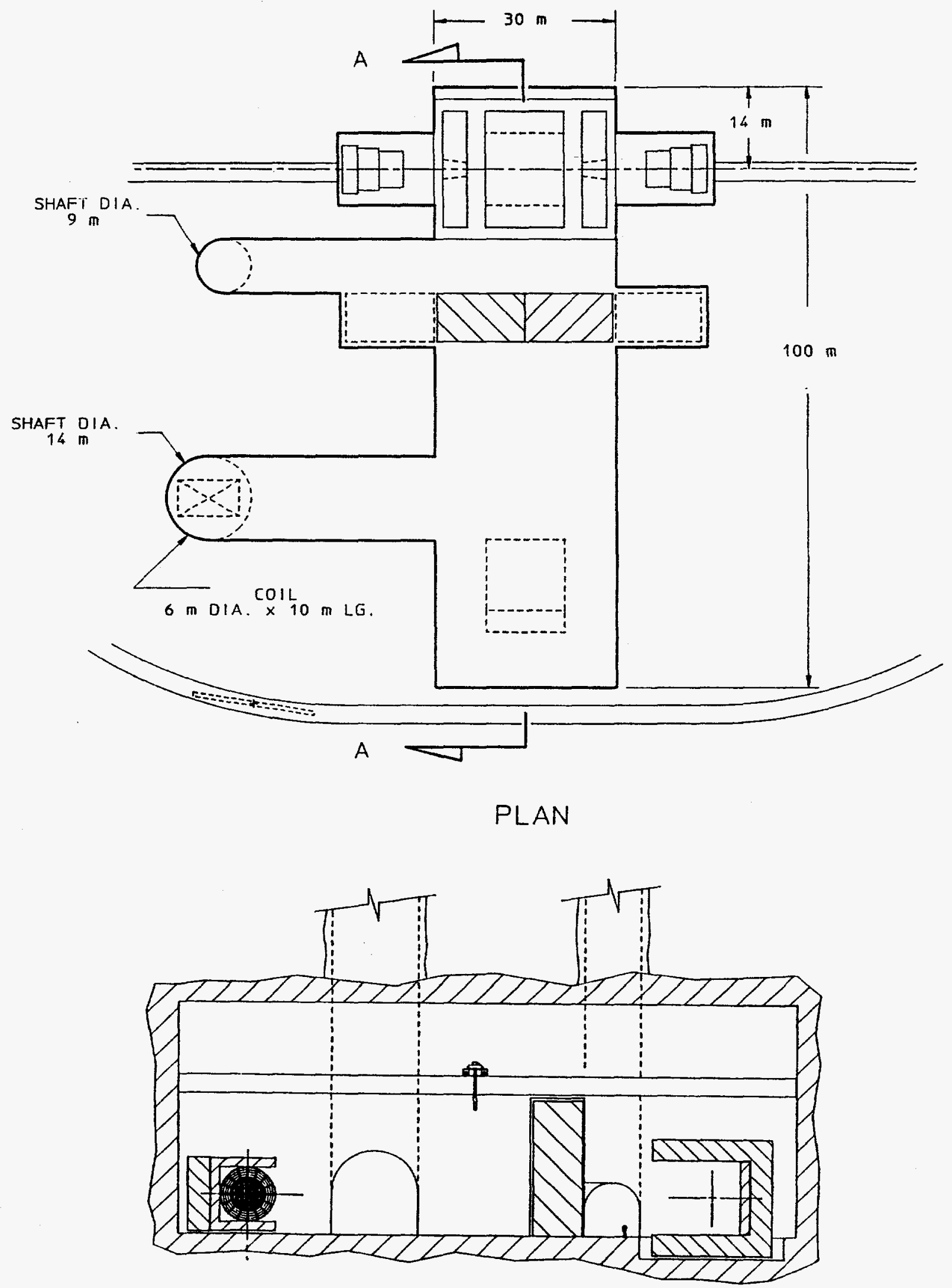

SEC A-A

FIG. 3.5 Deep Rock Location - Alternative 3. In this option both the collision hall and the assembly hall are in a single cavern transverse to the beamline 


\subsubsection{Alternative 1: One Cavern, Parallel to Beam}

From a design viewpoint, this alternative is relatively simple; the $30 \mathrm{~m}$ distance between the hall and the shafts allows for adequate pillars to carry the stresses in the rock around the hall.

The hall would be excavated downwards from the crown by first driving a construction access tunnel from one of the shafts and along the crown. The crown would be stabilized with appropriate reinforcement, and excavation would proceed downwards from that point. An interesting feature of this technique is that, at the appropriate point in the excavation, the work would be interrupted to install the reinforced concrete beams for the crane rails. These would be tied back into the rock using rock bolts. This makes the crane available quite early on, and eliminates the necessity of working far above the floor of the finished cavern to install the beams and erect the building crane.

\subsubsection{Alternative 2: Collision Hall with Assembly Hall}

From the point of view of geotechnical design, this layout is, again, satisfactory, provided the axes of the two halls are parallel and the halls are sufficiently separated to allow for adequate pillars between them. For the spans contemplated, this separation should be a minimum of $30 \mathrm{~m}$. The requirement for adequate pillar thickness also impacts the placement of the shafts, and the passages between halls and shafts.

The existence of the two large, adjacent caverns demands that special attention be given to the minimum rock cover above them. The effective span to be bridged will be greater than either span individually, closer to the sum of the two spans. The rule of thumb cited above would dictate a rock cover above the crowns, in this case, of $60 \mathrm{~m}$, rather than 30. This, of course, drives the minimum depth of the facility an additional $30 \mathrm{~m}$ underground.

From a construction viewpoint, the excavation and rock stabilization sequences will be similar to those described for Alternative 1, above. If it is desired that both halls be connected to one of the shafts, great care must be taken in excavation and in providing support to relieve any highly stressed condition. Provision of adequate pillars between the halls, shafts, and connecting passageways must be carefully studied.

\subsubsection{Alternative 3: One Cavern, Transverse to Beam}

From a geotechnical standpoint, it appears possible to use this alternative, although it does complicate the layout relative to access to the collider area. The combined effect on rock stability of the collider area shaft and the shielding door pockets must be carefully considered. 


\subsection{Near Surface and Surface Sites}

\subsubsection{Geotechnical Limitations}

A near-surface site for a collision hall is one where the hall can be constructed by making an open cut from the surface. The maximum depth for this type of construction is approximately $30 \mathrm{~m}$, in soil and approximately $45 \mathrm{~m}$, if the excavation extends into rock. The specified minimum cover over the accelerator tunnel is $9 \mathrm{~m}$ of soil. Given the half-height of the model detector, the bottom of the excavation will range from about 22 to $45 \mathrm{~m}$ below grade. For the model detector considered, the height to the top of the crane is approximately $34 \mathrm{~m}$. For a fully shielded enclosure at maximum depth, this places the top of the shielding at grade level. For lesser depths, the top of the shielding is above grade level, up to a maximum height of $22 \mathrm{~m}$ (see Fig. 3.6). The overburden is approximately constant at the nominal shielding thickness of $9 \mathrm{~m}$. Under these circumstances, a span of $40 \mathrm{~m}$ is feasible, greater than the $30 \mathrm{~m}$ maximum span for a deep cavern. A major geotechnical concern for near surface sites which will be at or near the top of rock will be handling of groundwater during the construction period.

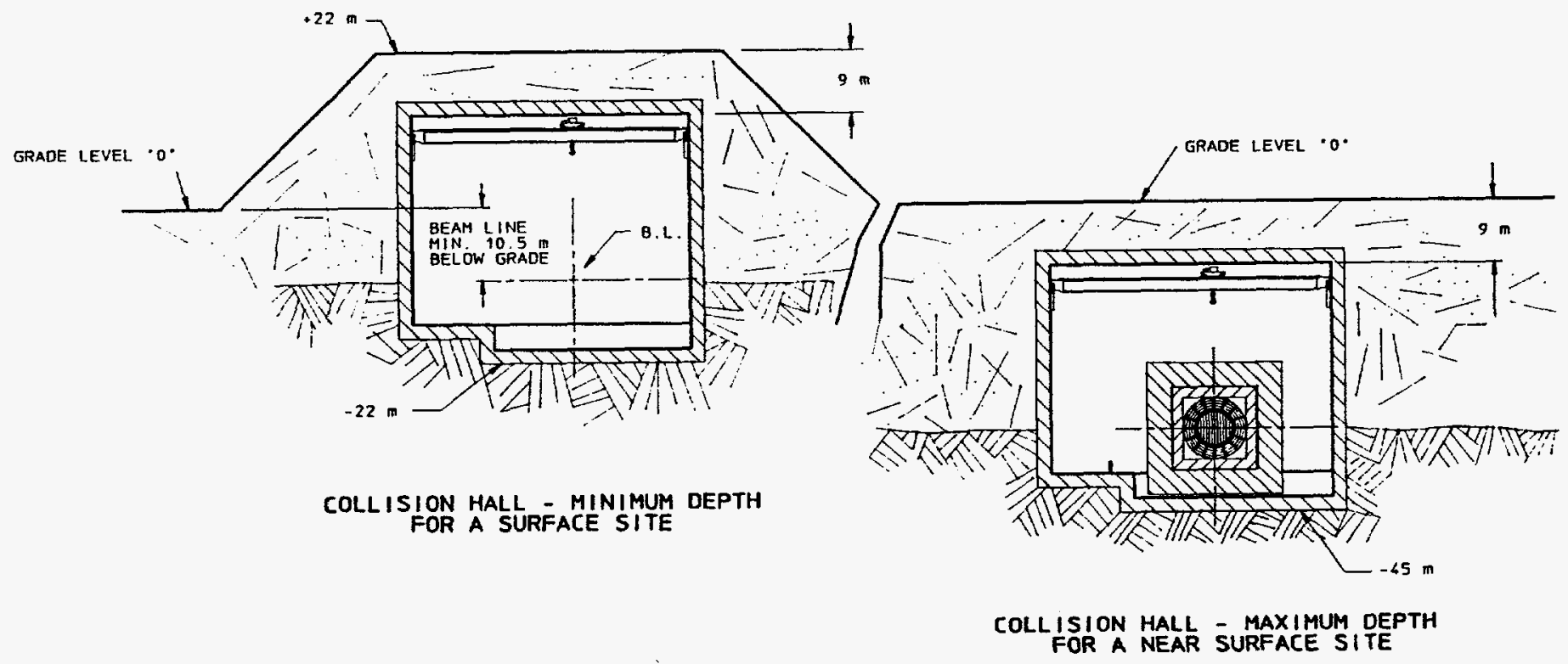

FIG. 3.6 Range of depths for surface location of experimental halls. 

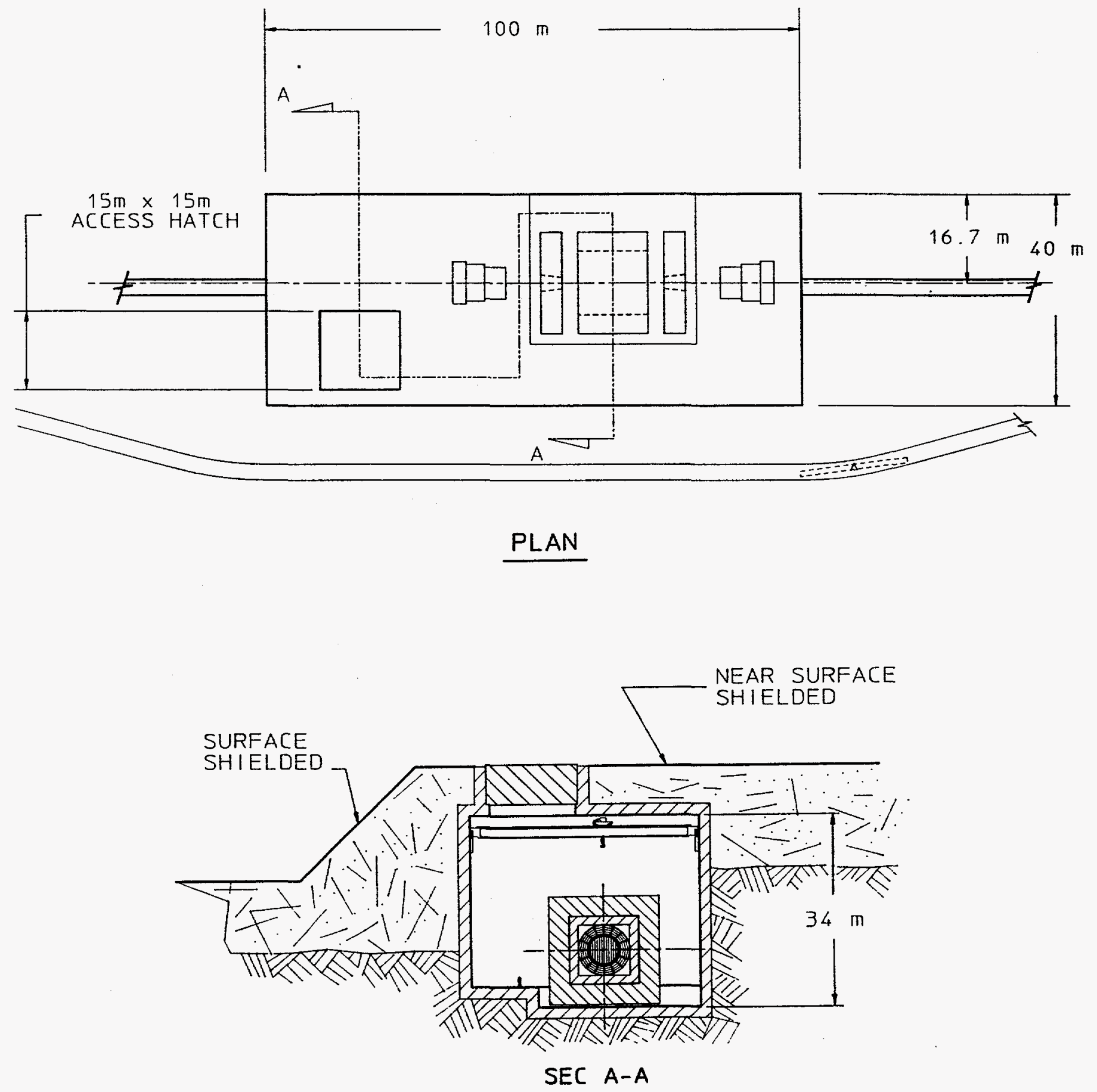

FIG. 3.7 Surface location - Alternative 1. Only a collision hall exists in this option. 

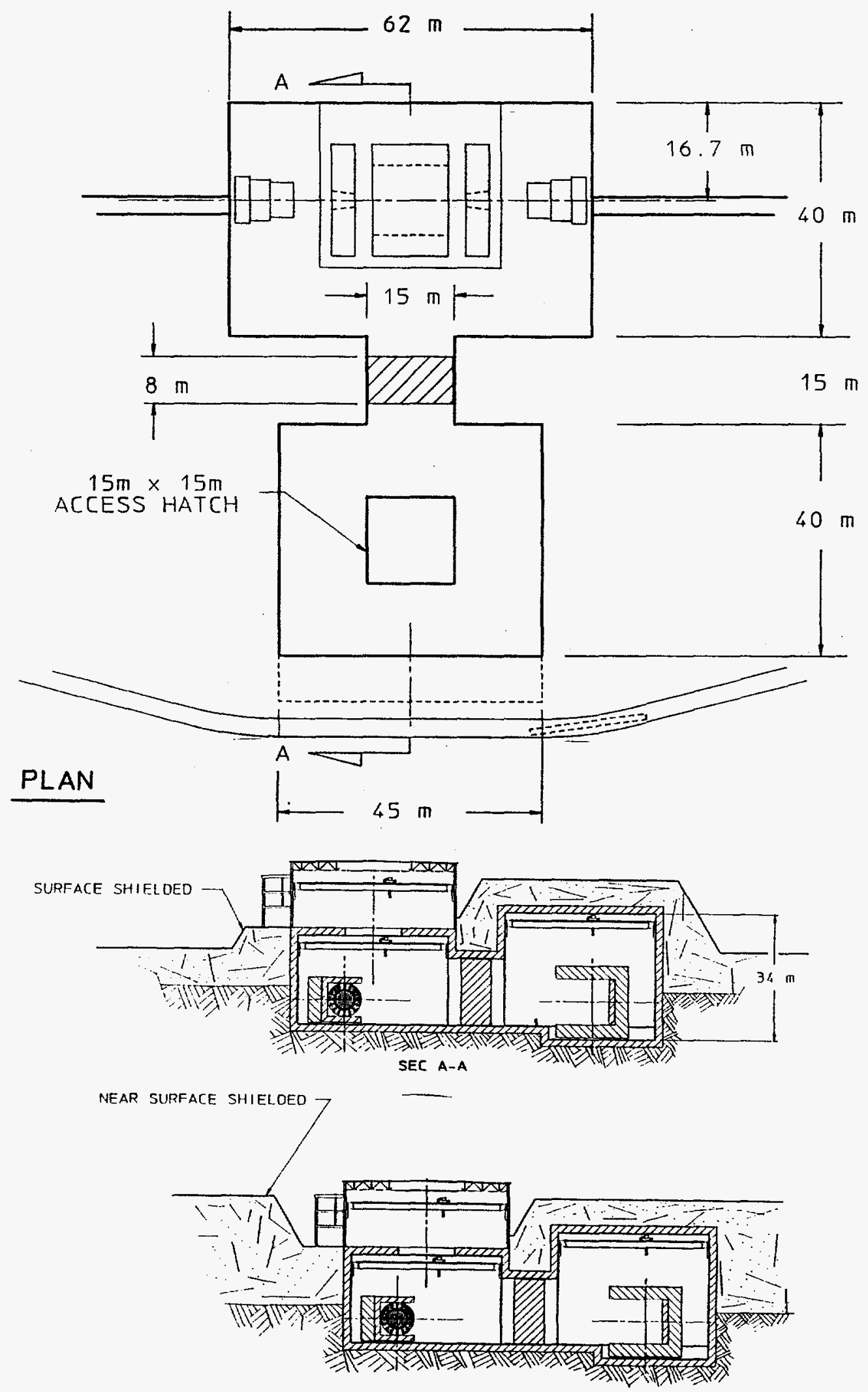

SEC A-A

FIG. 3.8 Surface location - Alternative 2. In this option both a collision hall and the assembly hall are constructed parallel to the beamline. 

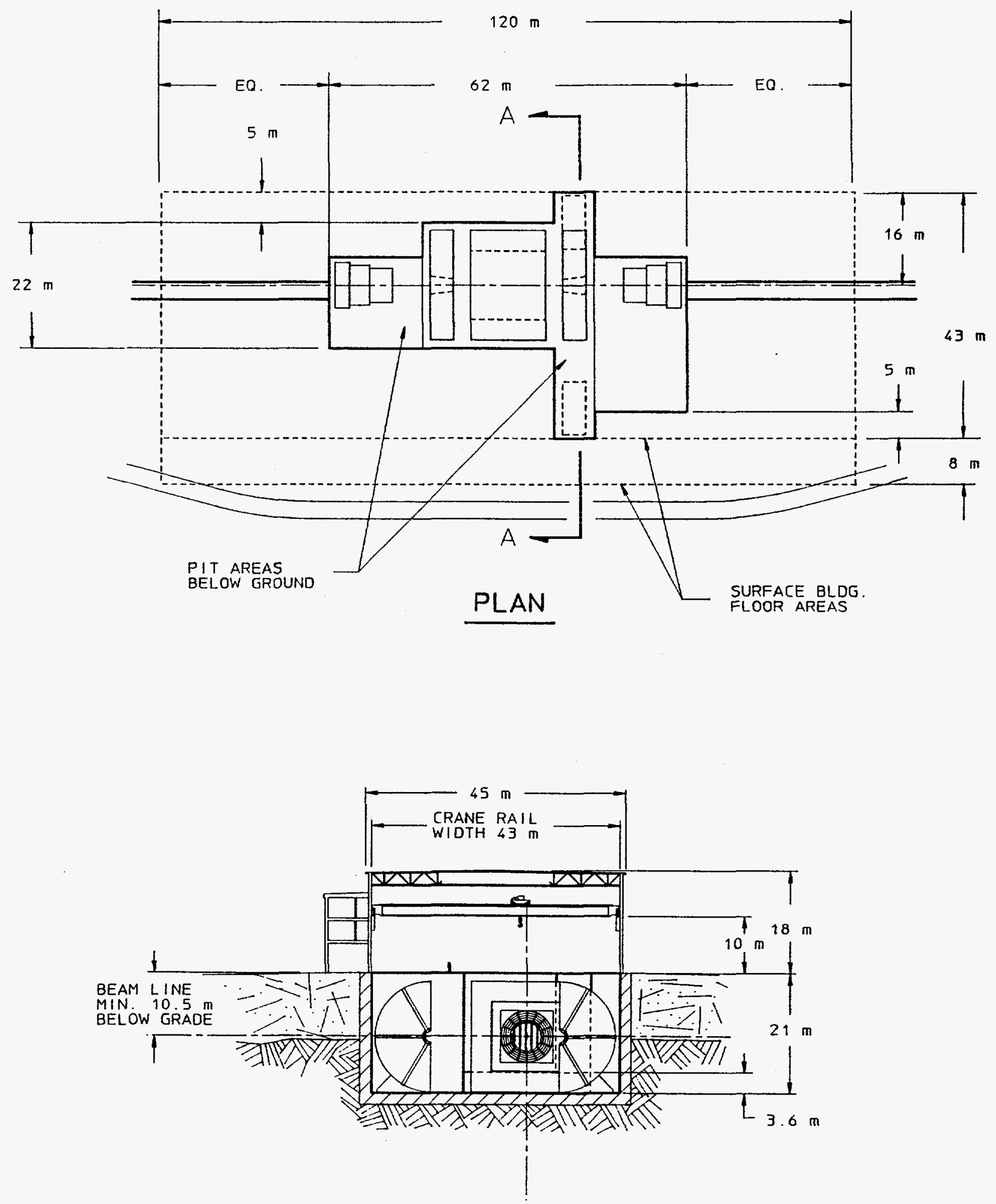

SEC A-A

FIG. 3.9 Surface location - Alternative 3. Self-shielded option. 


\subsubsection{Constructibility of Near Surface Sites}

A primary consideration in planning the construction of the SSC project must be "constructibility". This encompasses questions of the state of the construction art relative to the specifications for the required structures, the availability of materials required, and the expertise and experience of contractors in the field to meet the specifications for materials and techniques. The materials and techniques required for surface sites are very familiar to most large general contractors, especially those with experience in large highway and bridge construction.

A second aspect of constructibility that tends to favor near surface sites is the availability of a considerable amount of space to perform multiple tasks in parallel. This permits fairly flexible coordination of the various construction tasks. Relatively unencumbered near surface sites are, therefore, attractive from the point of view of design and construction contractors for the required civil works.

\subsubsection{Hall Options}

As for the deep sites, three options have been explored for assembling and servicing the model detector for the near surface sites. Alternative 1 (Fig. 3.7) provides for assembling and service the detector entirely in the collision hall in which it will operate. The hall must have sufficient space, suitably distributed, to accommodate all of the required operations. When beam is present in the hall, no work may be done on the major elements of the detector, but smaller elements of the detector could be readily moved to the staging building. In Alternative 2 (Fig. 3.8), the greater part of the detector would be assembled in the collision hall, but assembly of the inner components would be carried out in a second, adjacent enclosure, the assembly hall. The assembly hall would be connected to the collision hall by a portal which is sealed off by a movable shielding door. Facilities are provided for moving the inner assembly between the assembly hall and collision hall. With the shielding door in place, work can go on in the assembly hall while beams are present in the collision hall. Alternative 3 (Fig. 3.9) takes advantage of the fact that the massive detector, which is designed to absorb the products of the beam interactions, represents a considerable amount of transverse shielding. Supplemental concrete shielding, particularly for the spaces between the major detector elements, completes the required radiation shield. A standard industrial-type building covers the pit.

As noted above, all of the near-surface options require that the base of the enclosure be either in rock, or sufficiently close to rock or suitable bearing materials to make cost effective use of deep foundations to support the very large loads of the detector. 


\subsubsection{Alternative 1: Single Enclosure, Parallel to Beam}

From the point of view of detector assembly and servicing, this is similar to Alternative 1 for a deep site. Handling the large number of heavy pieces for the initial installation can be facilitated, since the enclosure is close to the surface. An access hatch or hatches can be provided in the roof of the enclosure for use in the initial installation, which could be sealed up and backfilled before beam operations. A drop hatch and access labyrinth from the staging building is provided for operations and maintenance use.

\subsubsection{Alternative 2: Collision Hall and Assembly Hall}

This option is essentially the same as the halls for CDF and D0. The portal would have the same span as for the D0 hall, which may be taken as a model for this hall. The inner core of the detector, could be moved between the assembly hall and the collision hall. The major structural considerations would be the span of the collision hall plus the 100 ton crane bearing on the lintel above the access portal. The weight of overburden for shielding adds to this concern. Access for initial installation in the collision hall would be supplied by a drop hatch accessible to a large crane, as for Alternative 1 .

\subsubsection{Alternative 3: Thin-roofed Hall}

Since the model detector is so massive, it is possible to consider a scheme in which the detector provides the bulk of the radiation shielding required. The radiation levels are discussed in Appendix D. Additional shielding, at least in the forward region, will be needed. The feasibility of this self-shielded scenario is discussed further in Sec. 4.1.7 and Appendix D. Structurally this alternative has the simplest layout, and provides the most access to the halls for detector assembly. In principle, the detector could be preassembled into larger pieces which could be rigged into the hall. This might lead to a shortened assembly time.

\subsection{Collision Hall Dimensions, Costs, and Schedules}

\subsubsection{Typical Hall Dimensions}

In Table 3.5, the relevant dimensions for the various near surface, surface, and deep rock possibilities are tabulated. For the purpose of this study, it is assumed that each experimental facility will constitute a construction package consisting of the following elements: i) site preparation; ii) one 14-meter and one 9-meter diameter shaft with access galleries, if necessary; iii) underground chambers; iv) concrete work; v) electrical work; vi) mechanical work; and, vii) staging building(s). It is further assumed that the sinking of the shafts and the construction of the underground chambers will be done by conventional drill and blast methods with the chambers being excavated by three drifts 
setting the arch, as described above, and three levels of excavation (benches) for the remainder of the cross-section.

TABLE 3.5. Range of IR Hall Possibilities

\begin{tabular}{|c|c|c|c|c|}
\hline & $\begin{array}{c}\text { Surface } \\
\text { Self-Shielded }\end{array}$ & $\begin{array}{l}\text { Surface } \\
\text { Shielded }\end{array}$ & $\begin{array}{l}\text { Near Surface } \\
\text { Shielded }\end{array}$ & Deep Rock \\
\hline Beam Center Elev. & $-10.5 \mathrm{~m}$ & $-10.5 \mathrm{~m}$ & $-33.5 \mathrm{~m}$ & $-80.5 \mathrm{~m}$ \\
\hline Shielding Thickness & $0 \mathrm{~m}$ & $9 \mathrm{~m}$ & $9 \mathrm{~m}$ & $\mathrm{n} / \mathrm{a}$ \\
\hline Coll. Hall Width & $40 \mathrm{~m}$ & $40 \mathrm{~m}$ & $40 \mathrm{~m}$ & $30 \mathrm{~m}$ \\
\hline Coll. Hall Length & $100 \mathrm{~m}$ & $100 \mathrm{~m}$ & $100 \mathrm{~m}$ & $100 \mathrm{~m}$ \\
\hline Coll. Hall Height & $34 \mathrm{~m}$ & $34 \mathrm{~m}$ & $34 \mathrm{~m}$ & $42 \mathrm{~m}$ \\
\hline Top Shielding Elev. & +18 (bldg) & $+22 \mathrm{~m}$ & 0 (surface) & 0 (surface) \\
\hline Ceiling/Roof Elev. & +15 (truss) & $+13 \mathrm{~m}$ & $-10 m$ & $-49 m$ \\
\hline Floor Elev. & $-21 m$ & $-21 m$ & $-44 m$ & $-91 \mathrm{~m}$ \\
\hline Btm. Excav. Elev. & $-22 m$ & $-22 m$ & $-45 m$ & $-92 \mathrm{~m}$ \\
\hline $\begin{array}{l}\text { Bedrock Elev. Range } \\
\text { (assumed) }\end{array}$ & -20 to $-60 m$ & -20 to $-60 m$ & -30 to $-90 \mathrm{~m}$ & $>-17 m$ \\
\hline Caisson/Pile Length & 0 to $38 \mathrm{~m}$ & 0 to $38 \mathrm{~m}$ & 0 to $45 \mathrm{~m}$ & $\mathrm{n} / \mathrm{a}$ \\
\hline Depth of Rock Excav. & 0 to $2 \mathrm{~m}$ & 0 to $2 \mathrm{~m}$ & 0 to $15 \mathrm{~m}$ & $42 \mathrm{~m}$ \\
\hline Hall Construction & $\begin{array}{l}\text { Steel Frame } \\
\text { \& Deep Pit }\end{array}$ & $\begin{array}{l}\text { Concrete } \\
\text { Box }\end{array}$ & $\begin{array}{l}\text { Concrete } \\
\text { Box }\end{array}$ & Rock Cavern \\
\hline
\end{tabular}

\subsubsection{Typical Collision Hall Schedules}

Using the typical collision halls specified in Table 3.5 above, the relative durations of the activities required for the construction of each facility can be estimated. These are tabulated in Table 3.6 below. The associated staging buildings are assumed to be constructed in parallel, with the exception of the self-shielded hall where the staging building is integral with the hall. 
TABLE 3.6. Construction Durations ${ }^{\dagger}$

\begin{tabular}{lcccc}
\hline \hline & $\begin{array}{c}\text { Surface } \\
\text { Self-shielded }\end{array}$ & $\begin{array}{c}\text { Surface } \\
\text { Shielded }\end{array}$ & $\begin{array}{c}\text { Near Surface } \\
\text { Shielded }\end{array}$ & $\begin{array}{c}\text { Deep Rock } \\
\text { Shielded }\end{array}$ \\
\hline Preliminary Design & $3-5$ & $3-5$ & $3-5$ & $3-5$ \\
Final Design & $7-9$ & $7-9$ & $7-9$ & $7-9$ \\
Bid/Award/Contract & $2-4$ & $2-4$ & $2-4$ & $2-4$ \\
START CONSTRUCTION & $12-18$ & $12-18$ & $12-18$ & $12-18$ \\
Site Preparation & $3-6$ & $3-6$ & $3-6$ & $2-4$ \\
Dirt Excav./Open Cut & $3-4$ & $3-4$ & $3-6$ & - \\
Excav. with Retention & $0-3$ & $0-3$ & $6-0$ & - \\
Shaft Excavations & - & - & - & $14-18$ \\
Shaft Concrete Lining & - & - & - & $2-4$ \\
Rock Excav./Open Cut & $0-2$ & $0-2$ & $0-10$ & - \\
Rock Excav./Caverns & - & - & - & $15-20$ \\
Rock Caisson Foundation & $0-3$ & $0-3$ & $0-3$ & - \\
Concrete Structure & $10-14$ & $18-24$ & $22-26$ & - \\
Steel Struct. \& Skin & $4-6$ & - & - & - \\
Concrete Cavern Lining & - & - & - & $7-10$ \\
Backfill & $2-3$ & $4-5$ & $2-3$ & - \\
Mech./Elect./Crane Fit. & $2-4$ & $2-4$ & $2-4$ & $4-7$ \\
BENEFICIAL OCCUPANCY & $24-45$ & $30-51$ & $38-58$ & $44-63$ \\
Mech./Elect. Complete & $3-6$ & $3-6$ & $4-8$ & $4-9$ \\
TOTAL CONSTRUCTION & $27-51$ & $33-51$ & $42-66$ & $48-72$ \\
Summary: Midrange Years & & & & \\
DESIGN \& CONTRACT & $1-1 / 4$ & $1-1 / 4$ & $1-1 / 4$ & $1-1 / 4$ \\
CONSTRUCTION & $3-1 / 4$ & $3-3 / 4$ & $4-1 / 2$ & 5 \\
$\quad$ TOTAL & $4-1 / 2$ yr. & 5 yr. & $5-3 / 4$ yr. & $6-1 / 4$ yr. \\
\hline \hline
\end{tabular}

\subsubsection{Comparative Costs of Collision Halls}

Cost estimates made by the Task Force for both deep and near-surface halls are summarized below in Tables 3.7 and 3.8. The construction elements differ sufficiently between the deep and shallow sites so that it is useful to present them separately.

$\dagger$ Total construction time is not simply the sum ot times for individual operations. Some work in parallel is assumed. 
TABLE 3.7 Deep Rock Location Cost Estimates

\begin{tabular}{|c|c|c|c|c|c|}
\hline Element & $\begin{array}{c}\text { Cost } \\
\text { Carrier }\end{array}$ & Quantity & Alt. $1 \& 3$ & Cost $(\mathrm{M} \$)$ & "CERN" \\
\hline $\begin{array}{l}\text { Underground Chambers } \\
\text { (excavation \& concrete) }\end{array}$ & $\mathrm{m}^{3}$ & 120,000 & 21 & 26 & 20 \\
\hline Shafts and Accesses & & & 5 & 5 & $6-10$ \\
\hline depth & $\mathrm{m}$ & $2 \times 100$ & & & \\
\hline diameter & $\mathrm{m}$ & $1 \times 9,1 \times 14$ & & & \\
\hline Electrical/Mechanical & job & lump sum & 6 & 6 & \\
\hline Staging Building & $\mathrm{m}^{2}$ & 5000 & 10 & 10 & \\
\hline \multicolumn{2}{|c|}{ TOTALS } & & 42 & 47 & \\
\hline
\end{tabular}

For all three alternatives for the deep site construction, the volumes are essentially the same. The major difference lies in the extra rock stabilization and support required around the portal region on either end of the gallery connecting the collision and access halls in Alternative 2. The collection labeled "CERN" is an extrapolation of the actual costs encountered for similar tasks in the LEP project.

TABLE 3.8 Surface Location Cost Estimates

\begin{tabular}{|c|c|c|c|c|c|}
\hline \multirow{2}{*}{ Element } & \multirow{2}{*}{$\begin{array}{c}\text { Cost } \\
\text { Carrier }\end{array}$} & \multirow{2}{*}{ Quantity } & \multicolumn{3}{|c|}{ Cost $(\mathrm{M} \$)$} \\
\hline & & & \multicolumn{2}{|c|}{ Shielded } & Self-shielded \\
\hline Excavation \& Stabilization & $\mathrm{m}^{3}$ & $114 \mathrm{~K} / 233 \mathrm{~K}$ & 6 & 11 & 5 \\
\hline Concrete & $\mathrm{m}^{3}$ & $20 \mathrm{~K} / 35 \mathrm{~K}$ & 8 & 11 & 6 \\
\hline Extra Invert \& Roof Structure & $\mathrm{m}^{3}$ & $7 \mathrm{~K}$ & 2 & 2 & - \\
\hline Electrical/Mechanical & job & lump sum & 6 & 6 & 4 \\
\hline \multirow[t]{2}{*}{ Staging Building } & $\mathrm{m}^{2}$ & 5000 & 7 & 7 & 7 \\
\hline & & & 29 & 37 & 22 \\
\hline
\end{tabular}


The minimum and maximum costs given for the shielded enclosures are based on the limiting cases for a near-surface site shown in Table 3.8, above.

When the cost and schedule estimates are considered, the near-surface, self-shielded option appears to be the most attractive option for constructing interaction regions for detectors of the size of the model detector. However, the feasibility of this option needs further examination; detector servicing and performance might be impaired by the additional shielding required. 


\section{Model Detector Assembly and Servicing}

The Task Force was given a model detector based on the Model B Detector developed at Snowmass 86. This detector is shown in Fig. 2.1 and will be referred to as the Model Detector in the text following. It is a large magnetic solenoid detector utilizing liquid argon precision calorimetry surrounded by a magnetized steel cave for muon detection. It is to be used for planning purposes only and does not represent an actual optimized design. However, it does demonstrate many of the problems of size and weight which will be encountered by the detectors which will be utilized at the SSC. The group was charged with the task of developing an assembly scenario for this detector which obeyed known transportation limits, reasonable crane requirements, minimal access requirements, and reflecting experience gained with assembling the present generation of large experimental detectors. For purposes of this exercise, it was assumed that most components would be fabricated off site and moved by commercial transport. This assumption does not negate having substantial spaces at the site which are used for final assembly operations when the scientific components are too delicate, too large, or too heavy to be moved by commercial transport. Space is also needed at the experimental site itself to support the operations taking place in the assembly and collision areas. A scenario was developed and a time scale calculated which shows that the detector can be designed, constructed, and assembled in a time span of $7-1 / 2$ years of which the last $3-1 / 2$ require operations in the completed experimental assembly and collision areas. This time line indicates a need to begin the design and construction of the experimental areas very early in the overall SSC construction schedule.

\subsection{Limits and Criteria}

\subsubsection{Transportation Limits}

The transportation of tall, wide, or heavy loads in most states requires permits. The acquisition of these permits, in most cases, presents no problems. However, if interstate travel is required, regulations may vary from state to state making the process more difficult and time consuming.

The weight of the load determines the number of axles on the trailer required. Typical trailer ratings for a given number of axles together with the availability of such trailers are given in Table 4.1. 
Table 4.1. Trailer Load Ratings and Availability

\begin{tabular}{rll}
\hline \hline Axles & Loads & Availability \\
\hline 9 & 80 tons & Common \\
13 & 110 tons & A few \\
15 & 130 tons & Rare \\
\hline \hline
\end{tabular}

Loads in excess of those shown will, in general, require special permits and special routing because most bridges and overpasses are designed for a known load per axle. Loads having a width greater than $8 \mathrm{ft} .6 \mathrm{in}$. also require special permits. If the width exceeds $14 \mathrm{ft}$., transportation may be limited to special times such as non-rush hours or special days such as Sunday morning. As a general rule, trucks with a loaded height in excess of $14 \mathrm{ft} .6 \mathrm{in}$. cannot travel on most highways, particularly interstates, due to overpass height limitations. Loads with a length in excess of $65 \mathrm{ft}$. will also require special permits.

Experience has shown that the transportation of cylinders having diameters greater than $6 \mathrm{~m}$ and lengths greater than $6 \mathrm{~m}$ is difficult. Short distances over specially selected routes, usually chosen by a state or local authority, may be possible. Transport over long distances (greater than a few miles) is close to impossible.

Other modes of transport such as trains or barges have their own limitations. A rule of thumb for trains is to keep loads under $12 \mathrm{ft}$. wide because the prevailing track spacing is $13 \mathrm{ft}$.. Loads up to $20 \mathrm{ft}$. high can be accommodated with special cars. Loads up to $90 \mathrm{ft}$. long, but of limited weight, can also be accommodated; heavy loads of up to 50 $\mathrm{ft}$. are standard. Barge transport is limited only by the length, width, and displacement of the vessel. Given the flexibility of rail transport, it is desirable to have a railhead located on the SSC site.

In summary, loads which exceed the values given in Table 4.2 may be transported under special permits, but should be avoided for frequent or repetitious loads.

Table 4.2. Normal Transportation Limits

\begin{tabular}{lcccc}
\hline \hline & Wt. (ton) & Width & Length & Height \\
\hline Road & 80 & $8^{\prime}-6^{\prime \prime}$ & $65^{\prime}$ & $14^{\prime}-6^{\prime \prime}$ \\
Rail & & $12^{\prime}$ & $90^{\prime}$ & $20^{\prime}$ \\
Barge & Displacement & limited & & \\
& & & &
\end{tabular}




\subsubsection{Crane Requirements}

The total number of cranes required depends primarily on the number of areas needing crane service. In general, one or two cranes is needed per area. Experience at other facilities has shown that in the assembly hall of the detectors a minimum of three (3) hooks of equal capacity, two trolleys on a single bridge, and a third on its own bridge, is preferred. Due to the size of the Model Detector, the minimum size hook considered appropriate is 100 tons. The two hooks on a single bridge would allow for the manipulation of loads parallel to the bridge and the second bridge would allow for the handling of loads transverse to the bridge.

A dedicated crane having a capacity of 25 tons may be required for the assembly of the liquid argon calorimeter (LAC). This is primarily a scheduling question. This bridge need not access the entire assembly area, but only that area reserved for the LAC assembly.

When items cannot be delivered to the assembly cranes directly, a surface crane will be required to do so. This crane should have a minimum capacity of 100 tons. The hook speed should be a minimum of $10 \mathrm{~m} / \mathrm{min}$. loaded and $30 \mathrm{~m} / \mathrm{min}$. unloaded.

Gantry cranes should be considered for use in the collision area during the erection of the muon steel. These types of cranes may be appropriate for temporary use in the near surface locations for the same purpose.

In all cases where additional cranes (over and above those required in the assembly area) are installed in the collision area, consideration should be given to their removal after erection of the muon steel.

Representative costs of the cranes discussed above are given in Table 4.3.

Table 4.3. Representative Costs of Cranes

\begin{tabular}{lllll}
\hline Location & Cost & Capacity & Lift & Span \\
\hline Shaft & $\$ 900 \mathrm{~K}$ & $100 / 20$ ton & $90 \mathrm{~m}$ & $30 \mathrm{~m}$ \\
Collision Area & $\$ 900 \mathrm{~K}$ & $100 / 100$ ton & $30 \mathrm{~m}$ & $30 \mathrm{~m}$ \\
& $\$ 750 \mathrm{~K}$ & $100 / 20 \mathrm{ton}$ & $30 \mathrm{~m}$ & $30 \mathrm{~m}$ \\
Assembly Area & $\$ 900 \mathrm{~K}$ & $100 / 100$ ton & $30 \mathrm{~m}$ & $30 \mathrm{~m}$ \\
& $\$ 750 \mathrm{~K}$ & $100 / 20$ ton & $30 \mathrm{~m}$ & $30 \mathrm{~m}$ \\
& & & & \\
\hline \hline
\end{tabular}




\subsubsection{Access to Experimental Area}

In the deep underground scenario, the location, number, and sizes of the shafts for access to the assembly area and to the collision area are peculiar to the hall design selected. Common to all is one large diameter shaft (14 m or more) which is used to lower large pieces into the pit. A second shaft having a diameter of around $9 \mathrm{~m}$ is required for smaller pieces, personnel access, elevator and stairs, and utilities.

In the near surface scenario, the contractor may choose to construct a ramp or tunnel to "muck out" during construction of the experimental area. Such an access probably provides no advantages to the experiment, but rather takes up much needed space at the pit level which can be more economically provided at the surface. If these types of access are provided by the contractor, filling in should be at the discretion of the laboratory.

The need for covered staging and assembly space in both scenarios at both the surface and at the pit levels cannot be over emphasized. The LEP and SLD experience have shown that their surface sites are too small and too congested.

\subsubsection{Detector Movement}

\subsubsection{Impact on Machine Operations}

Experience with large detectors has shown the need for access to them for several purposes:

a. Minor repairs and servicing of electronics on the detectors requiring a few hours,

b. Intermediate servicing requiring motion of large pieces of the detector such as the endplugs for work on the central tracking, requiring several days,

c. Long (shutdown) servicing to make major repairs on large detector elements or to install upgrades to the detector, requiring six months or longer.

As a guideline, it was felt that during the first few years of operation, access would be needed for the intermediate and long servicing on a $50 \%$ duty cycle. It was felt that the short access for minor repairs should be limited to 1 or 2 shifts and that detector designers be asked to design access corridors into critical interior portions of the detector alleviating the need to move any parts of the detector for these minor repairs.

The model detector can be divided into two parts, a "core" containing the calorimetry, magnet, and central tracking which requires more frequent servicing and the muon detection system consisting mainly of steel and large drift chambers which requires minimal servicing. The weights of the core and the muon system are 14,000 tons and 36,000 tons respectively. Because of the massive weight of the muon system and its relatively service-free nature, this group recommends that the muon detection system be built in place in the collision area and remain there for the duration of the experiment. 
Thus this group considered only scenarios where the central core was movable and the muon steel was movable only to the extent necessary to insert or extract the core.

\subsubsection{Assembly Considerations}

The model detector weighs approximately 50,000 tons. Except for special situations, it was felt that the maximum weight for piece handling should be less than 80 tons, consistent with crane and transportation capacity. This implies that over 500 pieces need to be handled to complete the detector. As a rule of thumb, one such piece a day can be installed, unless special handling (rotation, welding, alignment, etc.) considerations slow this down. In order to accomplish this rate in the relatively confined spaces of the assembly area and collision area, there is a need for three 100 ton hooks on two independent bridges as described in Section 4.1.2. It was also recognized that the erection of the muon steel, comprising $75 \%$ of the weight, must go on in parallel with other systems. In particular, the major effort of assembling the 8000 tons of precision calorimetry needs to proceed in parallel with its own dedicated area, cranes, and supply routes.

\subsubsection{Detector Movement}

Movement of materials in the 10,000 to 15,000 ton range is within the capability of existing technology. This can be accomplished with Hillman type rollers which are available up to an 800 ton rating. Two dozen are required to comfortably move 10,000 tons with hydraulic leveling to assure even loading. D0 expects to use 18 such rollers to move 5500 tons. Other movement schemes which employ pressurized oil or water skates are also feasible. There was general agreement that the movement of 50,000 ton loads is not practicable. This implies that the "core" of the detector (14,000 tons) can move; while the muon system ( 36,000 tons) must be built in place.

\subsubsection{Construction and Movement Scenarios}

\section{Separate Collision and Assembly Areas}

The optimum scenario would be to erect the steel for the muon detection system in place in the collision area and the precision calorimeter system in the assembly area. The steel flux return for the magnet would also be constructed in the assembly area . See Fig. 4.1a. After full assembly of the detector, major access to the core would be accomplished by splitting and sliding open the side wall of the muon steel, allowing the core to then be extracted and removed to the assembly area for maintenance. 


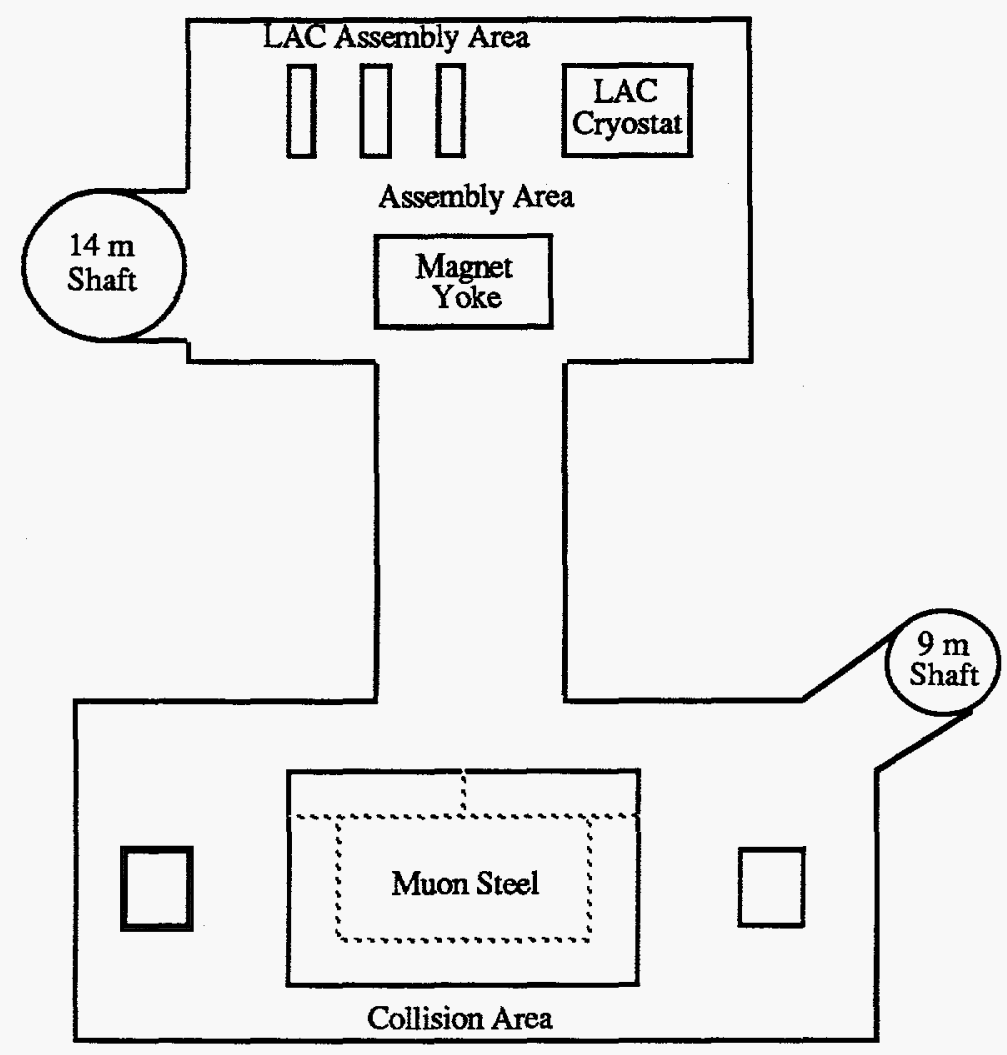

FIG. 4.1a: Schematic of experimental area with assembly and collision areas

\section{Collision Area Only}

In this scenario, assembly would be done in an elongated collision hall. See Fig. 4.1b. Access would be accomplished by splitting the end of the muon steel and extracting the core along the beamline. At a sufficient distance along the beam line the calorimeter could be extracted from the flux return. The detector would be constructed in the reverse of this. An interesting option, to be investigated, is to see if sufficient shielding could be put around the calorimetry after closing up the muon steel to allow work to proceed on the calorimetry while beam is in the machine. 


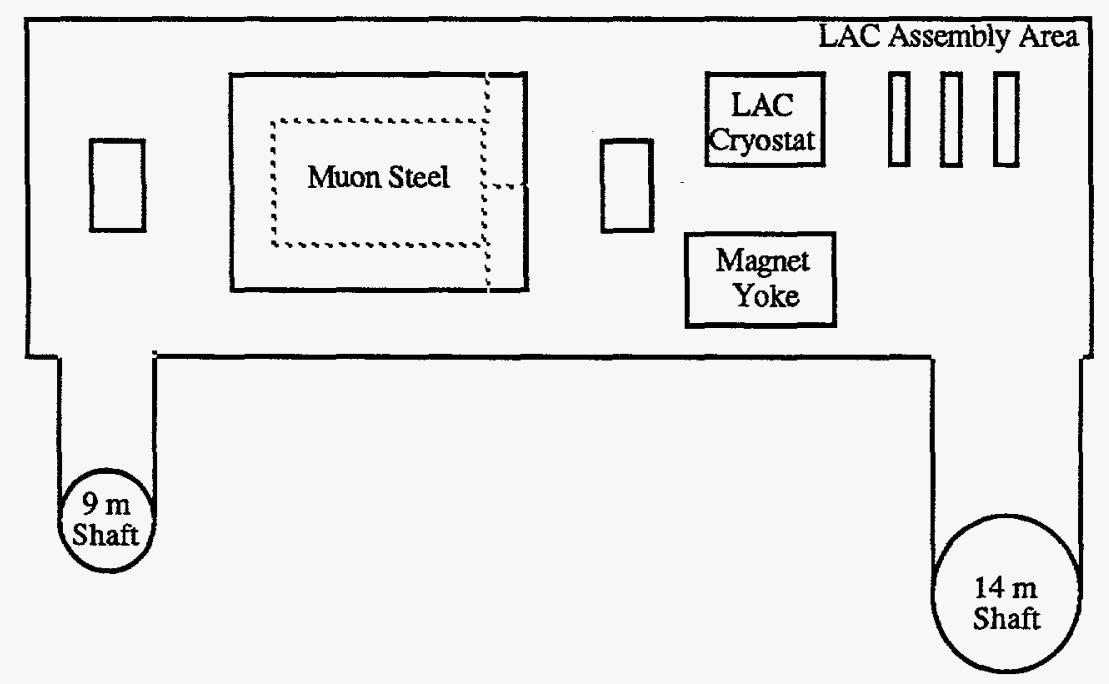

FIG. 4.1b: Schematic of Experimental Area with Collision Area Only

\subsubsection{Preassembly Space for Experiments}

Large amounts of preassembly space will be required outside of the actual assembly area. These areas are used for preassembly of large pieces, production and assembly of components like muon chambers, clean areas for wire chamber assembly, and areas for electronics development and test. Previous experience for LEP experiments and for CDF are detailed in Appendix C. We expect that the Model Detector will require $5000 \mathrm{~m}^{2}$ of such space, divided between heavy and light requirements.

\subsubsection{Earthquake Criteria}

Figure 4.2 is a seismic risk map of the United States. The risk scale ranges from Zone 0 where there is no risk of damage from earthquakes, to Zone 4 where there is a risk of major damage from an earthquake. SLAC is located in Zone 4 , and there are certain additional costs associated with design and construction of buildings, equipment, and experiments to survive an earthquake without significant damage. Building and equipment costs will increase about $5 \%$ to meet earthquake criteria in Zone 4.

Design and installation of large experimental components is complicated considerably by earthquake force considerations. SLAC's general criterion is that equipment and experimental components should withstand a $0.75 \mathrm{G}$ horizontal earthquake force unless dynamic analysis indicates that amplification will cause resonance and thus higher forces. 


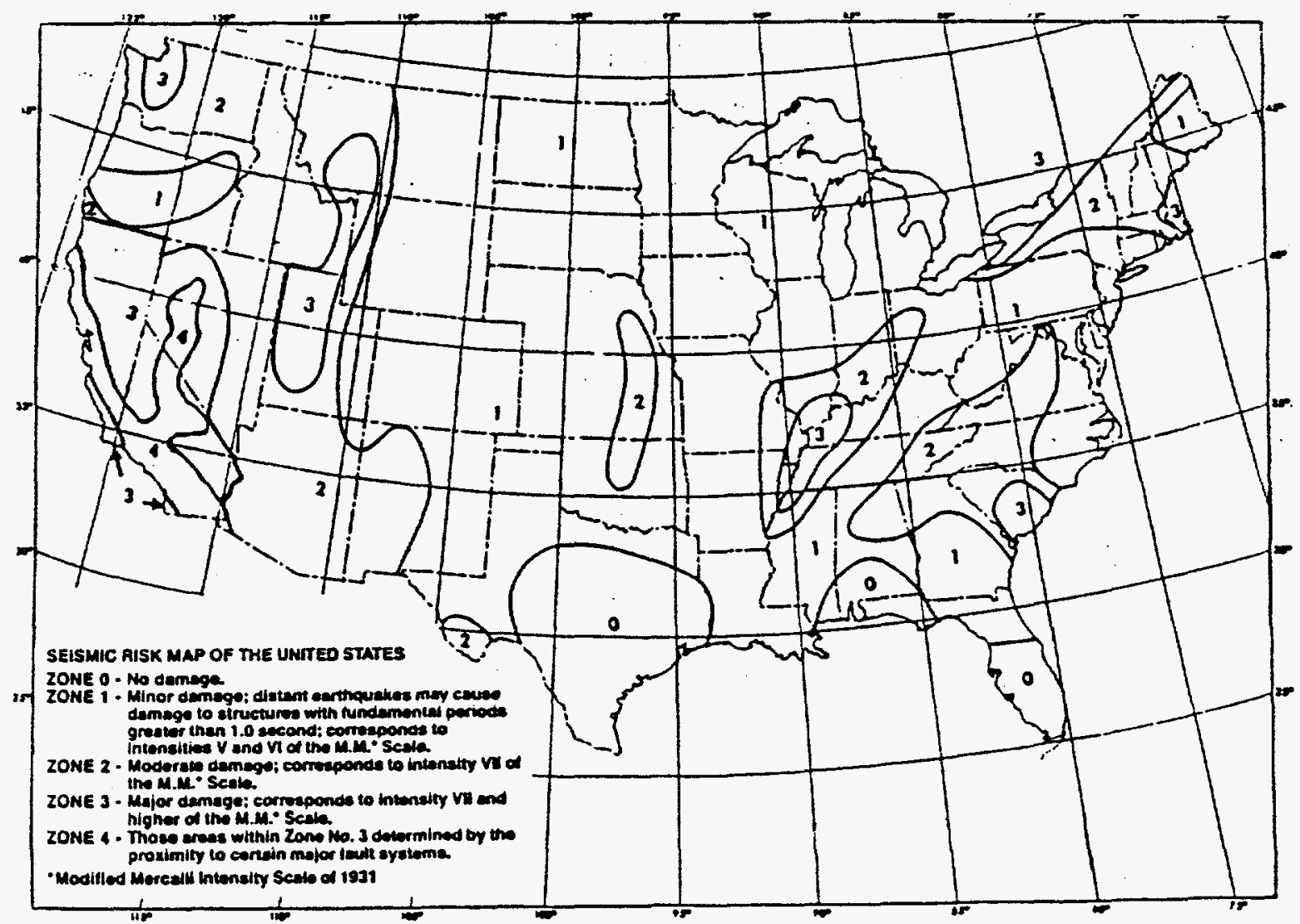

FIG. 4.2: Seismic Zone Map of the United States ${ }^{\dagger}$

The floor design of the experimental hall is already limited by the compressive strength of the base with several meters of reinforced concrete on top. It is questionable whether there is any reserve left for additional horizontal shear forces or vertical uplift forces. Depending on the shape of an object, it may be subject to horizontal shear forces and overturning forces. Figures 4.3 (a), 4.3 (b), and 4.3 (c) show a muon detector assembly, $5 \mathrm{~m}$ thick $\times 10 \mathrm{~m}$ wide $\times 20 \mathrm{~m}$ high, weighing 4000 tons. Figure $4.3 \mathrm{a}$ shows that this assembly will overturn at 0.227 horizontal $G$ force. The shear force to be resisted is 4000 $x 0.227=908$ tons. Figure $4.3 \mathrm{~b}$ show that the uplift to be resisted from a $0.75 \mathrm{G}$ horizontal force is 4600 tons. Figure $4.3 \mathrm{c}$ shows that if the uplift is resisted at the top of the assembly only an 1100 ton force is required. Because of these considerations provisions for restraining earthquake induced forces would have to be designed into the floors and walls of the experimental areas. Assembly of the muon detector steel may be further complicated by the need to restrain individual components. The required temporary tie bars and restraints would complicate assembly and result in higher costs and longer assembly times.

$\dagger$ Uniform Building Code, 1985 ed., page 135 


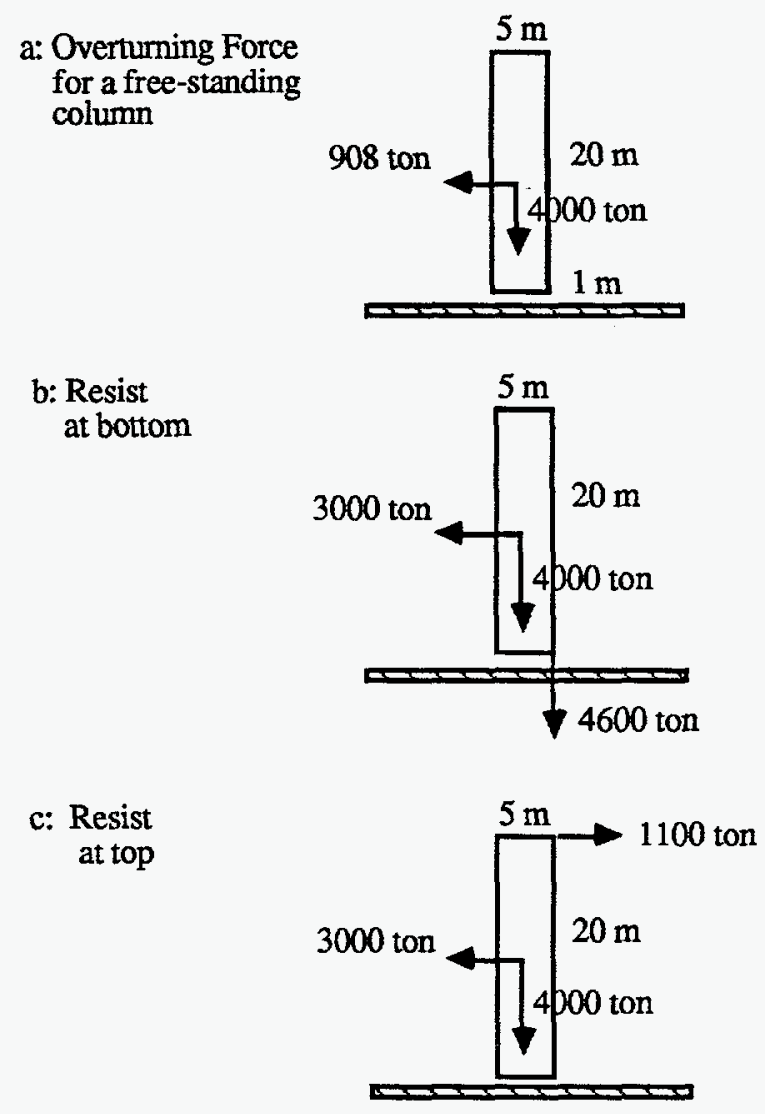

FIG. 4.3: Forces due to an earthquake ( $0.75 \mathrm{G}$ horizontal force)

\subsubsection{Self Shielding Criteria}

An evaluation of radiation levels in the IR with the Model Detector present, is given in Appendix D. We conclude that, with sufficient additional shielding around the forward detectors, radiation levels are within prescribed limits. Additional work needs to be done to assess the impact of this shielding on detector assembly and accessibility for servicing. A schematic of the additional shielding necessary is shown in Fig. 4.4.

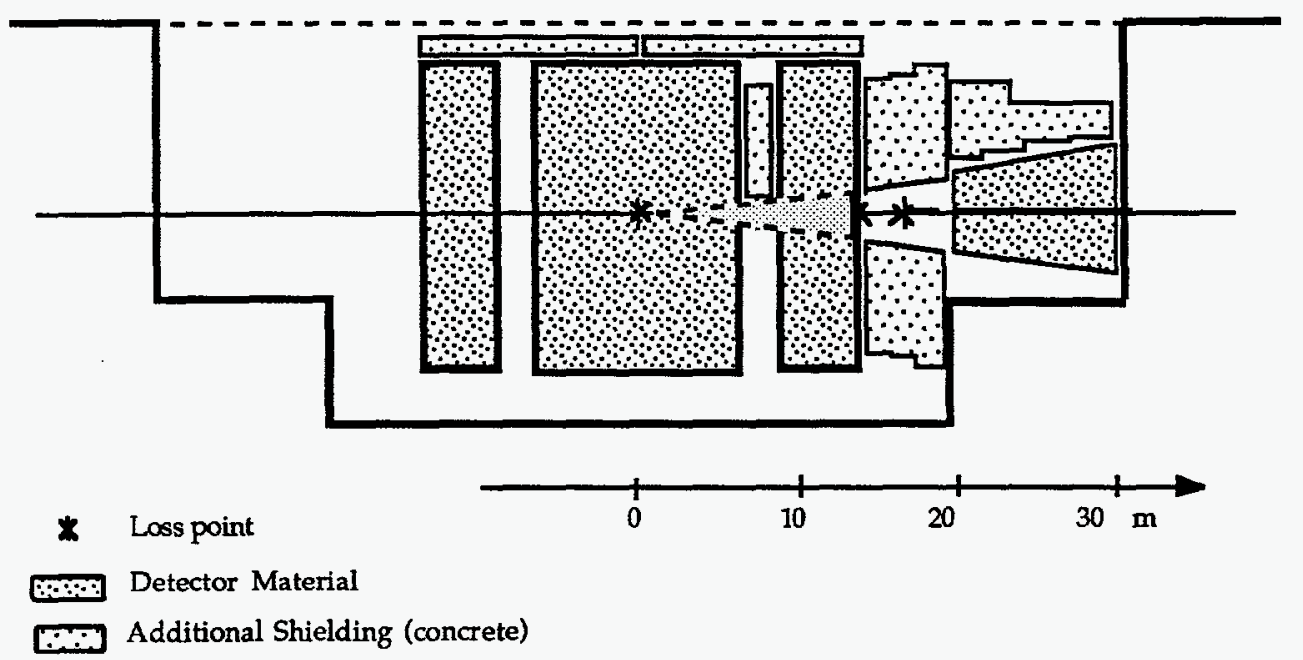

FIG. 4.4: A schematic of the self-shielded option. 


\subsection{Assembly Time Scale and Scenarios}

In order to develop a joint schedule for construction of an experimental hall and detector of this magnitude, a scenario was developed for the assembly of the model detector. We considered the detector as three main systems: the liquid argon calorimeter, the solenoid magnet, and the muon detection system. These three major systems must be assembled in parallel in order to shorten the total assembly time.

\subsubsection{Liquid Argon Calorimeter}

This system is the most complex of the three and will take to longest time to assemble. The entire system consists of three separate subsystems, the barrel, the two endcaps, and the two forward systems. The endcaps and the forward systems are relatively small, 396 tons and 496 tons each, respectively. For purposes of the scheduling scenario, these two systems are assumed to be assembled on the surface, brought into the experimental area already inside the dewars, lowered to the experimental floor, mounted on the appropriate steel, and made operational.

The central barrel liquid argon calorimeter is composed of two separate systems, the precision electromagnetic calorimeters and the precision hadron calorimeters. Both systems were assumed to be built up of wedge sections which were fabricated elsewhere, tested, and brought to the experimental assembly area . For ease of construction and handling, we set a limit of a weight of 10 tons on the hadron wedges and three tons on the electromagnetic wedges. This was accomplished by dividing the length of the barrel into five separate rings longitudinally. The precision EM calorimeters were further divided into 32 separate wedges in azimuth producing a wedge weighing 2.9 tons. The hadron calorimetry was assumed to be constructed out of wedges each of $1 / 2$ thickness and $1 / 64$ in azimuth. The average weight of the hadron wedges is 9.7 tons. These wedges are self supporting and can be stacked into rings which can be stabilized by connecting the end plates together. A construction method similar to this is used on the central liquid argon calorimeter of the D0 detector. For the model detector we do this five times instead of once as in the D0 detector. Each of these rings is then loaded into the central cryostat, cable connections are completed through the walls of the cryostat, and then tested. After all five rings have been installed in the cryostat, the cryostat is sealed, cooled, and tested. The central calorimeter system is then ready for installation with the rest of the components of the Model Detector. The steps and the time estimate to go through each of these steps is given in Table 4.4 . 
Table 4.4. Time Estimates for Calorimeter Development, Design, Construction, and Assembly

\begin{tabular}{|c|}
\hline 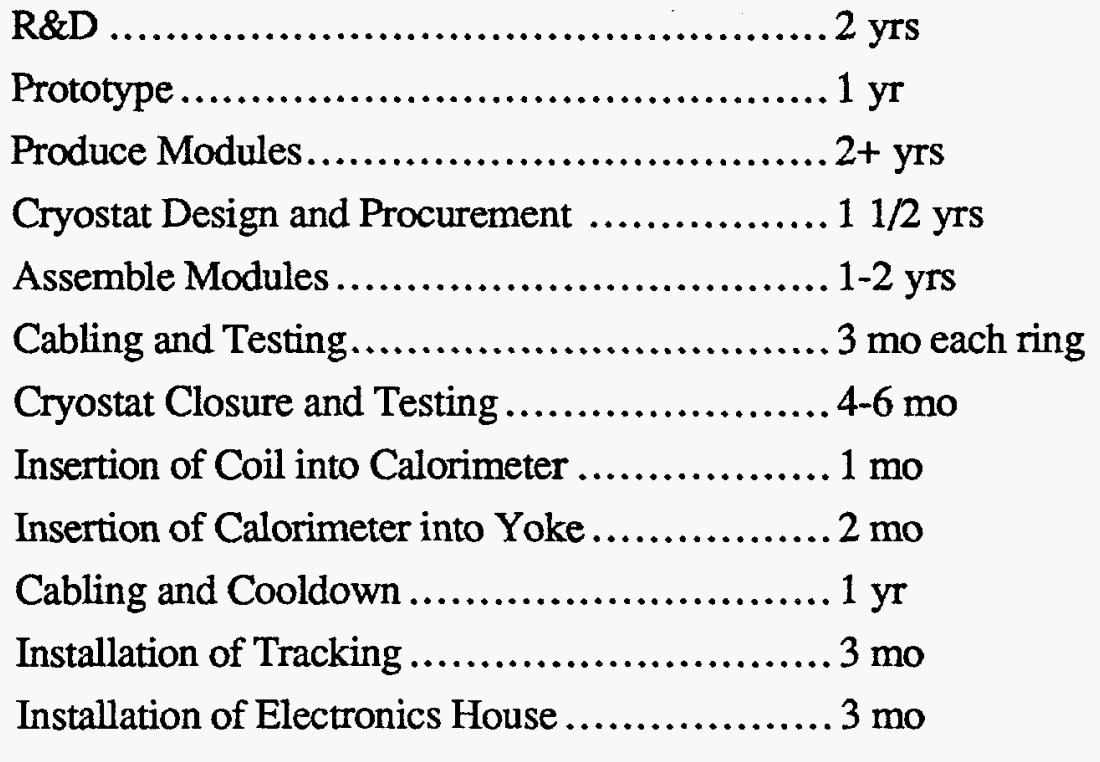 \\
\hline
\end{tabular}

When a critical path analysis (see Sec. 4.3) is done of the steps, the elapsed time was calculated to be $7-1 / 2$ years.

\subsubsection{Superconducting Solenoid Magnet}

The second major system of the Model Detector is the $5 \mathrm{~m}$ diameter, $10 \mathrm{~m}$ long superconducting solenoid magnet. This magnet is similar to those found in several of the LEP detectors and has been discussed in detail in Ref. 6, The Task Force Report on Detector R\&D for the SSC. The superconducting coil consists of a single layer helical winding of aluminum-stabilized superconductor, mounted inside an aluminum support cylinder. The conductor is indirectly cooled by conduction from a single cooling loop attached to the support cylinder. Some proposed detectors utilize much larger coils up to $7 \mathrm{~m}$ in diameter and $12 \mathrm{~m}$ long. If such a large coil is needed, it will probably have to be constructed on site because of the limits of what can be transported on public roads (see Sec. 4.1.1). However, we will use the smaller coil of the Model Detector for our analysis. What interests us here is the time scale and the steps necessary to build such a magnet and return yoke. An estimate of this is given in Table 4.5. 
Table 4.5. Time Estimates of Steps Necessary to Design and Construct the Superconducting Solenoid for the Model Detector
Design of Coil and Yoke $1 \mathrm{yr}$
Coil Fabrication 2 yrs
Fabrication of Yoke $1 \mathrm{yr}$
Preassembly of Yoke. $1 \mathrm{yr}$
Reassembly of Yoke $.6 \mathrm{mo}$
Insertion of Coil. $2 \mathrm{mo}$
Test of Coil $.2 \mathrm{mo}$
Mapping of Magnet $2 \mathrm{mo}$

It is assumed in this analysis that the yoke is preassembled at the factory in order to save time during the final assembly in the experimental area. A critical path analysis of the project (see Sec, 4.3) calculates a total elapsed time of four years necessary to design and construct such a magnet and return yoke.

\subsubsection{Muon Detection System}

\subsubsection{Design Considerations}

Three options for moving the central core detector from inside the central muon steel assembly have been considered. These options are sketched in Fig. 4.5. In Option A the central core moves along the beam direction. In this option the muon steel remains an integral unit and all steel pieces are of "standard" lengths. In Options B and $\mathrm{C}$, the core moves transverse to the beamline and a side wall of the muon steel is split and opens. In these cases there are many "non-standard" steel pieces that will increase the expense $(-10 \%)$ and complexity of the muon system. In all of the options a space of 0.5 to $1.0 \mathrm{~m}$ will be required below the central core detector to house the equipment and supports necessary for moving the core.

The entire muon detection system is to be constructed from continuous cast steel bars $0.25 \mathrm{~m} \mathrm{x} 1 \mathrm{mx} 19 \mathrm{~m}$. These bars can span the entire transverse width of the central muon steel. They weigh approximately 40 tons and can be transported on public roads. The muon steel is assumed to consist of three steel layers $1 \mathrm{~m}$ thick with $0.25 \mathrm{~m}$ gaps for chambers. The magnetic field in the muon steel is toroidal with its center on the beam axis. This requires that the long direction of the steel bars be transverse to the beam direction and that the steel be closed in the azimuthal direction to provide a continuous path for flux continuity. Openings for the chambers are thus on the faces perpendicular to the beam. Muon chambers will have to be inserted from these edges. 
It is estimated that to obtain 16-18 kilogauss in the muon steel, 1 million ampereturns will be needed. If a 30,000 amp power supply is selected, 32 turns are required around the outermost steel layers and fewer turns around the inner layers. Straight insulated lengths of $5 \mathrm{~cm}$ square copper bars are proposed for these coils. These lengths will be placed in the corners of the muon steel during construction. The magnetization of the intermediate muon toroids and forward muon toroids is again axially around the beam. Gaps for chamber insertion will be around the entire outer edges. Frames to accept muon chambers will be placed in the gaps for the entire muon detection system during construction. If the base steel is below floor level, space must be allowed at each end for insertion of the chambers.
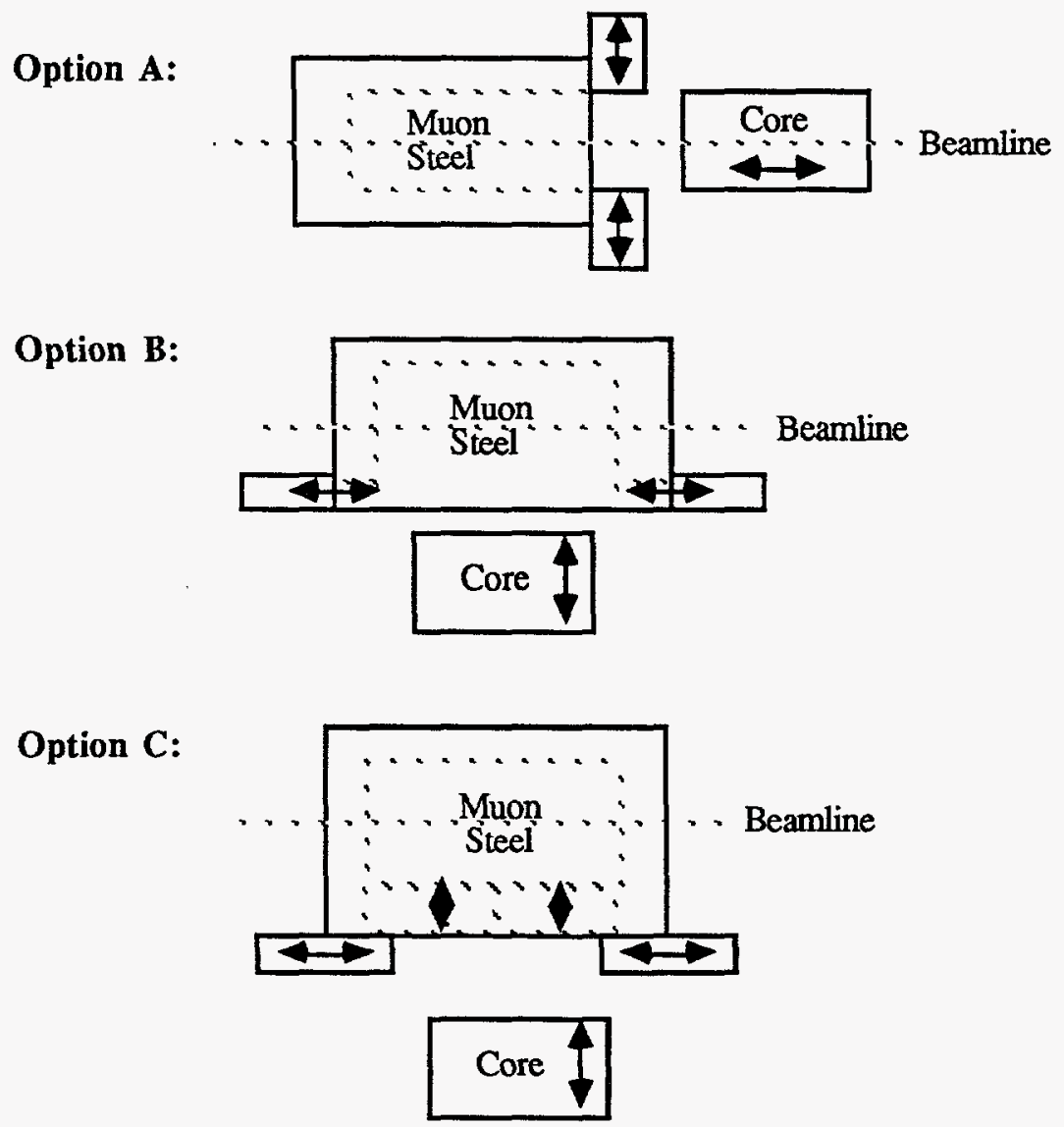

FIG. 4.5: Options for inserting core into muon steel.

\subsubsection{Experimental Hall Criteria}

The collision hall in the deep site option is assumed to be $30 \mathrm{~m}$ wide and $62 \mathrm{~m}$ long, with an attached assembly area. During the construction phase the muon system components would be fabricated on beamline while the core detector would be assembled in the underground assembly area. A 9 m diameter shaft is shown in Fig. 4.1(a) at one end of 
the hall for bringing in the 80 ton, $19 \mathrm{~m}$ long assemblies. This narrow shaft requires that the bars be lowered hanging vertical and then rigged into a horizontal position at the bottom of the shaft.

Also required is a steel storage area at the surface approximately $21 \mathrm{~m}$ wide and extending $150 \mathrm{~m}$ in length. This area is to be used for storing the bulk of the 40,000 tons of steel needed for the muon detection system. Most of the steel will be 40 ton steel bars, $0.25 \mathrm{~m}$ wide $\times 1 \mathrm{~m}$ high $\times 19 \mathrm{~m}$ long stacked two high. The open field storage area should be serviced by a 50 ton gantry crane capable of off-loading delivery trucks, and also of delivering the steel into the surface assembly building where the building crane will take over for lowering the steel down the shaft. Welding of pieces could take place in the storage area.

\subsubsection{Muon Detection System Time Schedule}

To estimate the time required to construct the muon detection system, it is assumed that 80 tons of steel per day can be rigged into the collision hall and erected. In Table 6.6 is an estimate of the number of 80 ton steel assemblies in the muon detection system. These time estimates are essentially independent of assumptions of the depth of the experimental halls, with the possible exception of the surface self-shielded option which could allow the possibility of rigging in much larger assemblies, thus shortening the total assembly time.

Table 4.6. Count of Muon Detection System Steel Assemblies

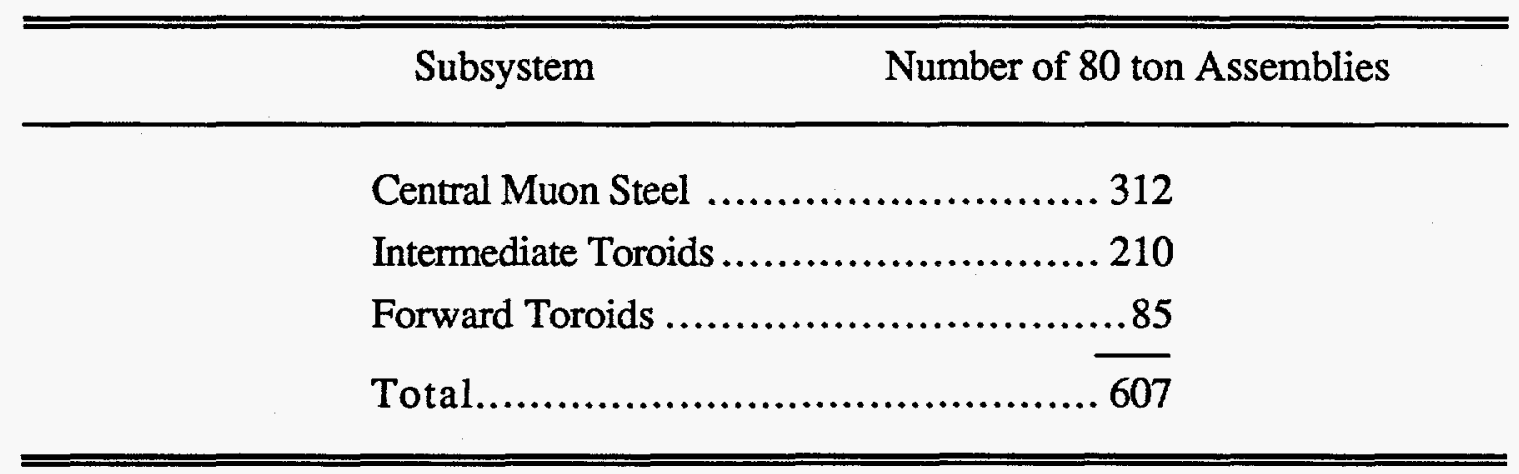

The total number of steel assemblies indicates that it will take 607 days ( 1 shift $=1$ day ) for construction of the muon detection system. This time is for steel erection only. Additional time must be included for the installation of magnetization coils and muon chamber support frames and for surveying. 8 days for the three above activities per central muon steel layer is estimated. This is to be compared to 26 days ( $~ 26-80$ ton pieces) to erect a central muon steel layer. Thus $30 \%$ (182 days) is added to the time required for steel erection. This makes the total estimated time 789 days. However, 
during these 182 additional days, the steel crews can work on other subsystems of the muon steel. If we assume that the forward toroids are erected in this manner, we save 85 days. Therefore, the final estimated number of days for erection of the muon detection system is 700 days. A critical path analysis calculates a total elapsed time of three years to erect the steel in the assembly hall (see Sec. 4.3). In a collision hall that has no assembly hall, these times may be lengthened if the same cranes must service both the muon steel and the core detector fabrication.

\subsection{Critical Path Analysis of Model Detector Assembly Scenario}

A critical path analysis study was made of the proposed Model Detector assembly scenario using the project management program MACPROJECT. The completion date of the detector was arbitrarily set to be July, 1996, in order to correspond to a possible completion of the machine installation. In order to shorten the overall elapsed time of assembly, it is necessary to carry on parallel and independent assembly operations for the three major detector systems. A short list of the important milestones is given below in Table 4.7.

Table 4.7. Major Milestones for Model Detector

Formation of Experimental Group ............1988

Start of Prototype R\&D...........................January, 1989

Completion of Calorimeter R\&D ..............January, 1991

Completion of Design Report .................January, 1991

Occupancy of Assembly Area.....................January, 1993

Occupancy of Collision Area.....................July, 1993

Detector Complete............................July, 1996

A simplified schematic of the Model Detector time line is given in Fig. 4.6. This timeline is extrapolated from experience with the present generation of large detectors. 


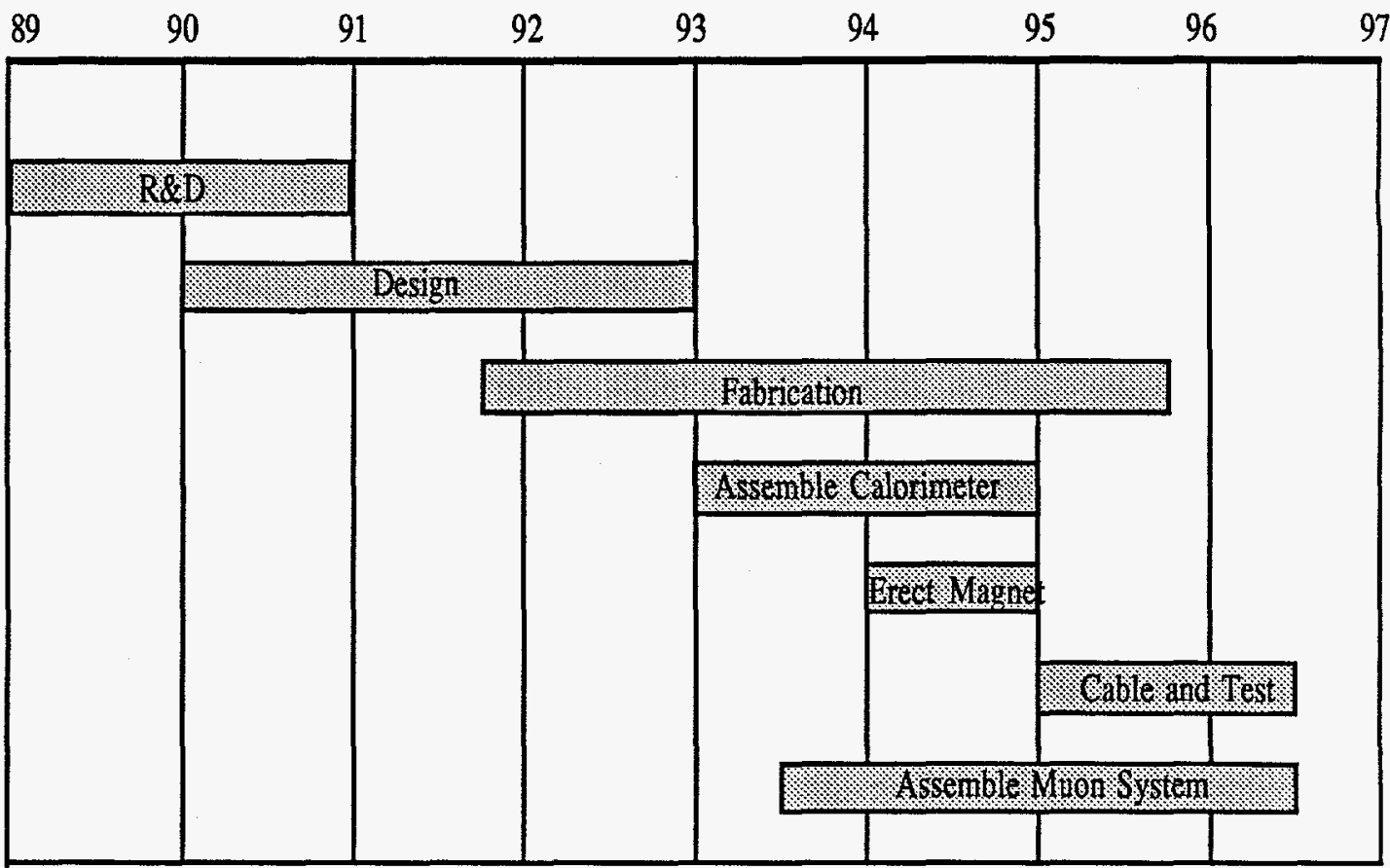

FIG. 4.6 Overall Schedule for Model SSC Detector

The first step to any complicated project is R\&D. For the Model detector it was felt that at least two years of R\&D were needed on the calorimeter systems before a final design could be started. The first year of the project is devoted solely to this $R \& D$ prior to writing a formal design report. $\mathrm{R} \& \mathrm{D}$ on the calorimeters can continue during this time, but should by of such a nature as to work out details within an agreed overall framework. By the end of the second year the design report should be complete and the R\&D should be finished. Final design can now begin on detector components. Typically, final design of complicated systems takes 6-12 months before fabrication can start. Fabrication will take a further 12-15 months before the pieces start being delivered. The assembly of the calorimeter would be the first task started in the experimental area, approximately $3-1 / 2$ years before expected beam. It would take about two years, which would be followed by another $1-1 / 2$ years of cabling and checkout. The assembly of the muon detection system would start about six months later and would take almost three years.

\subsubsection{Critical Path Analysis of the Liquid Argon Calorimeter Assembly}

A complete critical path analysis network diagram of the detector assembly is shown in Fig. 4.7. A complete table of tasks, estimated duration, and earliest and latest start and finish dates is given in Table 4.8. The upper section of the network diagram relates to the assembly of the liquid argon calorimeter. Upon completion of the design report, final design could begin on the cryostat. This cryostat design and procurement was assumed to take 24 months. This is the first element of the detector to go into the 
experimental area and sets the date for beneficial occupancy of the assembly area. That date is approximately January 1, 1993. Meanwhile, prototyping and production of the calorimeter modules have been going on so that the first arch of five has been produced by the time the cryostat assembly is complete. That arch is stacked in the assembly area by a crane dedicated to that purpose and when complete is moved into the cryostat. For the scenario, we have assumed that each arch is separately wired through the cryostat wall and tested while the next arch is being stacked. The process repeats itself five times. We have assumed that enough production facilities exist that the assembly process will always have enough modules to continue. The total elapsed time from start of stacking the first arch to completion and testing of the cabling on the fifth arch is almost $1-1 / 2$ years. Closing the cryostat and testing will take another six months. From start of work in the assembly area until completion of the central barrel calorimeter is estimated to take 25 months.

\subsubsection{Critical Path Analysis of Magnet Assembly}

The critical path network for the magnet assembly is shown in the middle level of Fig. 4.7. The final design would start upon completion of the design report and take approximately 12 months. The coil fabrication is assumed to take 24 months. The longest timeline is actually in the fabrication and assembly of the magnet yoke. This was a deliberate choice because we required preassembly at the factory in order to minimize the work later in the experimental area. This sequence has worked quite successfully for the SLD detector. Given the preassembly, the actual erection of the magnet yoke can be delayed until early 1994 and it is estimated that the coil could be tested and mapped within 12 months. This was delayed as long as possible in order to avoid interference with the calorimeter assembly which is being done in the same assembly area. After mapping, the coil is taken out of the yoke and inserted into the completed central barrel calorimeter. Then the two are reinserted into the yoke. Once this operation is complete installation of central tracking and final cabling can begin.

\subsubsection{Critical Path Analysis for the Muon Detection System}

The critical path network diagram for the muon detector system is shown in the lower third of Fig. 4.7. The assembly scenario assumes that the steel is fabricated off site, shipped to the experimental area, and assembled in place inside the collision hall. This work sets the date for the beneficial occupancy of the collision hall. Our estimate is that occupancy is required by July, 1993, for a detector completion of July, 1996. Our assembly scenario assumes sufficient space in either an assembly area or a collision hall to decouple the assembly of the muon steel and the precision calorimetry. If a decision is 
made to have only a collision hall, an independent crane system must be provided for the muon steel.

\subsubsection{Critical Path Analysis for Electronics Installation and Testing}

The last 15 months of the detector installation is occupied by final electronics installation and testing. These are shown as the last few tasks on the network diagram Fig. 4.7. After the calorimeter-coil assembly is inserted into the yoke, the final cabling can begin. The central tracking chamber, which has been fabricated elsewhere, is installed in the coil and the electronics house, which has been preassembled in modules elsewhere, is attached to the core. The model detector has many crates of electronics mounted directly on the detector itself, particularly those relating to the calorimetry and tracking; however, each of these crates has control cabling which must be connected to something outside the collision area. Those connections can either be made to an electronics house which is attached to the detector or up to the surface directly into the counting rooms. Given the numbers of channels involved, checkout of the system alone should take considerable time. The last step is to move the core detector form the assembly area into the collision area and install it in the muon steel. If the detector is built in the collision hall , the installation of the detector in the muon steel would take about the same time. 


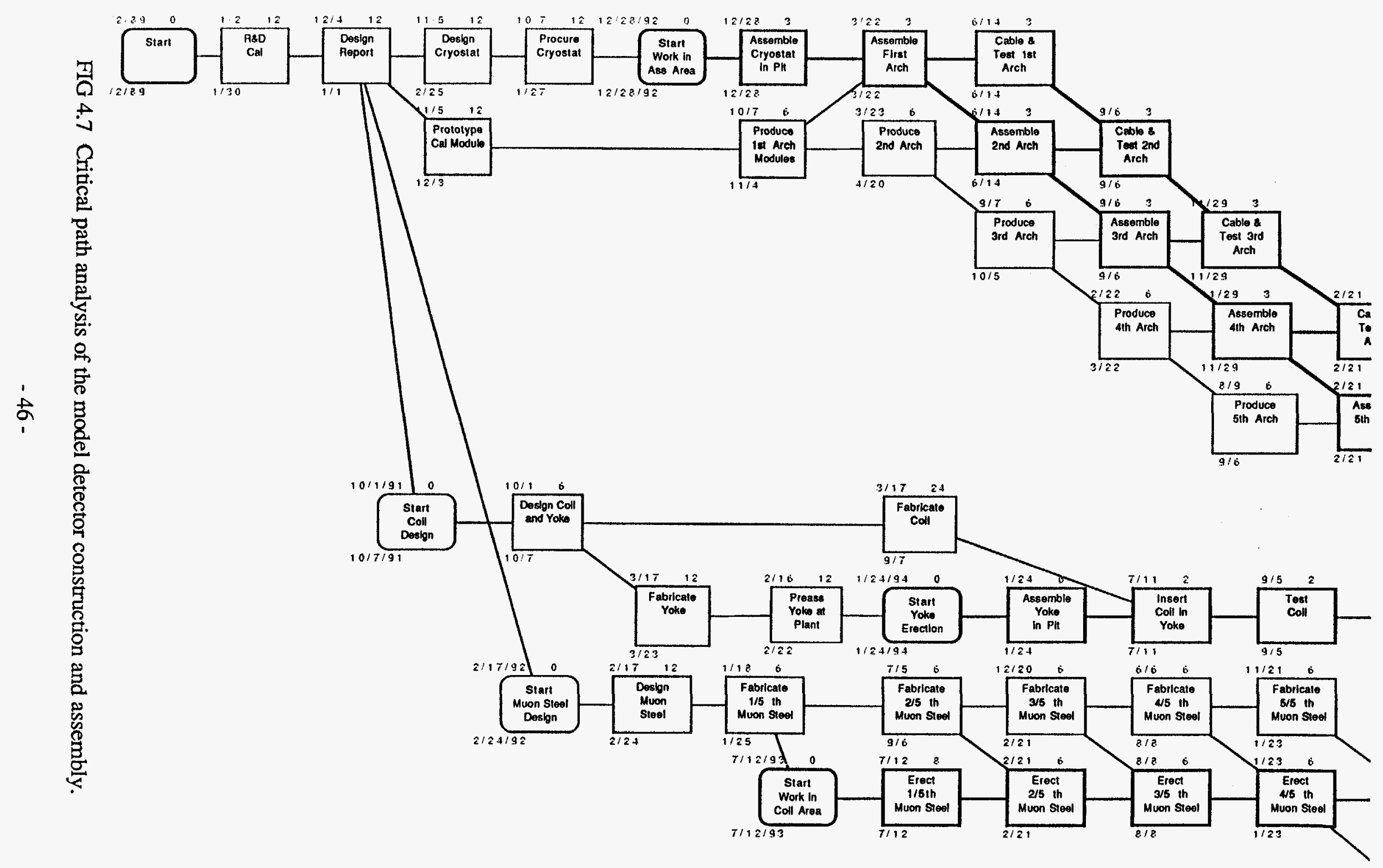




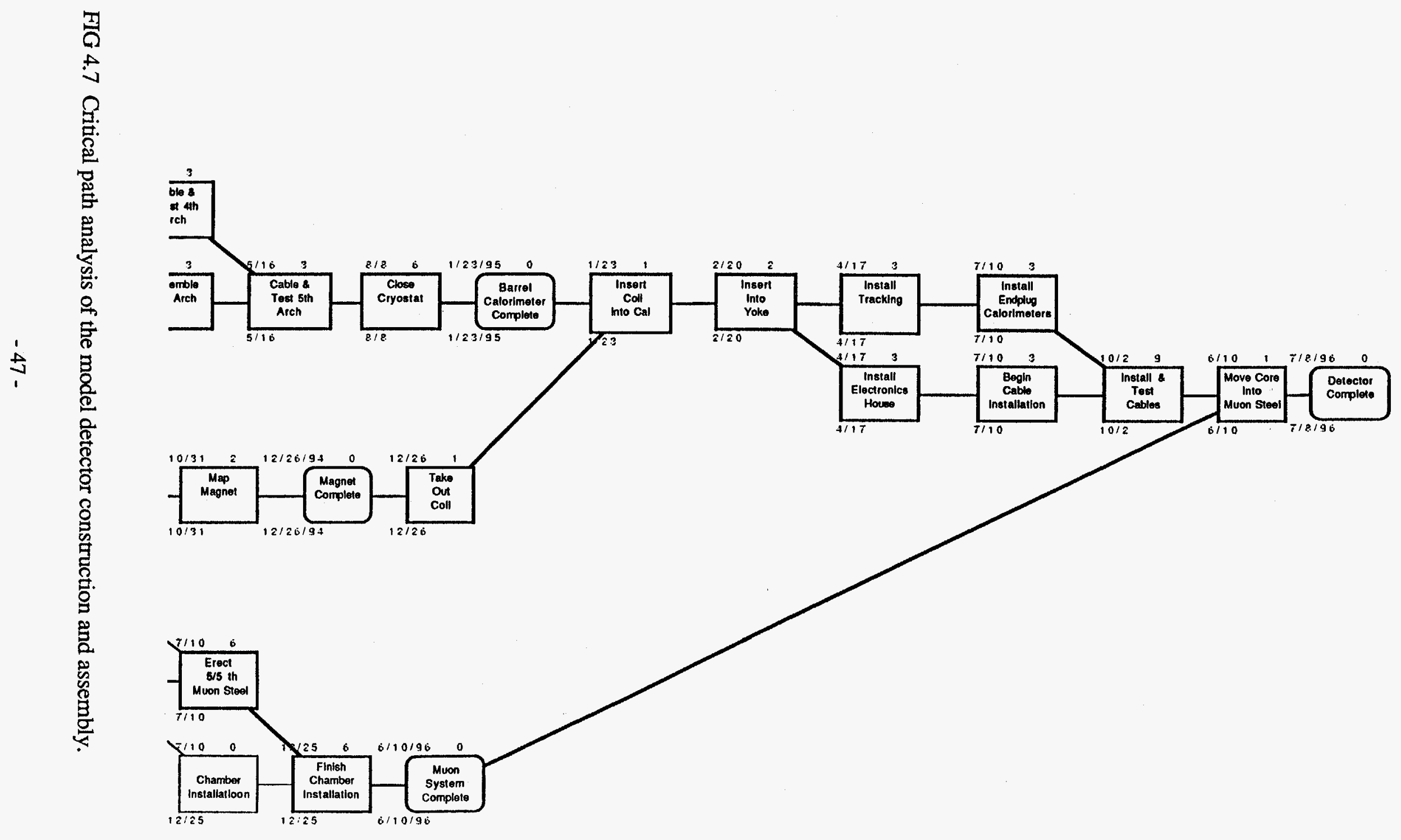


Table 4.8. Table of Tasks for Critical Path Analysis

\begin{tabular}{|c|c|c|c|c|c|c|}
\hline & Task Name & Monthe & Eatliea Stan & Earliea Finish & Lateat Stan & Latoen Finish \\
\hline & Sient & o) & $1 / 2 / 80$ & $1 / 2 / 809$ & 112180 & $1 / 21891$ \\
\hline & $2 \longdiv { \mathrm { A } 8 \mathrm { OCa } }$ & 12 & $1 / 2 / 89$ & $12 / 4 / 89$ & $1 / 30 / 89$ & $1 / 1 / 90$ \\
\hline & 3 Dessign Repon & 12 & $12 / 4 / 89$ & $11 / 5 / 90$ & $111 / 90$ & $12 / 3 / 90$ \\
\hline & 4 Stan Coil Dessign & of & $10 / 1191$ & $10 / 1 / 91$ & 1017191 & $10 / 7 / 91$ \\
\hline & 5 Design Cryostat & (2) & $11 / 5 / 901$ & $10 / 7 / 91$ & $2 / 25 / 91$ & $1 / 27 / 92$ \\
\hline & 6. Protonye Cal Module & (12) & $11 / 5 / 90$ & $1017 / 911$ & $12 / 3 / 90$ & $11 / 4 / 91$ \\
\hline & 7 Stan Muon Sieel Design & of & $2 / 17 / 92$ & $2 / 17 / 92$ & $2 / 24 / 92$ & $2 / 24 / 92$ \\
\hline & Design Coil and Yoke & 6 & $10 / 1 / 91$ & $3 / 17 / 92$ & 1017891 & $3 / 23 / 92$ \\
\hline & Procure Cryostat & (12) & $10 / 7 / 91$ & $9 / 7192$ & $1127 / 92$ & $12 / 28 / 92$ \\
\hline 10 & Design Muon Steat & 12! & $2 / 17 / 92$ & $1 / 18 / 93$ & $2 / 24 / 92$ & $1 / 25 / 93$ \\
\hline 11 & Start Work in Ale Ares & of & 121281021 & $12 / 28 / 92$ & 12128192 & $12 / 28 / 92$ \\
\hline 12 & 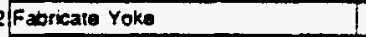 & 12 & $3 / 17 / 92$ & $2 / 16 / 93$ & $3 / 23 / 92$ & $2 / 22 / 93$ \\
\hline 13 & Fabricate 1/5 th Muon STeel & 5. & $1 / 18 / 93$ & $7 / 5 / 93$ & $1 / 25 / 93$ & $7112 / 93$ \\
\hline 14 & $4 \longdiv { \text { Produce ist Aren Modules } }$ & 6] & $10 / 7 / 91$ & $3 / 23 / 92$ & $\mid 11 / 4 / 91$ & $4 / 20192$ \\
\hline 15 & Aesemble Cryostet in Pit & 3) & $12128 / 92$ & $3 / 22 / 93$ & $12 / 28 / 02$ & 3122193 \\
\hline 18 & Slart Work in Coll Area & of & $7 / 12 / 03$ & $7 / 12 / 93 \mid$ & $7 / 12 / 93 \mid$ & $7 / 12193$ \\
\hline 17 & Preass Yoke at Plant & (12) & $2 / 16 / 93$ & $1 / 18 / 94$ & $2 / 22 / 93$ & $1 / 24 / 94$ \\
\hline 18 & Aesembio & 31 & $3 / 22 / 03$ & $8 / 24 / 93$ & $3 / 22193$ & $6 / 14 / 93$ \\
\hline 19 & Produce 2nd Arch & 5) & $3 / 23 / 92$ & 917192 & $4 / 20 / 92$ & $10 / 5192$ \\
\hline 20 & Fabricate Coil & 24 & $3 / 17 / 92$ & $1 / 18 / 94$ & $9 / 7 / 92$ & $7 / 11 / 94$ \\
\hline & Erwet $1 / 5$ in Muon Stool & 8 & $7 / 12 / 93$ & $2 / 21 / 94$ & $7 / 12 / 93$ & $2 / 21 / 94$ \\
\hline 22 & 2 Fabricate $2 / 5$ in Muan Steet & का & $715 / 93$ & $12 / 20 / 93$ & $9 / 6 / 93$ & $2 / 21 / 94$ \\
\hline 23 & Start Yoke Erection in Pit & of & $1 / 24 / 94$ & $1 / 24 / 94$ & $1 / 24 / 84$ & $1 / 24104$ \\
\hline 24 & Produce 3rd Arch & 6) & $917 / 92$ & $2 / 22193$ & $1015 / 92$ & $3 / 22193$ \\
\hline 25 & Assomble 2nd Arch & 3) & $6 / 14 / 93 \mid$ & $9 / 6 / 23$ & $6 / 14 / 93$ & $918 / 93$ \\
\hline 25 & Cable \& Teat fat Areh & 3] & $6 / 14 / 93$ & $9 / 8 / 93$ & $6 / 14 / 03$ & $916 / 93$ \\
\hline 27 & Eruet 215 in Muon Steel & 6) & $2 / 21 / 94$ & 818104 & $2 / 21 / 94$ & $8 / 8104$ \\
\hline 28 & Fabricate $3 / 5$ th Muon Steet & 6) & $12 / 20 / 93$ & $8 / 8 / 94$ & $2 / 21 / 94$ & $8 / 8 / 94$ \\
\hline 22 & Assembte Yoke in Pit & 6] & $1 / 24194$ & $711+184$ & $1 / 20194$ & $3111 / 94$ \\
\hline 30 & Cade \& Test 2nd Aren & 31 & 916193 & $11 / 28 / 83$ & $9 / 8 / 93$ & $11 / 28 / 93$ \\
\hline 31 & Assemble 3rd Areh & 31 & $9 / 8 / 03$ & $11 / 29 / 83$ & $9 / 6 / 93$ & $11 / 29 / 93$ \\
\hline 32 & 2 Produce ath Arch & 6) & $2 / 22 / 93$ & $8 / 9 / 93$ & $3 / 22193$ & $9 / 8 / 93$ \\
\hline 33 & Ereet $3 / 5$ th Muan Stoet & B] & $8 / 8104$ & $1 / 23195$ & 818194 & $1 / 23 / 95$ \\
\hline 34 & $\sqrt{\text { Fabricate } 4 / 5 \text { th Muon Sieel }}$ & 8) & $6 / 6 / 94$ & $11 / 21 / 94 \mid$ & $8 / 8 / 94$ & $1 / 23 / 95$ \\
\hline 35 & insert Coil in Yoke & 2 & $7 / 11 / 84$ & $9 / 5184$ & $7111 / 04$ & $9 / 5 / 24$ \\
\hline 36 & Cable \& Test 3rd Aren & 3 & $11 / 29 / 93$ & $2 / 21 / 94$ & $11 / 29 / 93$ & $2 / 21184$ \\
\hline 37 & Assemble 4th Arch & 3) & $11 / 29 / 93$ & $2 / 21 / 94$ & $11 / 29 / 93$ & $2 / 21 / 94$ \\
\hline 38 & Produce 5eh Areh & 6) & $8 / 9 / 931$ & $1 / 24 / 94$ & $9 / 6 / 93$ & $2 / 21 / 94$ \\
\hline 39 & Ersect 4/5 th Muon Slool & 5 & $1 / 23 / 95$ & 7110125 & $1 / 23195$ & 7110195 \\
\hline 40 & Fabricate 5/5 in Muon Stael & 6) & $\mid 11 / 21 / 94$ & $5 / 8 / 251$ & $1 / 23 / 95$ & $7 / 10 / 95$ \\
\hline 41 & Tout Goil & 2 & $9 / 5 / 94$ & $10 / 31 / 94$ & 915194 & $10 / 31 / 84$ \\
\hline 42 & Assambie 5th Areh & 3 & $212+194$ & $5 / 18 / 24$ & $212+194$ & $5 / 18194$ \\
\hline 43 & Cable \& Teat ath Arch & 3 & $2 / 21 / 94$ & $51+8 / 84$ & $2 / 21 / 04 \mid$ & $5 / 16 / 94$ \\
\hline 44 & Chamoer Instaltatioon & of & $7 / 10 / 95$ & $7 / 10 / 95$ & $12 / 25 / 95$ & $12 / 25 / 95$ \\
\hline 45 & Eroet $5 / 5$ th Muon Stoef & (5) & $7 / 10 / 05$ & $12 / 25 / 05$ & 7110105 & $12 / 25 / 95$ \\
\hline 46 & Map Magnet & 2) & $10131 / 04$ & $12 / 26 / 94$ & $10 / 31 / 94$ & $12 / 28 / 94$ \\
\hline 47 & Cable \& Teat 5 in Areh & 3) & $5 / 18184$ & $8 / 8104$ & $5 / 18194$ & $8 / 8 / 94$ \\
\hline 48 & Finiah Chamber Installation & B) & $12 / 25 / 95$ & $6 / 10106 !$ & $12 / 25 / 95$ & $6 / 10196$ \\
\hline 49 & Megnet Complete & a & $12 / 28104$ & $12 / 28 / 94$ & 12126184 & $12 / 26194$ \\
\hline 50 & Close Cryostat & 5) & $8 / 8 / 94$ & $1 / 23 / 95$ & 818104 & $1 / 23 / 25$ \\
\hline 51 & Take Out Coil & 11 & $12 / 28 / 04$ & $1 / 23 / 05$ & 12128104 & $1 / 23 / 05$ \\
\hline 52 & Muon System Complete & of & 6190196 & 8190195 & $6 / 10198$ & 8110190 \\
\hline 53 & Berrel Calorimeter Completel & of & $1 / 23 / 95$ & $1 / 23 / 95$ & $1 / 23 / 95$ & $1 / 23 / 95$ \\
\hline & Insert Coil into Cal & 1 & $1 / 23 / 05$ & $2 / 20125$ & $1 / 23195$ & 2120195 \\
\hline & Insert into Yoke & 2 & $2 / 20105$ & $4 / 17 / 05$ & $2 / 20105$ & 4117195 \\
\hline & Inatall Electronice Houseo & 3. & $4 / 17195$ & 7190195 & $4 / 17 / 95$ & 7810195 \\
\hline & Install Traeking & 3 & 4117195 & $7 / 10 / 05$ & $4 / 17 / 95$ & 7110125 \\
\hline & Begin Cable Installation & 31 & 7110195 & $10 / 2 / 95$ & $7 / 10105$ & $10 / 2195$ \\
\hline & Inatall Endplug Calorimetera & 31 & 7110105 & $10 / 2 / 95$ & $7 / 10 / 95$ & $10 / 2 / 95$ \\
\hline & Inatals \& Tost Cables & 9 & 1012195 & $6 / 10128$ & 1012195 & 5180198 \\
\hline & Move Core into Muon Stoed & 1 & $5 / 10196$ & 718196 & $8 / 10 / 58$ & $7 / 8108$ \\
\hline & Detsetor & o] & $7 / 8 / 00$ & 7181901 & 718106 & $7 / 8108$ \\
\hline
\end{tabular}




\section{Overall Schedule}

In this section, we present estimates for the total time required from initiation of the design of the experimental hall complex to the completion of the assembly of the model detector. A summary of the design and construction schedules for the four different hall options is given in Table 5.1. At this time there is considerable uncertainty in the time required to construct and outfit the experimental hall complex. A more accurate time estimate requires knowledge of the geotechnical characteristics of a specific site for the SSC. Nevertheless in our estimation there is a clear correlation between the depth of the experimental halls and the required construction time. The minimum depth of the experimental halls is determined by the radiation shielding required above the tunnel. It is our opinion that an experimental hall complex located at this minimum depth can be constructed in a significantly shorter time than halls located at substantially greater depths. Additional time might be gained if self-shielding can be used rather than global radiation shielding, depending upon the constraints imposed by self-shielding. This deserves further study.

A summary of the time required to assemble the model detector has been given in previous sections of the report. The need for parallel assembly of the major subsystems (muon system, magnet return yoke and precision calorimetry) is evident, if an optimal schedule is desired and feasible. Such parallel assembly obviously requires sufficient assembly areas and crane facilities. At present, within our uncertainties, the time required to assemble the detector will be approximately the same for surface, near-surface and deep locations of the experimental halls. With the possible exception of the self-shielded option, initiation of design and construction of this experimental hall must precede the start of prototype detector $\mathrm{R} \& \mathrm{D}$ for the model detector. This conclusion applies only to the facilities and detector of the magnitude considered here.

In Fig. 5.1 we plot the total time required from initiation of design of the experimental halls to completion of assembly of the model detector. In this figure we show the range of estimates for hall construction given in Table 3.6. In order to compare the different options (in depth) for the experimental halls and assembly time, we give in Table 5.1 the midrange estimates below for the total time required for design and construction of the experimental halls plus detector assembly:

TABLE 5.1. Midrange Construction Plus Detector Assembly Times

Surface self-shielded.............................8 years

Surface shielded ............................. $8^{1 / 2}$ years

Near surface shielded........................... 91/4 years

Deep rock ................................... 93/4 years 
The implications of this simplified comparison are clear, surface location of the experimental halls results in the shortest time for completion of the experimental halls and detector assembly and self-shielding, if possible, should be pursued. With the possible exception of the self shielded option, initiation of design and construction of this experimental hall must precede the start of prototype detector R\&D for the model detector. This conclusion applies only to the facilities and detector of the magnitude considered here.

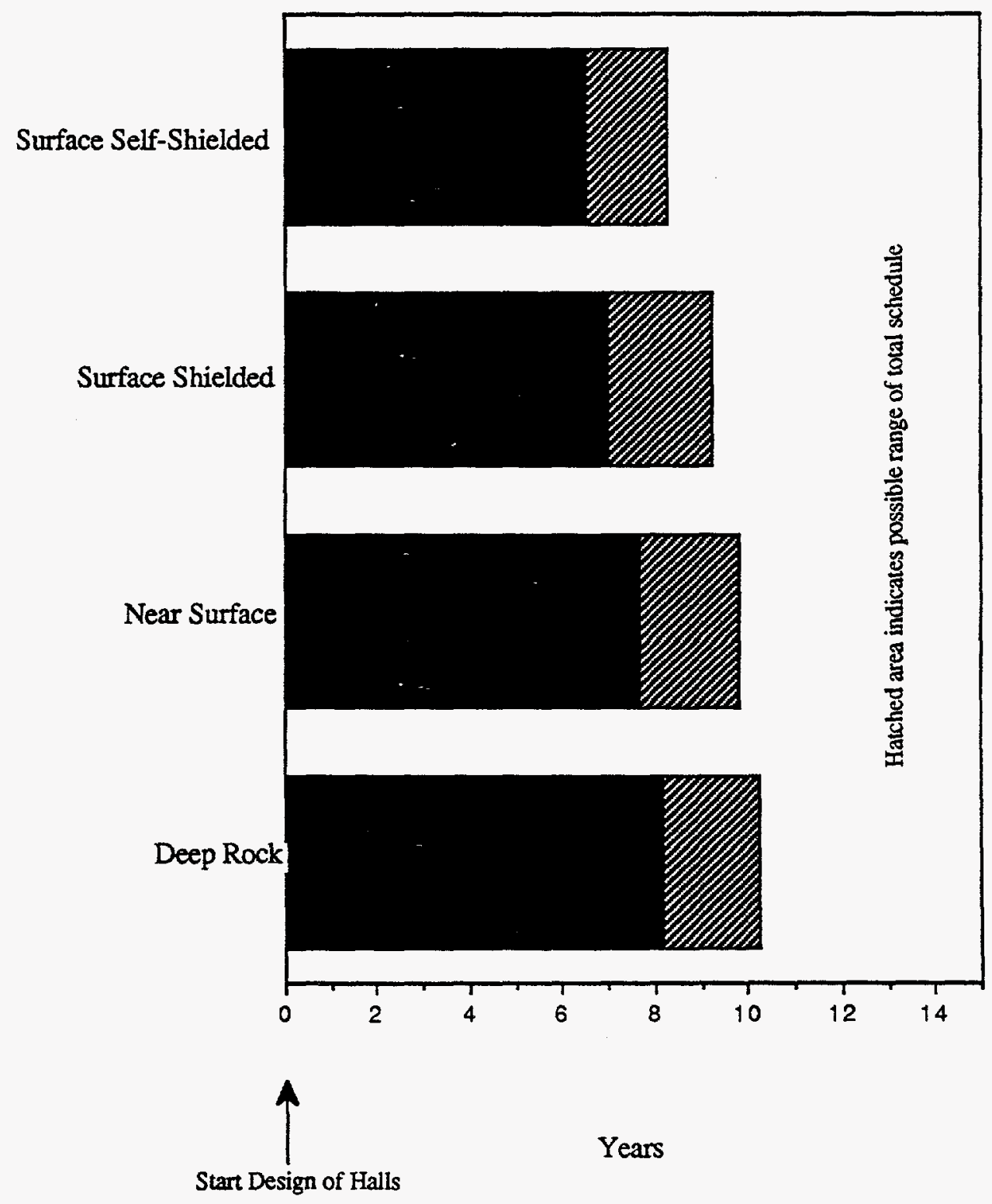

FIG. 5.1: Overall schedule for experimental hall design and construction plus assembly 


\section{Implications and Recommendations}

In this section we summarize and discuss the implications of the Task Force study. It should be strongly emphasized that many of the conclusions of the Task Force apply to detectors of the physical scale of the model detector described in Sec. 2. In the absence of a well defined experimental program for the SSC it is not possible to reach definite conclusions regarding the overall requirements, schedule and cost for all experimental halls and facilities for the SSC. We also note that the model detector itself is not an optimized device nor the end product of a lengthy and careful engineering design; it has been employed solely as a useful "tool" for the deliberations of this Task Force.

From our studies it is apparent that the experimental hall complex required for SSC-scale detectors can be constructed under a variety of assumptions regarding the eventual SSC site. There are, however, significant differences in the schedule and the cost of the experimental hall complex and detector assembly between surface and deep underground locations, with the deep underground being more expensive, and requiring a longer time for construction. The difference in cost and schedule for the experimental facilities between a surface site and a deep underground site may amount to approximately $\$ 25 \mathrm{M}$ and two years for housing the model detector.

For deep underground locations there will likely be a limitation from the feasible free span in underground excavations, which could restrict the transverse size of SSC detectors to less than about $25-30 \mathrm{~m}$.

For these reasons, based solely on considerations of experimental halls and detector assembly, a surface location for the experimental halls would be preferred. However, the interaction of a surface location of the experimental halls with the construction of the machine tunnel requires additional study. Such a study could,for example, indicate that a deep site would be preferred from considerations of overall project schedule and cost.

Given the physical scale of the model detector considered by the Task Force, construction of the complete model detector in an assembly area and subsequent movement into the beam position is not desirable and not feasible in a cost effective manner. A major part of the model detector, the muon system, should be built in place on the beamline. For detectors of more modest scale, this may not be required but such detectors were not examined by the Task Force.

It is feasible, given reasonable geotechnical conditions, to construct both an assembly hall/area and a collision hall/area of the required size. The decision, therefore, to build all of the model detector in place or to build part of the detector in an assembly hall must be based on considerations of schedule, cost, detector assembly and servicing and optimal operation of the SSC. We find that the difference in construction schedule between the collision-hall-only option and the collision + assembly-hall option to be small, given 
roughly equal total excavated volume for each case. The option with an assembly hall will likely be somewhat more expensive to allow shielding doors or walls and facilities for detector movement. A precise estimate of the cost differential awaits a more detailed design of the detector movement requirements and of shielding specifications but is likely to be less than $10 \%$ of the total cost of the sum of civil construction and detector assembly. Given the requirement for parallel assembly of the major subsystems of the model detector, the presence of a separate assembly area would appear to be slightly preferred to reduce the confusion factor present with a common assembly volume for three separate operations. Having an assembly area or beam bypass around the collision hall is clearly preferred for optimal accelerator operations and scheduling. Discussion of a possible beam bypass is beyond the charge to the Task Force and therefore we may only provide conclusions in the absence of a possible bypass. The flexibility inherent in having the capability of retracting the most sensitive parts of the model detector during the initial accelerator operation and in the case of a major detector component failure (eg. superconducting coil failure) is desirable. For detectors of more modest scale it would also be possible to construct the complete detector in an assembly area. If a detector is to be constructed on beamline, reliability of that detector will be an important design issue.

From our study, the time required to design and construct the experimental hall complex when added to the time required to assemble the model detector approaches may even exceed the time required to complete the accelerator complex. One should therefore examine carefully if detectors of the scale of the model detector are optimal and if necessary should encourage a "fast - start" to design and construction of experimental facilities and of such detectors.

In the sections below we summarize the implications of the Task Force study in detail.

\subsection{Implications for SSC Site}

The use of prudent and cost effective civil construction techniques may limit the allowed elevation of the experimental halls and hence of the SSC tunnel. For open cut construction a reasonable maximum depth of the hall invert is about $45 \mathrm{~m}$ from the ground surface, provided that competent rock is available at the $30-50 \mathrm{~m}$ depth or closer to the surface. A maximum feasible depth of a vertical cut in soil is approximately $30 \mathrm{~m}$. For a deep underground location, a free span of approximately $30 \mathrm{~m}$ is required to accommodate the model detector. This in turn requires a nominal competent cover of approximately $30 \mathrm{~m}$ above the crown of the underground hall. In the case of side-by-side collision and assembly halls, additional good rock, up to total of about $60 \mathrm{~m}$, may be required for roof stability. For halls smaller than required for the model detector less free span and rock cover would be needed. 
The importance of the above is that there may be an undesirable range of elevations at which to locate the SSC tunnel if the model detector is to be accommodated. This range is approximately from $33 \mathrm{~m}$ below ground surface (if the experimental hall is excavated from the surface) to $60 \mathrm{~m}$ (possibly $90 \mathrm{~m}$ for deep multiple halls) depth of the tunnel center below top of rock (if the hall is excavated as an underground cavern). Note that ground surface and top of rock may not necessarily coincide requiring an even deeper underground location. A somewhat smaller undesirable region would result for detectors of smaller scale than the model.

Considerations of schedule and cost of the experimental halls tend to favor a surface location. However, the influence of a surface location on the schedule and cost of constructing the tunnel must also be considered to arrive at an optimal solution. Shallow tunnel depths may involve substantial lengths of tunnel construction in soil.

The large weight load from the model detector will require direct bearing on rock or indirect bearing by means of deep foundations. Hence the surface or near surface locations would benefit from top of rock elevations near or above the hall invert level.

\subsection{Implications for Experimental Halls}

The shafts required to construct the experimental halls should not be used for construction of the SSC tunnel. Parallel construction of the SSC tunnel and of the experimental halls should be strongly encouraged. Shaft sizes envisioned for the experimental halls are well within the capabilities of normal construction techniques.

Deep rock underground halls will likely be limited to free spans of about $30 \mathrm{~m}$ in competent rock. Detectors of the size of the model detector can be accommodated in height and length of an underground hall, given competent rock conditions. Halls of the appropriate size for the model detector can be constructed in a near surface or surface location, given reasonable geotechnical conditions. For a deep rock location it might be advantageous to drive the accelerator tunnel through the hall region as a first step in the construction of the halls.

The number and distribution between permanent and temporary cranes required in the experimental halls depends on the elevation of the halls (surface on underground) and on the number of halls (collision only, or collision + assembly). Capacity of at least 100 tons will be required for timely assembly of much of the model detector. Smaller capacity (eg. 20 tons) will be required for assembly of other parts of the model detector. A recommended configuration would include two bridges, one bridge of 100 ton capacity with two 100 ton hooks, and one bridge of 100 ton capacity with a 100 ton hook and a 20 ton hook. 


\subsection{Transportation Requirements}

Construction of detectors of the scale of the model detector will require routine transport of loads of up to about 100 tons for time periods of years. Local road conditions must be such as to allow this usage. Transportation of a few heavier loads and loads of large size will need to be facilitated under special circumstances. A railhead on site would be useful in facilitating the movement of the many heavy pieces of the detector considered here.

\subsection{Civil Construction Schedule and Cost}

As noted above considerations of schedule and cost of the experimental halls indicate that a surface location is preferred. At any elevation, design and construction of an experimental hall to house the model detector will require more time than indicated for the largest hall described in the SSC Conceptual Design Report. This change results directly from an increase in detector size from those detectors considered for the Conceptual Design Report. It should be emphasized that the construction schedule and cost of all of the experimental halls and facilities cannot be accurately examined until the initial experimental program for the SSC is better known. It is quite likely that all experimental halls will not be of the size required to house the model detector. It is necessary to define at least the initial complement of detectors so that the experimental halls may be designed in a timely manner so as to allow initiation of accelerator operations.

\subsection{Detector Design and Assembly}

Given the apparent scale of the model detector, such a detector must be designed so as to facilitate routine servicing without the routine movement of 1000 's of tons of iron. In addition, substantial planning and preassembly will be required to minimize assembly time, either on beamline or, in part, in an off-beamline assembly area. We suggest that assembly time and servicing issues be addressed early in the design stage of the detector(s).

It does not appear feasible to move the massive steel muon system of the model detector from an assembly area to a collision area or vice versa. If the size of this detector system is appropriate, then it must be constructed essentially in place, closely coupling the accelerator construction schedule with the construction of this part of the detector. It does appear feasible although not easy to move the return yoke (of the model detector) and its contents from/to an assembly area. Of course, these conclusions may not apply to detectors of more modest physical scale. Clearly for detectors constructed in place on the beamline, reliability is a very important consideration.

The physical scale of the model detector begins to approach the limitations imposed by civil construction techniques and allowable time scales, particularly for an under- 
ground location. It is important therefore to examine with some care the appropriate physical scale for the largest SSC detectors.

\subsection{Recommendations for Future Studies}

The cost and schedule estimates made by the Task Force are relatively crude and do not take into account important potential variations in geological and other conditions. We recommend, at the appropriate time, more extensive and detailed estimates of schedule and cost for the experimental facilities.

The impact of our conclusions on accelerator operations and start-up must be investigated. Although it is our belief that it is possible to decouple initial operation of the core of the model detector and of the accelerator, there remains a close connection with a substantial part of the model detector assembly schedule and of the accelerator schedule.

The interaction of hall depth and tunnel depth needs additional study. This interaction, however, is very site dependent.

The conclusions and implications of this study should be presented to the community of potential experimental high energy physicists at the SSC to introduce them to the realities of civil construction limitations, schedules and costs. 


\section{References}

1 Proceedings of the 1982, 1984 and 1986 Snowmass Workshops.

2 Cost Estimate of Initial SSC Experimental Equipment, SSC-SR-1023, June 1986

3 Task Force on Radiation Shielding, SSC-SR-1026, 1987

4 E. Hoek, E.T. Brown, "Underground Excavations in Rock,"Institution of Mining and Metallurgy, London, U.K., 1980. In particular, Appendix 1, pp. 397-448.

5 E. J. Cording, A. J. Hendron, Jr., D.U. Deere, "Rock Engineering for Underground Caverns," Proceedings of the Symposium on Underground Rock Chambers, ASCE, N.Y., 1971, pp. 567-600.

6 Report of the Task Force on Detector R\&D for the SSC, SSC-SR-1021, 1986 


\title{
Appendix A - Task Force Participants
}

\author{
G. Bachy (CERN) \\ R. Bell (SLAC) \\ D. Bintinger (CDG) \\ F. Bonaudi (CERN) \\ T. Brekke (UC Berkeley - consultant to RTK) \\ K. Bull (RTK) \\ W. Davies-White (SLAC) \\ G. Drouet (CDG) \\ P.J. Ehlers (consultant to RTK) \\ M Gilchriese (CDG) \\ J. Grimson (FNAL) \\ A. Gursoy (Parsons, Brinckerhoff) \\ F. Halbo (SLAC) \\ W. Kienzle (CERN) \\ D. Luckey (MIT) \\ M Marx (Stony Brook) \\ W. Nestander (FNAL) \\ T. O'Rourke (Cornell) \\ G. Riddle (RTK) \\ P. Rohrer (BNL) \\ J. Sanford (CDG) \\ D. Theriot (FNAL), Chairman \\ J. Tompkins (CDG) \\ T. Toohig (CDG) \\ T. Winch (PSL/Wisconsin) \\ S. Wojcicki (CDG)
}




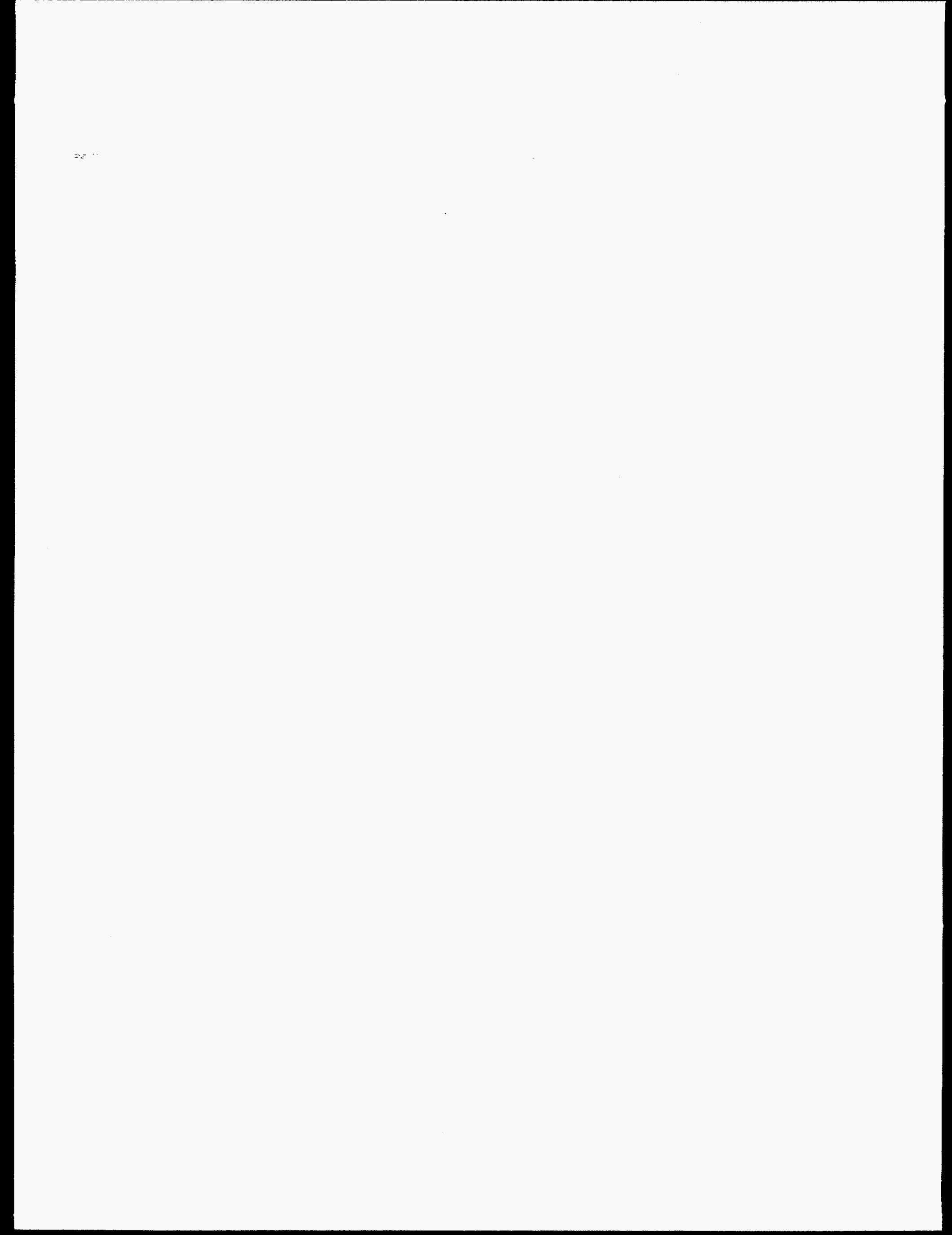




\section{Appendix B}

\section{Summary Report of the IR Working Group}

E.D.Courant

Broakhaven National Leboratory, Uprom, New Yotk 11973

M. G.D. Gilchriese

Comell Universiny, Ithuce, New York 14853

1. Lech and D. Theriot

Fermilab, Banvin, Illinois 60510

R. Schwitwer.

Hawerd Universiny, Combridge, Masschusens 012138

A. Gemen

Lowrence Benteley Laborcuory, Berteiley, Californil 94720

D. Groom D. E. Johmean (Fermilab ). S. Peges. J. Sanford T. Toohig, and S. Wojcicid

SSC Centrai Design Group," d/ Lowreace Berteicy Laborntory, Berteley, Califomia 94720

\section{Stort:}

UCLA, Los Angeles, Californix 90024

\section{Summary}

\section{The goals of the woricing group were to}

- determine the dimensions of collision and assembly halls required for experiments at the SSC:

- improve and expand on the latrice and IR optics designs described in the SSC Conceptual Design Report (CDR);

- discuss the luminosity vs frce space trade-off in the high luminosity IRs;

o determine machine requirements for experimental magnet compensation:

- estimate backgrounds and induced radioactivity in the IR regions;

- formulate lattice designs for the option to build a bypass of either of the clustered IR regions described in the CDR;

- present arguments for and against such a bypass inciuding experiment staging and scheduling; and

o make recommendations for future study.

The dimensions of collision and assembly halls required for the $4 \pi$ detectors which have been described for the SSC are substantially larger than existing halls at Fermilab, LEP, etc. The option of building such large detectors in-place should be given serious consideration. The SSC latice with clustered IRs is flexible and can probably accommodate most of the experiments described to date, although there may be some scheduling conflicts between experiments desiring very low luminosity and those requiring the maximum luminosity. The variation of luminosity for deviations around the nominal $+20 \mathrm{~m}$ free space in a high luminosity IR is not substantial for changes of a few meters which may be important to accommodate experimental apparatus. Focusing IR quadrupoles of the maximum feasible gradient should be used. Compensation of solenoidal magnets in experiments is not needed, and dipole experimental magnets can also be handied. The flux of low energy neutrons produced by the interactions in apparatus of particles produced in the pp collisions will be significant but probably manageable; more calculations are needed. Radioactivation of apparatus in the forward direction will occur. Detectors and people must be shielded from the activated elements, in part by temporary shielding, during access periods.

\footnotetext{
Operated by Universities Research Associerion fox the U.S. Deparment of Energy
}

It is technically feasible to construct a bypass for a clustered IR region on either side of the machine. The penalties are an increase in machine circumference, additional tunnel length for the bypass and more magnets and associated systems. A bypass on the same side of the machine as the injector, to put all experimental facilities on one side of the machine, would substantially increase the circumference of the machine uniess the number of intersection regions were reduced. A bypass on either side could have a significant impact on the construction of experimental halls and might make it easier to build experiments in-place. Such a bypass would also allow more flexibility in staging the experimental program. A detailed estimate of the required funding, including experimental facilities and staging of experiments, needs to be done very soon. The bypass option has such a large impact on the overall machine and experiment plan that it requires immediate attention by the Central Design Group. While it is not at all clear that constructing a bypass is the proper choice, the concept does require additional study.

\section{Detector Sizes and Collision/Assembly Hall Dimensions}

In this section we will discuss the sizes of detectors for the SSC, and the dimensions of collision halls and assembly halls that result from the detector dimensions. The parameters of large $4 \pi$ detectors for the SSC have been described in previous workshops ${ }^{1}$ and reports ${ }^{2}$ and at this meeting. Although there are many uncertainties in the nature of $4 \pi$ detectors for the SSC, many examples exist, a few of which have been explored in some detail. We therefore can use these examples with reasonable confidence to determine the shape and size of collision and/or assembly halis for $4 \pi$ detectors. Detectors for forward/backward experiments have also been described in reports ${ }^{2}$ and at this meeting. 4,5,6 Such experiments roughly fall into three classes, based on physics interest and luminosity requirements: (1) forward, for studies of rare $B$ decays, $t$ decays and other high mass particles, etc. ${ }^{4}$; (2) very forwari, some overiap with (1) and studies of diffractive production of new and old particles; and (3) elastic or almost elastic scattering. 6 Because of the many possibilities for experiments in the forward direction, it is more difficult to determine the sizes of the associated collision and assembly halls. In order to have definite examples we have chosen to determine the appropriate hall dimensions for a forwand detector such as that described in SSC-SR-1023 or the TASTER experiment described in these proceedings ${ }^{4}$ and the quadrupole spectrometer first deseribed by Bjorken. ${ }^{5}$ These examples should be representative of needs in the forward direction. The collision and assembly hall needs for elastic scattering experiments are minimal and will not be described here. 6 Many other experinental arrangements are possible at the SSC. For example, detectors $7,8.9$ with magnetic spectrometers at $90^{\circ}$ will require collision halls with considerable transverse but reduced longitudinal dimensions. We will briefly diseuss this possibilty. Other "special purpose" detectors have not yet been described in sufficient detail to determine the appropriate hall sizes. 
TABLE 1. The dimensions in meters of $4 \pi$ detectors

\begin{tabular}{|c|c|c|c|c|c|}
\hline Derector & $\begin{array}{l}\text { Closed } \\
\text { Length }\end{array}$ & $\begin{array}{l}\text { Reurotod } \\
\text { Lengeth }\end{array}$ & $\begin{array}{l}\text { Height } \\
\text { Centrol }\end{array}$ & $\begin{array}{l}\text { Width } \\
\text { Centril }\end{array}$ & $2^{2}$ \\
\hline Model A & 26 & 40 & 19 & 19 & 20 \\
\hline Model B & 27 & 40 & 19 & 19 & 20 \\
\hline Iron Muon & 25 & 40 & 19 & 19 & 20 \\
\hline L3' & 25 & 36 & 24 & 24 & \\
\hline D1 & 28 & 36 & 15 & 15 & 18 \\
\hline $\mathrm{CDF}^{\prime}$ & 16 & 25 & 12 & 12 & 9 \\
\hline DO' & 22 & 33 & 13 & 13 & \\
\hline UA1' & 16 & 20 & 13 & 13 & \\
\hline
\end{tabular}

\begin{tabular}{|c|c|c|c|c|c|}
\hline $\begin{array}{l}\text { Length } \\
\text { Eocor d }\end{array}$ & $\begin{array}{l}\text { Height } \\
\text { forom }\end{array}$ & $\begin{array}{l}\text { Width } \\
\text { Eocondd }\end{array}$ & $\begin{array}{l}\text { Core } \\
\text { Lengin }\end{array}$ & $\begin{array}{l}\text { Core } \\
\text { Hejight }\end{array}$ & $\begin{array}{l}\text { Core } \\
\text { Widtin }\end{array}$ \\
\hline 11 & 9 & 9 & 14 & 12 & 12 \\
\hline 11 & 9 & 9 & 13 & 12 & 12 \\
\hline 12 & 9 & 9 & 12 & 9 & 9 \\
\hline 11 & 8 & 8 & 15 & 8 & 8 \\
\hline \multirow[t]{3}{*}{9} & 9 & 9 & 11 & 12 & 12 \\
\hline & & & 12 & 8 & 8 \\
\hline & & & 11 & 9 & 9 \\
\hline
\end{tabular}

The dimensions of $4 \pi$ detectors described in Refs. 1-3 are given in Table 1. To understand the meaning of the various dimensions, refer to Fig. 1.

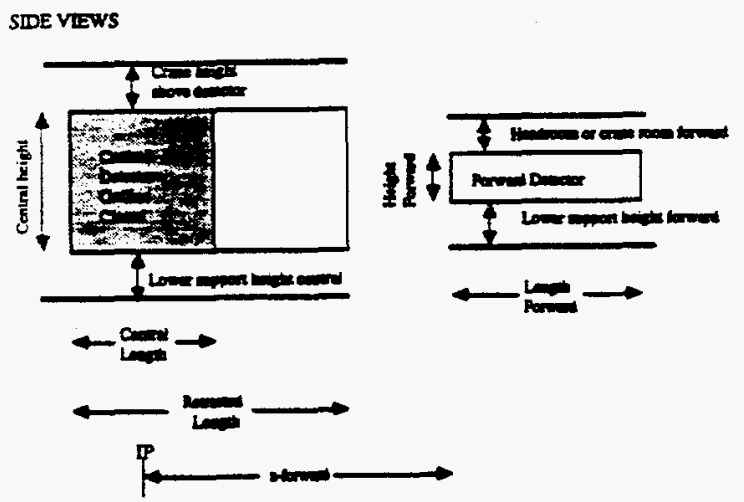

END VEWS

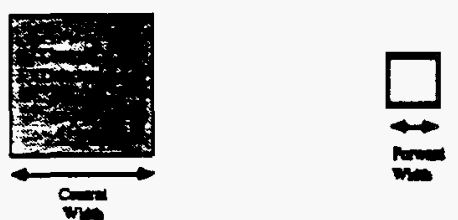

TOP VEWW

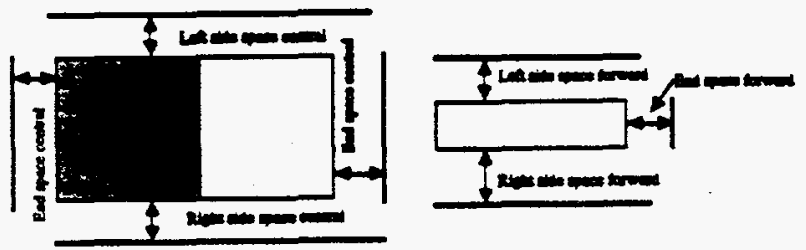

Fig. 1 Explanation of the dimensions given in Table 1, and in the text.

The "core" refers to that part of the central detector which might be rolled out of the beamline. The core does not include magnetized iron for muon measurements, on the sides or in large angle forward tirection (intermediate toroids). The dimensions given in Table 1 nclude electronics, shielding and any other equipment directly attached to the major detector elements except support structures beneath the major pieces of the detector. These dimensions are uncertain to at least $\pm 1 \mathrm{~m}$ since many of the details of detector construction have not yet been explored.

The dimensions of the collision halls for the $4 \pi$ detectors can be determined under two different assumptions. In the "traditional" way the detector is assembled in an assembly hall and then moved, piecewise if necessary, into the collison hall. Alternatively, the detector can be assembled directly in the collision hall; the "build-in-place" option. In this case the assembly hall is eliminated Is this necessary for the very large $4 \pi$ detectors? In the case of the L $33^{\prime}$ detector, as conceived, it is necessary to build it in place. For the other very large detectors (Model A, Model B, Iron Muon Spectrometer, and D1) it is possible to arrange the detector so that the central core of the detector can be rolled out of the beam line, although not quickly - see the discussion by the $4 \pi$ detector group in these proceedings. Although it is possible to remove the central cores of these detectors, they are still massive, considerably larger than existing detectors. In the buildin-place option, routine maintenance could be done during weelly or bi-weekly machine down times but major repairs or upgrades could only be done during long shutdowns. The machine and detector schedules are therefore closely coupled. The build-in-piace scenario aiso requires a tight coupling of the machine and detector construction schedules to allow a detector to be operational at turn on. This makes scheduling more complex, but likely raises the priority of funds for the detectors to be built in piace. The decision to build-in-place or to construct assembly halls must be made on technical grounds (what is the cost of moving such large objects) and funding decisions for each detector or detector type.

For both cases, a simple algorithm (using a spreadsheet) has been developed to use the dimensions given in Table 1 to determine the size of the halls under the two options above. To determine the size of the collision hall in the case when there is both a collision and an assembly hall, the procedure is relatively simple. To the dimensions in Table 1 one must add clearance around the detector outline for the detector in an open configuration. Although the clearance dimension will likely vary slightly from detector to detector, representative values are given below.

- crane (100 ton?) space (includes crane) - central detector - $5 \mathrm{~m}$

- crane (10 ton?) space - forwand region - $3 m$

- lower supports - central - $2 \mathrm{~m}$ (this may appear to be large, but working space for muon chambers and electronics may be needed beneath the detector in addition to supports

- lower supports - forward - $1 \mathrm{~m}$

- side space central (left and right) - 4m

- side space forward - left - $3 \mathrm{~m}$

- side space forward - right - $6 \mathrm{~m}$

- end space central - $4 \mathrm{~m}$

o end space forward - $6 \mathrm{~m}$ 
Adding these to the dimensions given in Table 1, we obtain the collision hall dimensions in Table 2.

TABLE 2. Collision hall dimensions in meters, and volume in $\mathrm{m}^{3}$ for $4 \pi$ detectors

Cental Central Central 2-hail Forwer Forward Forward Total Detector Length Height Width Ecowand Length Height Width Volume

$\begin{array}{lllllllll}\text { Model A } & 48 & 26 & 27 & 24 & 13 & 13 & 18 & 36426 \\ \text { Model B } & 48 & 26 & 27 & 24 & 13 & 13 & 18 & 36426 \\ \text { Iron Muon } & 48 & 26 & 27 & 24 & 14 & 13 & 18 & 36636 \\ \text { L3 }^{\prime} & 44 & 29 & 32 & & & & & 40832 \\ \text { D1 } & 44 & 22 & 23 & 22 & 13 & 12 & 17 & 24630 \\ \text { CDF' }^{\prime} & 33 & 19 & 20 & 16.5 & 11 & 13 & 18 & 14850 \\ \text { D0' } & 41 & 20 & 21 & & & & & 17220 \\ \text { UA1' } & 28 & 20 & 21 & & & & & 11760\end{array}$

The ciearance space transverse to the beam in the forward directions is asymmetric to allow removal of detector elements, space for detector support systems (gas, cooling, etc.) and passage into the tunnel region. For the CDF' (upgraded CDF), DO' (upgraded DO) and UA1' (upgraded UA1) detectors the dimensions in Table 2 are probabiy slight overestimates of the actual requirements. In particular, the crane capacity and the supports beneath the detector are likely to be smaller, which would reduce the height by about $2 \mathrm{~m}$. Also the dimensions assume that the central cores of the detectors (except L3) will roll out of the beam.

Of course, underground halls of the size in question do not have box-like dimensions, so the values given in Table 2 outline the useful rectangular volume rather than the true shape. The collision hall (and assembly hall) shapes are more quasi-cylindrical. For the large detectors, the axis of the cylinder should run parallel to the beam direction to reduce the required unobstructed span to a minimum. For the Model A or Model B $4 \pi$ detectors, a cross-section view of a somewhat more realistic outline is shown in Fig.2. If the hall is mostly consuructed in a circular cross section and then filled in, there is substantial extra space at the top and sides of the hall. Some of this space can be used for air ducts, cable-ways, etc. For comparison, a similar view of the L 3 detector at LEP is shown in Fig. 3 . In our model there is considerably more "empty" space surrounding the detector outiline for the SSC than there is for L3 (or other) LEP detectors. This would seem prudent, at present, to allow for future expansion of the SSC detectors and uncertainties in the actual dimensions.

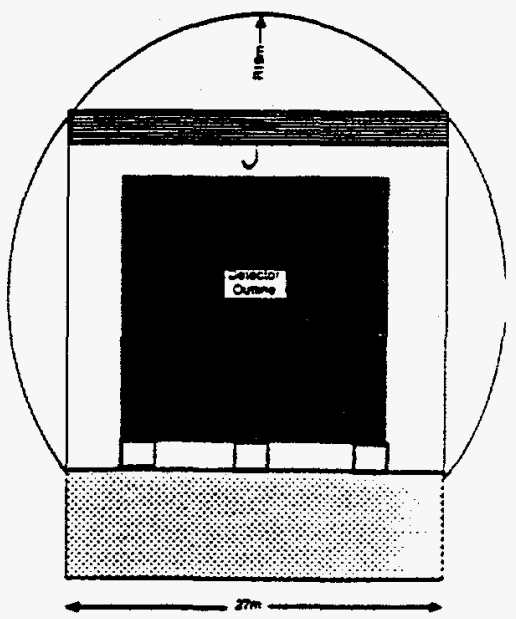

Fig. 2 A beams-eye view of the collision hall for large $4 \pi$ detectors.

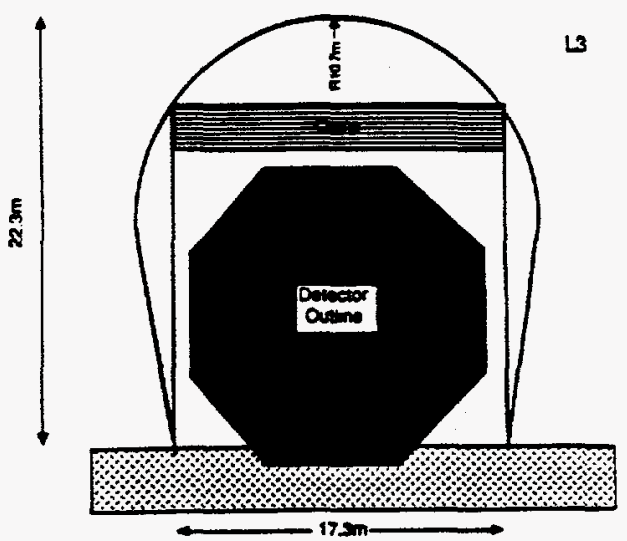

Fig. 3 A beams-eye view of the collision hall for the $\mathrm{L} 3$ detector at LEP.

The dimensions of the assembly hall can aiso be determined from Table 1 plus added space. Reasonable values for the additions are

- crane (100 ton) height $-5 m$

- space for removable shielding-wall thickness between the collision hall and the assembly hall $-7 \mathrm{~m}$

- clearance around the central component of the detector to allow passage through the access door - $1 \mathrm{~m}$

- space for assembly/disassembly

The dimensions of the assembly hall may be calculated from the numbers above and from Table $l$ as given beiow

Hall length $=2 \times$ core length (from Table 1$)+2 \times$ forward length (from Table 1)

Hall width $=2 \times$ core width (Table 1$)+$ forward width (Table 1) + shieiding thickness

Hall height $=$ core height $($ Table 1$)+$ clearance + crane height

Door height $=$ core height $($ Table 1$)+$ clearance

Door length $=$ core length (Table 1$)+2 \times$ clearance

This yields the assembly hall dimensions given in Table 3 . The L3' (similar to the L 3 detector at LEP) is assumed to be built in place and does not require an assembly hall (but does require access shafts). A plan view of the collision and assembly halls for the Model A or Model B detector is shown in Fig. 4. Again these dimensions are for the useful voiume and do not include extra space from excavation.

TABLE 3. Assembly hall dimensions for $4 \pi$ detectors

$\begin{array}{lcccccc}\text { Derectr } & \begin{array}{c}\text { Door } \\ \text { Length }\end{array} & \begin{array}{c}\text { Door } \\ \text { Height }\end{array} & \begin{array}{c}\text { Hall } \\ \text { Leneth }\end{array} & \begin{array}{c}\text { Hall } \\ \text { Width }\end{array} & \begin{array}{c}\text { Hall } \\ \text { Height }\end{array} & \begin{array}{c}\text { Toual } \\ \text { Yolume }\end{array} \\ \text { Model A } & 16 & 14 & 50 & 40 & 19 & 38000 \\ \text { Model B } & 15 & 14 & 48 & 40 & 19 & 38480 \\ \text { Iron Muon } & 14 & 11 & 48 & 34 & 16 & 26112 \\ \text { L.' } & & & - \text { none required - } & & \\ \text { D1 } & 17 & 10 & 52 & 31 & 15 & 24180 \\ \text { CDF' } & 13 & 14 & 40 & 40 & 19 & 30400 \\ \text { D0' } & 14 & 10 & 24 & 23 & 15 & 8280 \\ \text { UA1 } & 13 & 11 & 22 & 25 & 11 & 8800\end{array}$




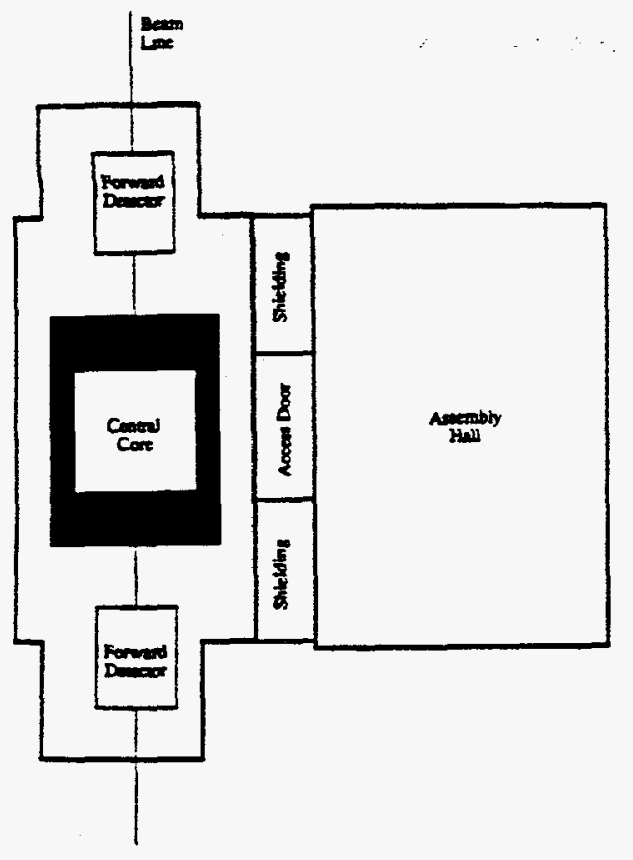

Fig. 4 Plan view of the collision and assembly halls for the Model A or Model B detector. The drawing is to scale.

For the option without an assembly hall (or possibly the L3' detector), the collision hall size must expand Space for access shafts must also be included. Again an algorithm may be developed using the dimensions in Table 1 . The formulae are similar to that for the assembly hall space and are given below

Hall length $=$ retracted length $($ Table 1$)+2 \times$ forward length (Table 1$)+4 \times 6 \mathrm{~m}$ (or $2 \times 6 \mathrm{~m}$ without forward detector)

Hall width - same as Table 2

Hall height - same as Table 2 - lower supporr distance

The resulting dimensions of the collisions halls are shown in Table 4. For reference a plan view for the Model A or B detector is shown in Fig. 5 . Note the placement of the access shafts. It may be advantageous to have an access shaft over the collision hall rather than to the side for the larger detectors, if possible. In this design the additional space in the collision hall is added along the beam direction to keep the unobstructed span of the excavated hall to a minimum. It may be useful to increase this span somewhat, even if support pillars are needed, to allow more room for sideways expansion of the detectors (more iron for muon measurements).

TABLE 4. Collision hall dimensions for the build-in-place option

$\begin{array}{lcccc}\text { Derector } & \begin{array}{c}\text { Hall } \\ \text { Leneth }\end{array} & \begin{array}{c}\text { Hall } \\ \text { Width }\end{array} & \begin{array}{c}\text { Hall } \\ \text { Height }\end{array} & \begin{array}{c}\text { Total } \\ \text { Volume }\end{array} \\ \text { Model A } & 86 & 27 & 24 & 55728 \\ \text { Model B } & 86 & 27 & 24 & 55728 \\ \text { Iron Muon } & 88 & 27 & 24 & 57024 \\ \text { L'' } & 48 & 32 & 29 & 40832 \\ \text { D1 } & 82 & 23 & 20 & 37720 \\ \text { CDF' } & 67 & 20 & 17 & 22780 \\ \text { D0' } & 45 & 21 & 18 & 17010 \\ \text { UA1' } & 32 & 21 & 18 & 12096\end{array}$

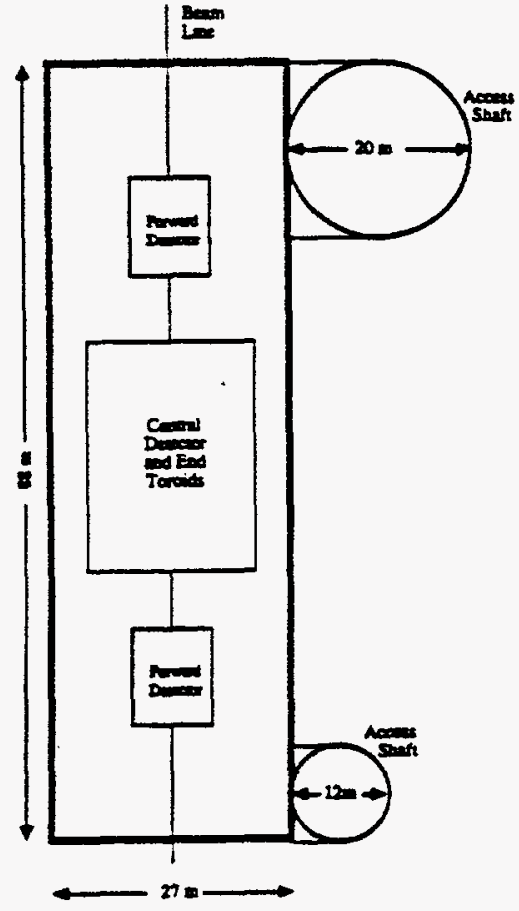

Fig. 5 Collision ball for Model A or Model B detector. No assembly hall.

A similar exercise has been done for the forward detectors. The approximate dimensions of these detectors are given in Table 5 .

TABLE 5. Dimensions of special purpose forward detectors.

$\begin{array}{lcccc}\text { Detrectix } & 2 \text { front } & \text { Length } & \text { Eeight } & \text { Width } \\ \text { SSC-SR-1023 } & 5 & 105 & 6 & 6 \\ \text { TASTER } & -1 & 20 & 14.5 & 14.5 \\ \text { Quadrupole spect. } & 10 & 1000-2000 & 1-3 & 1-3\end{array}$

The transverse dimensions of the quadrupole spectrometer detector elements are uncertain and will likely vary strongly with the distance from the IP. Again the collision hall dimensions may be obtained by adding the appropriate clearance space. In this case, however, the required space depends strongly on which forward detector is considered. The components of the very long quadrupole spectrometer are smaller in transverse dimension than the more conventional shorter spectrometers. We therefore give two values for the required space; the first for the conventional magnetic spectrometers and the second a range for the quadrupole spectrometer in parentheses

- crane $[20 \operatorname{ton}(10$ ton $)]-4 m(3 m)$

- support space beneath the detector $-1 \mathrm{~m}(1 \mathrm{~m})$

- crane $[20$ ton(10 ton $)]-4 m(3 m)$

- support space beneath the detector - $1 \mathrm{~m}(\mathrm{~lm})$

- left side space $-3 m(1-2 m)$

- right side space $-6 \mathrm{~m}(2-4 \mathrm{~m})$

o space where the forward collision hall begins to merge with the tunnel $-3 \mathrm{~m}$

The resulting collision hall dimensions are given in Table 6 . 
TABLE 6. Collision hall dimensions for special purpose forward detectors.

$\begin{array}{lcccc}\text { Detector } & \text { Haif-length } & \text { Height } & \text { Width } & \text { Volume } \\ \text { SSC-SR-1023 } & 108 & 11 & 15 & 17820 \\ \text { TASTER } & 23 & 19.5 & 23.5 & 10540 \\ \begin{array}{l}\text { Quadrupole. } \\ \text { Spectrometer }\end{array} & 1000-2000 & 5-7 & 4-9 & (20000-126000) \times 2(?)\end{array}$

Note that the half-length means the distance from the interaction point to the wall of the collision hall. Since these detectors may only be on one side of the IP, the collision halls would be very asymmetric. It is not clear if the quadrupole spectrometer can easily be implemented on one side only, hence the factor of 2 in Table 6 . For comparison to the volume of the quadrupole spectrometer, the volume of the tunnel is about $7000 \mathrm{~m}^{3}$ per kilometer. The dimensions of the remainder of the hall opposite to the forwand detector cannot easily be specified. An example, however, would combine an upgraded detector (eg. CDF) with either of the short detectors. The resulting hall sizes would then be the appropriate combination of dimensions in Table 2 and Table 6.

For these detectors, assembly in place is not a likely possiblity, except by using the bypass option (see discussion later). Compared to the large $4 \pi$ detectors, the sizes of the the components of the forward detectors are relatively modest. Also, unlike the $4 \pi$ detectors, there is no central component which can be profitably rolled out of the beam. For forward detectors, much of the assembly work could be done away from the $\mathbb{R}$ and a modest staging area would suffice.

Magnetic spectrometers at $90^{\circ}$ have been described at Snowmass $184^{7,8}$ and at the Fermilab Trigger Workshop. 9 Such spectrometers cover a small rapidity range near $y=0$ on one side of the beamline. The length of such spectrometers may vary strongly, depending upon the particle momentum or jet energy range of interest. VanDalen and Hauptmann in '84, and Theodosiou and Bensinger and Giokaris last year ${ }^{9}$ describe spectrometers $12-15 \mathrm{~m}$ in length, transverse to the beamline, and $\pm 8 \mathrm{~m}$ along the beam. Giokaris and Majewski ${ }^{8}$, however, describe one $70 \mathrm{~m}$ long. The latter eleariy requires a collision hall of unusual shape. The short $90^{\circ}$ spectrometers might be accommodated into a $4 \pi$ collision hall of the build-in-place variety. They would be tight or impossible matches to a collision hall with assembly hall uniess the shielding between the halis were permanently moved It is likely that jet or particle spectrometers at $90^{\circ}$ would operate in conjuction with other detector elements, either a forward spectrometer or a modest calorimetric central detector. This experimental package has not been described in sufficient detail to determine realisric dimensions for collision halls or assembly halls. More work is needed to define such detectors.

\section{Lattice and IR optics}

Two experimental configurations for the SSC lattice have been discussed in which $\beta^{*}$ may be very large ${ }^{10}$ :

a) elastic scattering and very low $p_{T}$ physics

b) high rapidity coverage, beyond the $|y|=5-6$ covered by other experiments but not including elastic scattering

Exploratory studies were made of possible IR designs for each of these types of experiments.

The elastic scattering and very low $\mathrm{P}_{\mathrm{T}}$ experiments require an $\mathbf{P}$ with large $\beta^{*}$, variable between 400 and $4000 \mathrm{~m}$, and a suitable detector location whose betatron phase, $\psi$, from the $I P$ is such that sin $\psi$ is reasonably high. Such an IR has been designed by A. Garren and $D$. E. Johnson by modifying the low- $B$ IR design of the CDR see Fig.6. The modifications involve use of shorter quadrupoles and the addition of vertical dipole magnets six meters from the $\mathbb{P}$. The dipole magnets are necessary because large crossing angles are needed for large $\beta^{*}$ as discussed later. The dipoles bend the beam parallel to the horizontal direction, enabling beam to pass through the quadrupole triplets with displacements of about $5 \mathrm{~mm}$ or less. The detectors for elastic scattering are placed at spool piece locations next to a quadrupole, seven half-cells from either end of the straight section. At this location, the vertical $\beta$ function is about $310 \mathrm{~m}$, close to its maximum value. The betatron phase between a detector and the collision point is close to an odd multiple of $90^{\circ}$. Over the $\beta^{*}$ range of $400-4000 \mathrm{~m}$, the range of sin $\psi$ is -1.0 to -.91 .

High rapidity experiments may require long drift lengths from the collision point for detectors. Fig. 7 shows a long straight section designed by A. Garren, made by combining the two "future IRs" of the CDR layout into a single long $\mathbb{R}$. By doing this, a free space between quadrupoles of about 1500 meters may be obtained. The beams could be made to cross twice, at either end of this space or elsewhere if desired. If there is a beam crossing near the middle of the free space, a larger $\beta^{*}$ range would be possible.

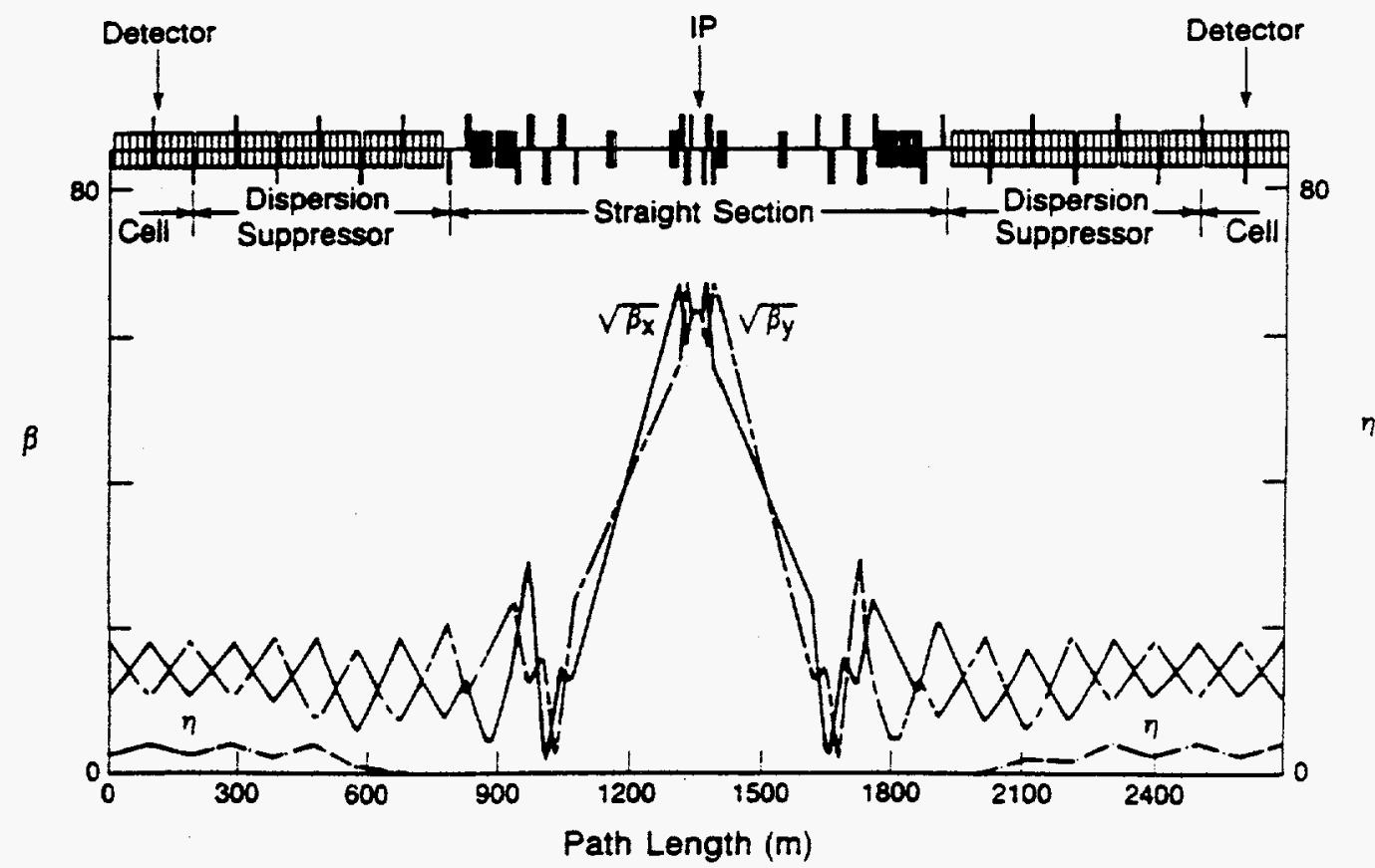

Fig. 6 Module containing interaction point with high $\beta^{-}$for elastic scattering and low $\mathrm{p}_{\mathrm{T}}$ physics. 


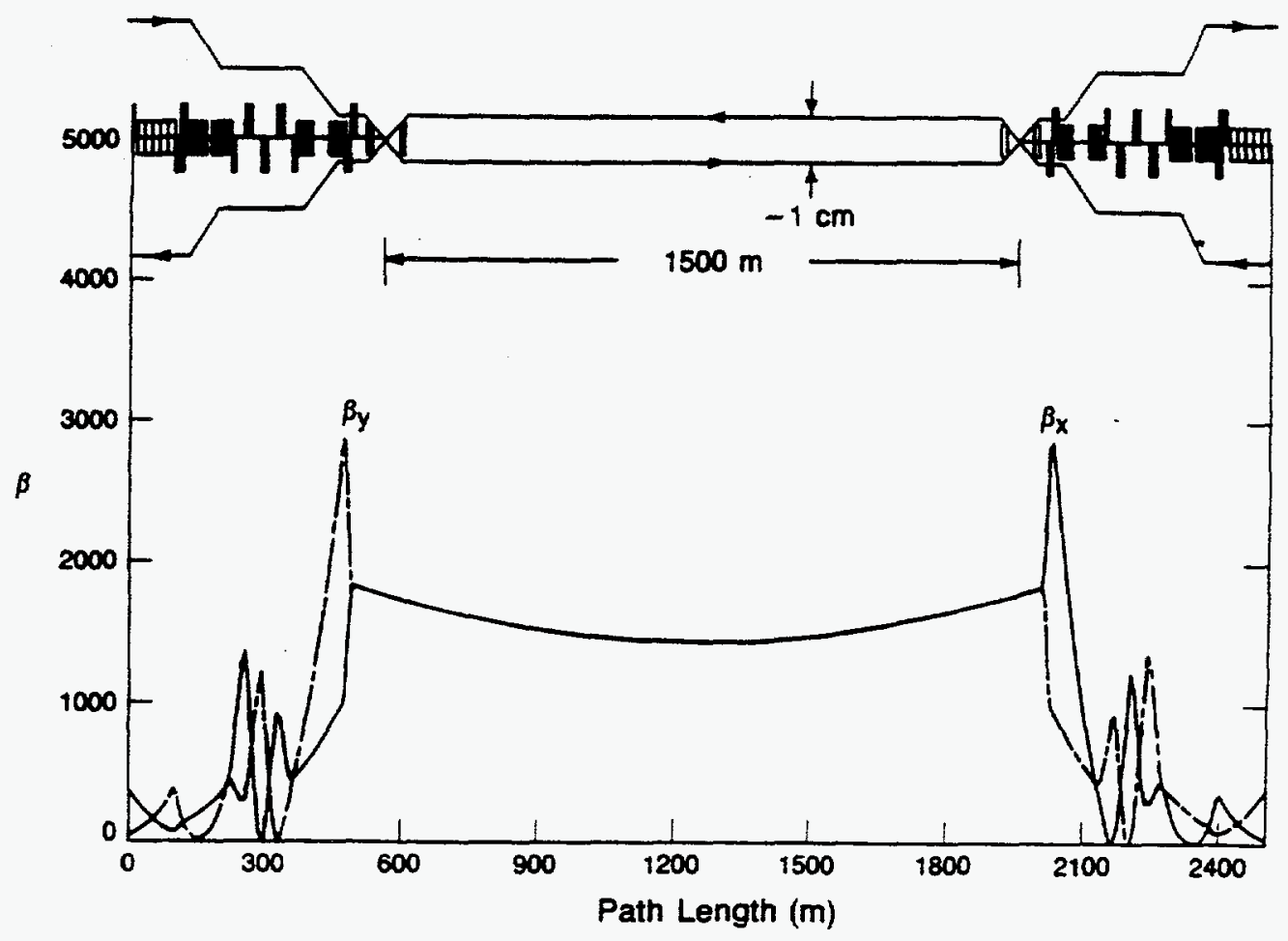

Fig. 7 Very long interaction region for high-rapidity experiment, made by coalescing the two "future" IRs.

For elastic scattering, the scattering angle must be large compared to the intrinsic spread due to the beam emittance. This implies $\beta^{*} \geq 4000 \mathrm{~m}$. The free space $\left(\mathrm{L}^{*}\right)$ for the elastic scattering experiments can be modest and will likely be determined by crossing angle requirements as discussed below. However, the free space for high rapidity coverage must be very long, $\approx 1-2 \mathrm{~km}$. The corresponding requirements for $\beta^{*}$ are not as well defined, except that $\beta^{*}$ must be large enough to reduce the luminosity to a manageable value. For our example we take $\beta^{*}=500 \mathrm{~m}$ and $L^{*}=1000 \mathrm{~m}$.

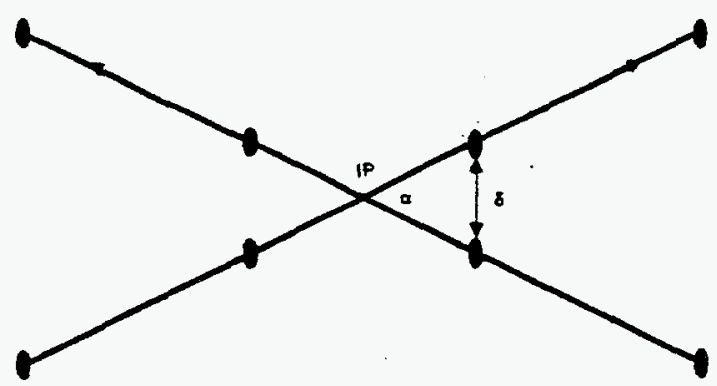

Fig. 8 A schematic diagram of beam crossing region.

Because of the larger $\beta^{*}$, the transverse bunch size at the collision point will be much larger than in low $\beta^{*}$, high luminosity, IRs. The transverse bunch sizes for the two cases under consideration are $430 \mu$ and $150 \mu$ for $\beta^{*}$ of $4000 \mathrm{~m}$ and $500 \mathrm{~m}$, respectively. Because the bunch sizes are larger, the beam crossing angle must be increased to prevent (a) regions of satellite luminosity, and (b) disruption via the beam-beam interaction. The beams must be separated by some minimum distance each time they cross as shown in Fig. 8. At the first crossing, $\delta / \sigma=m$, must be some minimum vaiue, determined by either the absence of satellite interactions or by beam-beam disruption limits. The precise requirement for the latter is uncertain but we use the value given in the CDR of $m=7$. For this value, satellite luminosity is negligible. Given this criterion, the minimum opening angle, $\alpha$, vs $\beta^{*}$ can be determined as shown in Fig. 9.

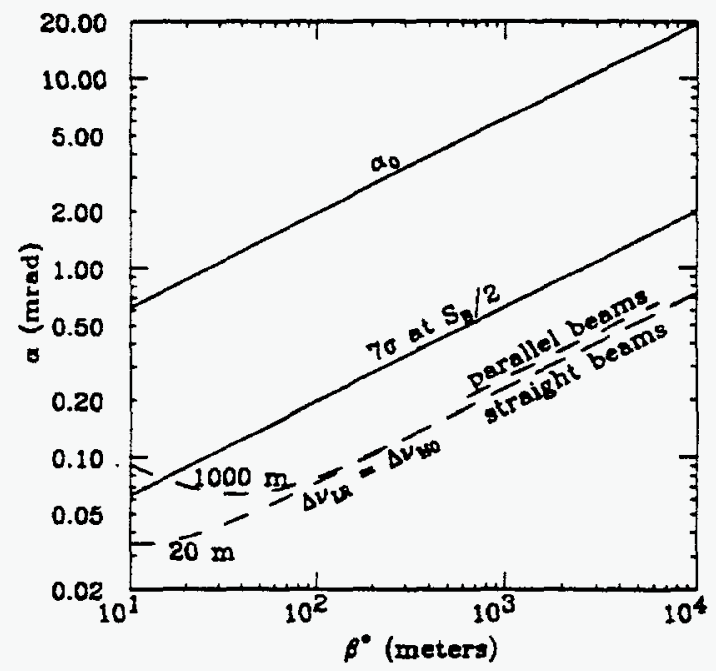

Fig. 9 Crossing angle constraints for different $\beta^{*}$. See text for more explanation.

An upper limit on the crossing angie results from considering headtail interactions of the intersecting bunches which excite synchrotron and betatron oscillations. 11 This limit is also shown in Fig. 9.

The other possible limitation on the crossing angle comes from long-range interactions between the bunches which cause a spread in tune shift. This limitation varies slightly if the beams are kept parallel for a substantial fraction of the free space by using dipoles or if the beams are undeflected - see Fig. 9. The minimum crossing angle requirement to avoid disruption is more severe. 
In order to change $\beta^{*}$. one would like to operate roughly in the middle of the allowed range: a few milliradians for the elastic scattering experiment and perhaps a milliradian for the high rapidity experiment, to allow tuning over a range of $\beta^{*}$. If the beams are not deflected by dipoles berween the collision point and the first focusing quad, they will be separated by a distance $\alpha L^{*}$ at the first quad. For example, if $L^{*}$ is $1000 \mathrm{~m}$ and $\alpha$ is $1 \mathrm{mrad}$, then the separation will be $1 \mathrm{~m}$, clearly requiring separate IR quadrupoles. If there are dipoles before the quadrupoles, this can be reduced. However, this separation ignores the effects of quadrupoles, as part of a spectrometer, before the $\mathbb{R}$ quadrupoles. For the elastic experiment, $\alpha$ might be, say, $4 \mathrm{mrad}$ so the separation at $20 \mathrm{~m}$ will be $8 \mathrm{~cm}$, too large for a single quadrupole but too small for separate quadrupoles. The solution is to either increase the free space, to at least $100 \mathrm{~m}$, or to add dipoles before the quadrupoles.

The nominal space between $\mathbb{R}$ quadrupoles in a high luminosity intersection region is $\pm 20 \mathrm{~m}$. Although it is probably possible to fit experimental apparatus for large detectors into this space, it will be a tight fit near the beam line in the forward/backward directions. ${ }^{3}$ The trade-off between luminosity and free space has been discussed in detail by D. E. Johnson in an SSC Internal note and contribution to this conference. ${ }^{12}$ Assuming that the IR quadrupoles have a gradient of $230 \mathrm{~T} / \mathrm{m}$ as described in the CDR, the luminosity vs free space $\left({ }^{*}\right)$ is shown in Fig. 10. Increasing the free space by $\pm 3 \mathrm{~m}$ reduces the luminosity by about $10 \%$. This amount of extra space may be very useful. If the field gradient in the quadrupoles can be raised by a modest amount, by operation at lower temperature for example, the full luminosity can be retained while increasing the free space by a few meters.

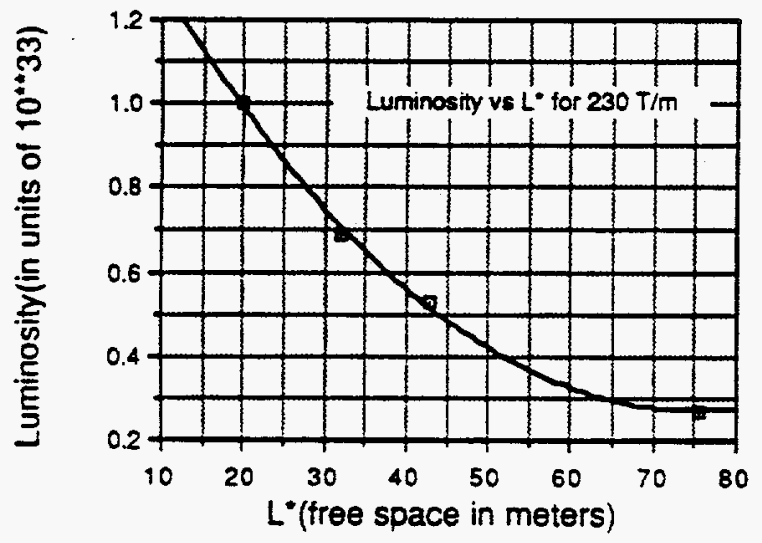

Fig. 10 Luminosity vs free space in high luminosity IR.

\section{Experimental Magnet Compensation}

Compensation of experimental magnets is discussed in detail in the contribution of S. Peggs to these Proceedings. ${ }^{13}$ Solenoid magnets will not require any compensation. For the cases of dipole experimental magnets considered it is possible to devise compensation schemes, although there will be a limit on the allowed JBdl to avoid large crossing angles. The bend direction of the experimental dipole should be perpendicular to the natural separation plane of the beams. At the cost of sacrificing luminosity from larger crossing angies, large dipole bends could be accommodated.

\section{Backgrounds and Radioactivity in the Intersection Regions}

The large luminosity at the SSC means that radiation levels from the primary pp collisions, and from secondary interactions of these particles with material could be high. Radiation damage to detector elements resulting from minimum ionizing particles produced directly in the $\mathrm{pp}$ collisions has been discussed before. ${ }^{14}$ Damage to machine elements is discussed in the Conceptual Design Report.
There are other background related problems which could be significant. These are

- beam gas losses

o non-linear beam loss mechanisms

- neutron production

0 induced radioactivity

Beam losses from residual gas in the beam pipe are discussed in the CDR. ${ }^{15}$ The loss rate due to beam gas collisions will be 1.7 protons-cm $\mathrm{cm}^{-1} \mathrm{~s}^{-1}$ for a pressure of $10^{-9} \mathrm{Torr}$. In a high luminosity IR, collisions in the $160 \mathrm{~m}$ between vertical bend magnets will produce a background rate of $27 \mathrm{KHz}$. Since the pp interaction rate at full luminosity is $100 \mathrm{MHz}$, the beam gas rate is negligible. This background will only be significant for longer straight sections and lower luminosity experiments.

A much more serious problem is likely to be beam loss from unknown or partially understood reasons. In particular, the so-called nonlinear beam losses discussed by Jacques Gareyte ${ }^{16}$ at this meeting could be significant. The belief is that intrabeam scattering replenishes the tails of the beam distribution and particles in these tails are quickly lost, within minutes, due to beam-beam interactions. It is believed that such processes are responsible for occasional large backgrounds observed by experiments in the SppS collider. These backgrounds oceur despite careful scraping far from the detectors, and are alleviated by skillful tuning of the machine. The severity of this problem for the SSC is not yet known, but the large currents in the SSC mean that only a small fraction of the beam particles need to be lost for this to be a background. The severity of this background depends on its rate relative to the interaction rate of $10^{8} \mathrm{~Hz}$. Clearly, collimators and scrapers judiciously and generously placed around the rings, must be included in the SSC design. If possible, more caiculations of beam loss rates from these mechanisms should done for the SSC.

Estimates of neutron production from proton losses around the ring and from the interaction of the particles produced in the pp collisions with IR quadrupoles, collimators, or calorimeters have just begun. Estimates of neutron fluences (neutrons $/ \mathrm{cm}^{2}$ ) in the SSC tunnel are based on measurements at the Tevatron, and an extrapolation in energy using hadron cascade simuiations. In the tunnel, the fluence (at the tunnel wall) in one SSC year $\left(10^{7} \mathrm{sec}\right.$ ) is estimated to be in the range of $2.8 \times 10^{10} \mathrm{~cm}^{-2}$, although there are substantial uncertainties in such estimates - the rate could well be higher.

The situation in experimental areas is much more complex. ${ }^{17}$ Neutrons are produced predominantly by interactions of particies produced in the primary collision with IR quadrupoles and any calorimeters or collimators in front of the quadrupoles. Compared to the rate in the tunnel, the effective neutron production rate from interactions in the quadrupoles may be 100-200 times greater - a very serious problem. However, the quadrupoles near the interaction point either are shielded by experimental apparatus, or could be shielded rather easily. An accurate quantitative estimate of the effects of such shielding, using neutron transport codes, has not yet been made.

However, a crude estimate of the such shielding effects can be made. Measurements of the neutron energy spectrum produced at the Tevatron ( $800 \mathrm{GeV}$ coasting beams) are shown in Fig. 11.18 Roughly the same shape is obtained at $150 \mathrm{GeV}$, so we will assume that the neutron spectrum is similar in shape at the SSC. (Of course the number of neutrons will be much higher at the SSC, since more energy is available in each beam paricle. The spectral shape should remain about the same since the neutrons primarily come from the end products of a hadronic cascade in the ring magnets.) The spectrum peaks at roughly $200 \mathrm{KeV}$ and most of the neutrons have energies between $10 \mathrm{KeV}$ and a few MeV. For $4 \pi$ detectors, there will be a substantial amount of iron (muon toroids) surrounding part of the $\mathbb{R}$ quadrupoles close to the intersection point and toroids shielding electronics on the end walls of the central detector. The neutron total cross section on iron in the energy region of interest is shown in Fig. 12. 19 There is substantial resonant structure in the cross section. This means that the iron will act as an energy selective filter. 


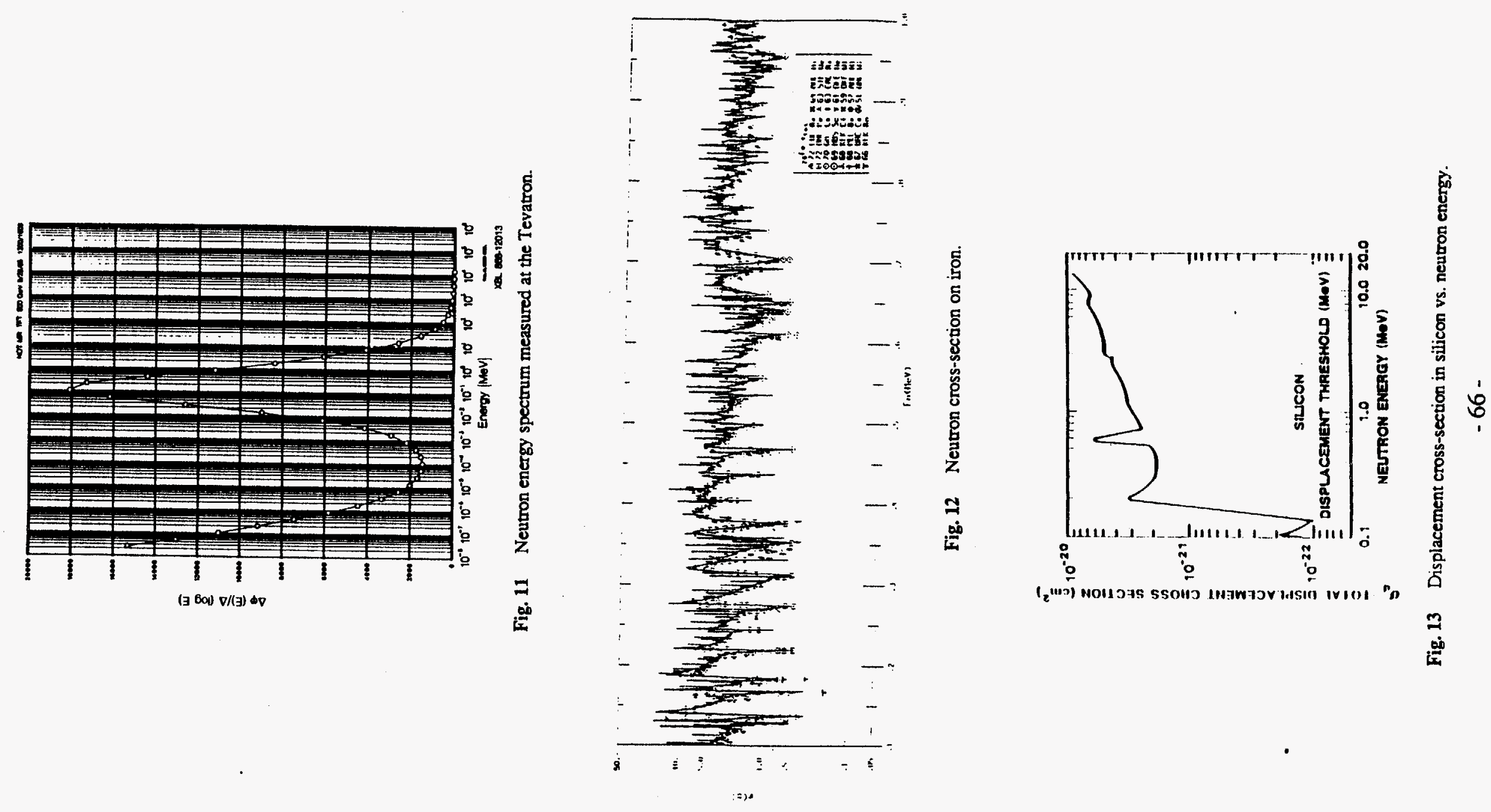


Crudely, the cross-section average is about 5 barns in the relevant energy region. This implies an "interaction length" of about $2.5 \mathrm{~cm}$ in iron. At these low energies the neutrons do not lose much energy in a collision with an iron nucieus, and they are scattered isotropically. In a collision with a nucleus of atomic number $A$, a neutron with energy $E$ has an average final energy, $E$, given by ${ }^{20}$

$$
E=E_{0} \frac{1+r}{2} \text { where } r=\frac{(A-1)^{2}}{(A+1)^{2}}
$$

For iron $A=56$ and $\mu=(1+r) / 2=0.966$. After $n$ collisions, the energy is $E_{0} \mu^{n}$

The number of collisions to go from $E_{0}$ to $E_{f}$ is given by

$$
\mathrm{n}=\left[\ln \left(\mathrm{E}_{\mathrm{o}}\right)-\ln \left(\mathrm{E}_{\mathrm{f}}\right)\right] /[-\ln \mu]
$$

As an example, take $E_{f}=2 \mathrm{MeV}$ and $E_{f}=0.150 \mathrm{MeV}$ and $A=56$ (iron), then $-\ln \mu=0.035$, and $n=74$ collisions. Below energies of about $150 \mathrm{KeV}$, damage to silicon (in electronics components) drops rapidly (see Fig. 13). Since the scattering is isotropic, the distance the neutron goes is about $\sqrt{74} \lambda=21.5 \mathrm{~cm}$, assuming 5 barns as the cross section. If the cross section were $0.5 \mathrm{~b}$, which is possible because of its resonant structure, the distance would be about 215 $\mathrm{cm}$. Note that a modest amount of iron will even "thermalize" most of the neutrons, ie. reduce them to energies of about $0.025 \mathrm{eV}$. Again taking $5 \mathrm{~b}$ as the cross section (an underestimate below $1 \mathrm{KeV}$ ) yields a length of $57 \mathrm{~cm}$. This simple calculation suggests that electonies in $4 \pi$ detectors might be effectively shielded from neutrons by iron and other material in the detector itself.

The study of radioactivation of detector or machine components in the $\mathbb{R}$ region has also just begun. The components near the $\mathbb{R}$ which might become significantly radioactive from activation by particle interactions are calorimeters near the beam, collimators in front of the IR quadrupoles and the quadrupoles themseives. Very preliminary estimates of radioactivation have been made assuming that iron is the material of interest. ${ }^{21}$ For an iron target the principal sources of radioactivity induced by interactions are isotopes of manganese, mostly $\mathrm{Mn}^{54}$, which has a half-life of 312 days. Modeling a quadrupole as an iron cylinder with a $13.8 \mathrm{~cm}$ outer radius and a $1.7 \mathrm{~cm}$ inner radius, the activity level at the the outside surface of the cryostat ( $44 \mathrm{~cm}$ from the beamine) is estimated to be $140 \mathrm{mrem} / \mathrm{hr}$. For comparison, the activity at the surface of uranium plates used in the DO calorimeter, negiecting the contribution from $\alpha$ particles which are easily stopped, is about $200 \mathrm{mrem} / \mathrm{hr}{ }^{22}$ Modest shielding, $1 / 4$ inch of acrylic, for example, drops this to $5-10 \mathrm{mrem} / \mathrm{hr} .22$ Activation of collimators and calorimeters close to the beam will also occur although the magnitude of the activation depends on the material composition. Collimators for example are very unlikely to be iron. Calorimeters could be uranium, tungsten, lead or iron. Activation resulting in 100 or so $\mathrm{mrem} / \mathrm{hr}$ will be a safety problem, but one which could be handled by placing temporary shielding over the activated material when access is required. Detector elements should be designed to minimize the need for access near areas that will become activated. Detector readout elements - wire chambers, for example - which are close to the activated components must be shielded by material which will not be activated.

\section{Bypass Options - Lattice and Machine Considerations}

It is possible to configure the lattice of the machine to allow the construction of a bypass of either ciustered IR region. The details of the lattice are discussed in the paper by $D$. E. Johnson, contributed to this conference. ${ }^{23}$ In the latrice described in the CDR, magnets are very closely packed to minimize the circumference. In order to create the potential for two separate beam channels, without removing magnets, additional magnetic elements and hence space must be added. In the design described by Johnson, six normal cells. each half filled with normal dipoles, are added to the end of each arc. Special splitting dipoles can be placed in the free regions in these cells to deflect the beam into the bypass when desired. To keep the total bend constant in the machine, six cells in each arc have been removed. The configuration for a bypass of the east $\mathbb{R}$ cluster is shown in Fig. 14. A bypass for the west cluster would be similar.

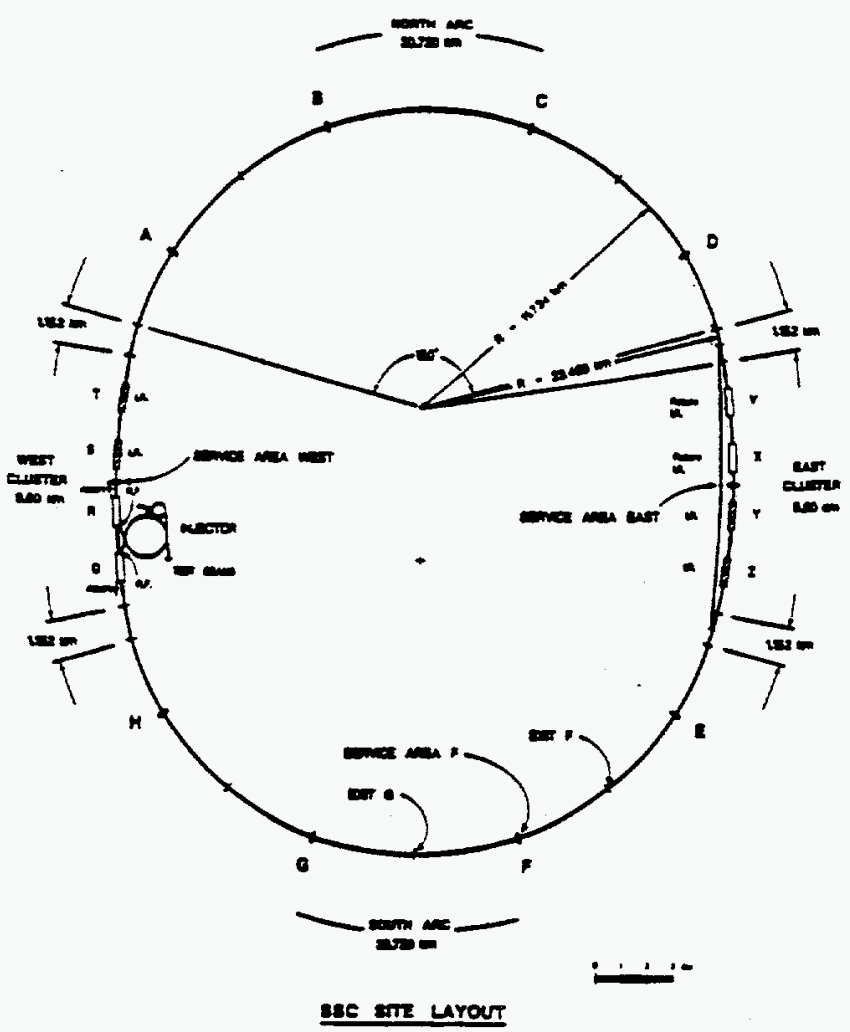

Fig. 14 SSC layout showing a bypass of the East experimental cluster.

The implementation of a bypass described by Johnson will increase the circumference of the machine, add the length of the bypass to the total tunnel length, and increase the number of magnets required. These increases are summarized in Table 7. In Table 7, we have assumed that four IRs are to be bypassed on either side, substantially increasing the circumference of the ring for a west bypass. If this condition were removed, the number of IRs in the main ring reduced, the length of the bypass could be shortened. For example, the number of straight sections in a cluster might be reduced to three or even two. In the latter case, only two experiments could be operational at any one time, the remaining two straight sections being used for injection. These two options have not been studied in detail.

TABLE 7. A summary of the CDR and bypass options.

$\begin{array}{llll} & \text { CDR } & \begin{array}{c}\text { East } \\ \text { Bypass }\end{array} & \begin{array}{c}\text { West } \\ \text { Bypass }\end{array} \\ \text { No. of potential IRs } & 6 & 6 & 4-4 \\ \text { Circumference }(\mathrm{km}) & 82.9 & 85.3 & 89.9 \\ \text { Total tunnel length }(\mathrm{km}) & 82.9 & 97.2 & 101.8 \\ \text { No. of dipoles } & 7680 & 8308 & 8308 \\ \text { No. of quadrupoles } & 1520 & 1724 & 1736\end{array}$

\section{Bypass Options - Impact on Experimental Facilities}

The machine requirements for implementing one or more bypass sections of the main SSC ring have been discussed in the previous section of this report. In this section, we discuss the impact of such a bypass or bypasses on collision/assembly halls and on construction and operation of experiments. 


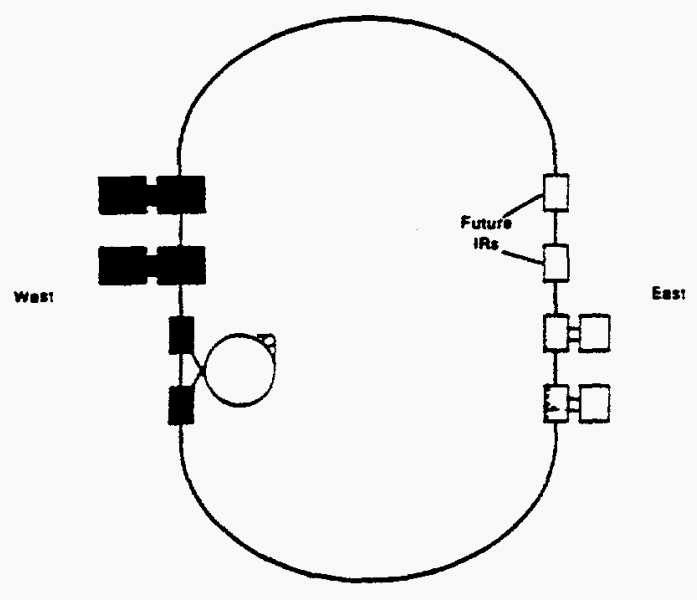

Fig. 15 A representation of the layout of experimental facilities as described in the Conceptual Design Report.

To provide a basis for discussion of the bypass options, we first briefly describe the experimental facilities outlined in the SSC Conceptual Design Report. There are two experimental regions on the same side of ring as the injector (the West side) and four on the other side (the East side) - see Fig. 15. Four of the IRs would be operational at turn-on of the machine, two on each side. At each of these IRs there would be a collision hall and an assembly hall. Although most of the experimental (and other) support facilities would reside on the West side, it is likely there would be need for considerable support facilities on the East Side as well. 24 Compared to the bypass options described below the advantages of this scheme are

- minimum tunnel length

- minimum number of magnets and amount of associated systems

The disadvantages are

- inefficient utilization of underground space. With only a few exceptions, assembly halls have seldom been used after the initial construction of a large detector. Collision halls aiso tend to be uncersized, without room for detector upgrades. Construction of the large access portal between the collision and assembly halls is difficult. Rolling many-thousand ton detectors requires massive supports beneath the detectors and strong floors into the assembly hall. To some extent these problems could be overcome by building detectors in place, independent of the bypass option. A bypass, however, gives more flexibility as described below.

- the collision/assembly halls are on the critical path (this is a disadvantage from the machine point of view, not from an experimental viewpoint). The large underground caverns for the halls require the longest lead time of the underground work.

o some of the detector components are on the critical path. Even with assembly halis, it is very likely that major parts of the large detectors (eg. iron muon spectrometers) must be built in place. These may need to be lowered through the roof of the collision hall, purting them on the critical path

- construction of halls at the two IRs not in the initial complement requires shutring down the machine for a year or more.

There are two types of bypass options to be considered: bypass the East IR cluster, or bypass the West IR cluster. ${ }^{25}$ Implicit in our discussion is the assumption that the bypass or the original ring can be functionally identical for experiments. First we discuss bypassing the East cluster of interaction regions as shown in Fig. 16a. With respect to collision and assembly halls, it is possibie to have: no assembly halls (Fig. 16a); assembly halls common to both the original ring and the bypass (Fig. 16b); assembly halls for each of the eight IRs; or some mix of these. If there is an assembly hall shared by both legs of the machine major detector components can be shared. For example, one might begin initial operation with an upgraded central detector (eg. CDF, DO'.......) in one leg, while constructing a forward spectrometer in the other leg. Upon completion of the forward spectrometer, the proven central detector could be moved through the shared assembly hall into the leg with the spectrometer. Of course, having shared assembly halls adds to the cost and difficulty of underground excavation. Also the common assembiy halls could not be used while beams are in the bypass because of radiation safety.

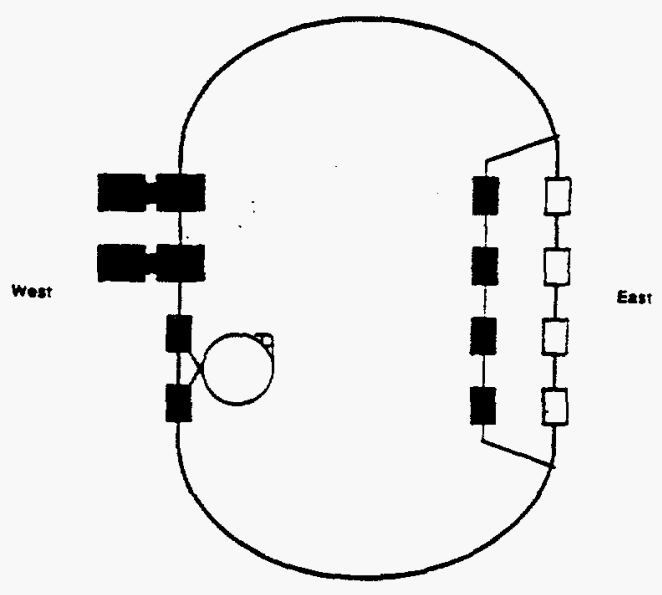

Fig. 16a Experimental layout with an East bypass. Experiments on the East would be built in place.

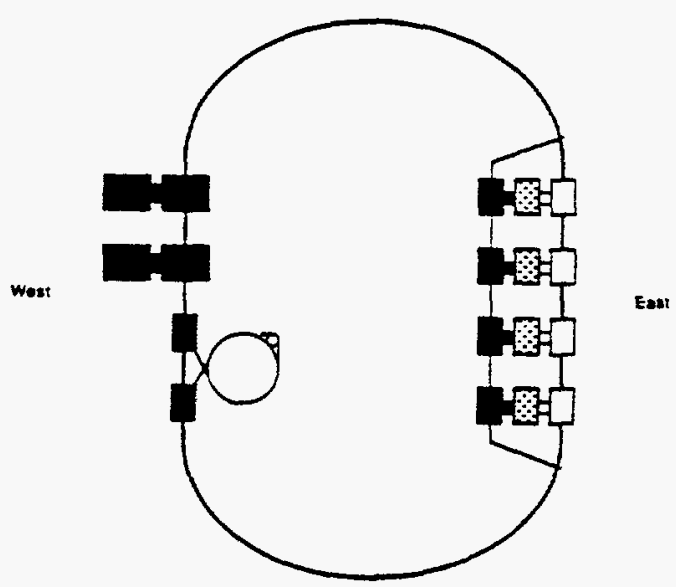

Fig. 16b Experimental layout with East bypass. In this option, there would be an assembly hall shared by all experiments.

The advantages of bypassing the East cluster are

o the East IRs, for initial machine operation, no longer are on the critical path. A simple bypass to provide beam transport but no experiments would suffice. This assumes that halls for experiments on the East could be completed after commissioning the machine and start of operation of the detectors on the West Side. Of course for an experimentalist with an East-side detector this is not an advantage. It is not 


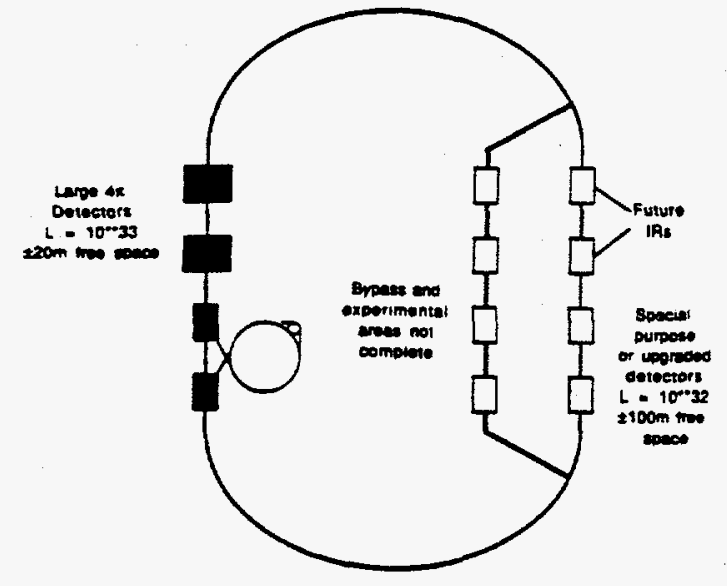

Fig. 18a An example of a possible initial complement of experiments. This would be Stage 1 in the experimental program.

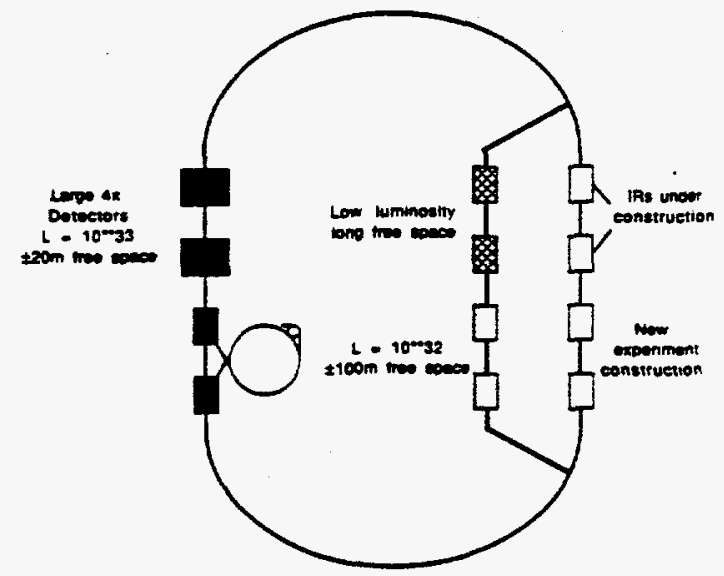

Fig. 18b An example of a possible Stage 2 of the experimental program Experiments are in place in the bypass. Construction underway in the main leg.

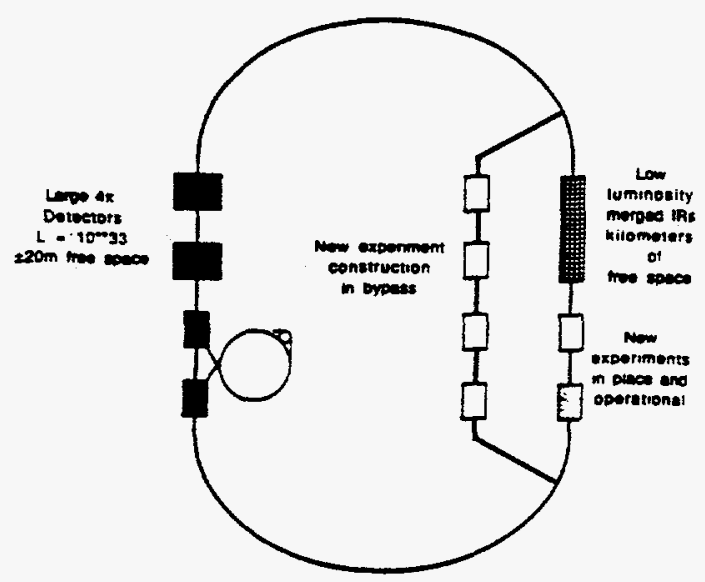

Fig. 18c An example of a possibie Stage 3 in the experimental program. New experiments are underway in the main leg again. Two IRs have been coalesced to form very long straight sections.

\section{Recommendations}

Our most important recommendation is that the ramifications of the various bypass options should be the subject of a concentrated study by the Central Design Group and consultants as soon as possible. The desirablility of a bypass must be weighed against the cost.

Somewhat coupled to the above, are decisions about the existence of assembly halls and the size of collision halls. A cost cormparison between building in-place and the customary collision/assembly hall situation must be made.

Various quantitative studies of neutron backgrounds, radioactivation and other backgrounds in the $\mathbb{R}$ halls should be initiated.

\section{References}

${ }^{1}$ Report of the $4 \pi$ Detector Group, Broceedings of the 1984 Summer Study on the Desion and Utilization of the Superconducting Super Collider.

2SSC Special Report, SSC-SR-1023.

${ }^{3}$ Report of the $4 \pi$ Detector Group, in these Proceedings.

${ }^{4}$ Report of the Heavy Fiavor Group, in these Proceedings.

SJ. D. Bjorken in the Proceedings of the Workshon on Triggering Data Acouisition and Computing for High Energy/tigh Luminosity Collidess, Fermilab, November, 1985, p. 363.

${ }^{6} \mathrm{See}$ contributions to these Proceedings

${ }^{7}$ G. J. VanDalen and J. Haupptmann, Proceedings of the 1984 Summer Sudy on the Desion and Utilization of the Supercondncting Super Collider p. 659.

${ }^{8} \mathrm{~J}$. Bensinger and N. Giokaris, Proceedings of the Workstopen on Trigqering. Data Acauisition and Comnuting for High Eneroy/High Luminosity Colliders, Fermilab, November, 1985, p. 377; and G.E. Theodosiou p.415.

IN. Giokaris and S. Majewski, Broceedings of the 1984 Summer Stuciv on the Desian and Utilization of the Superconductine Super Collider, p. 647.

${ }^{10} \mathrm{D}$. Groom, SSC-N-88 and the report of the Low $\mathrm{P}_{\mathrm{T}}$ Physics Group, conuribution to these Proceedings.

${ }^{11}$ A. Piwinski, SSC-N-57 (January 1986).

${ }^{12}$ D. E. Johnson SSC-N-151 and contribution to these Proceedings.

${ }^{13} \mathrm{~S}$. Peggs, contribution to these Proceedings.

${ }^{14} \mathrm{M}$. Gilchriese in the Broceedings of the 1984 Snowmass Summer Study p. 607; T. Kondo et al. p. 612. See also SSC-SR-1021.

${ }^{15}$ SSC Conceponual Desion Report, section 4.8.4.

16J. Gareyte, contribution to these Proceedings.

${ }^{17}$ D. Groom, SSC Note, SSC-N-228 (1986).

${ }^{18} \mathrm{~J}$. McCaslin et al., SSC- 58.

${ }^{19}$ D. I. Garber and R. R. Kinsey, Neurron Cross Sections, Vol. II, BNL 325 (1976).

20J. Gover and J. Srour, Sandia Report, SAND 85-0776, Chap. 2 (1986).

${ }^{21}$ D. Groom, SSC Note, SSC-N-219 (1986).

${ }^{22} \mathrm{H}$. Gordon, private communication. 
ciear if all of the bypass tunnel and experimental halls can be constructed while the machine is operating. Radiation safety and vibrations from the construction are a potential problem. This needs additional study.

o there are more potential IRs and hence experiments. Even if they share the beam, experiment down time would be minimized

o if no assembly halls are built, the useful underground space is maximized on the East side, although the total volume may eventually be about the same, since the number of collision halls doubled. Complications associated with moving detectors would be eliminated.

- assuming that the large detectors are on the West side, their productivity would be enhanced, since the beam could be switched around the East side experiments within days or less. At the start of the experimental program this would be particularly useful to allow staging and debugging of experiments on the East side would be bypassed, so scheduling problems would not be completely eliminated.

o the construction of long IRs, including coalescing 4 to 2 IRs in the bypass is made easier

The disadvantages of building a bypass for the East cluster are

- the circumference of the ring must increase by about $3 \%$ (see Table 7)

- the bypass tunnel must be constructed which adds about $14 \%$ to the total tunnel length required

- more magnets and associated systems are required (see Table 7)

- although the bypass and the main leg are almost the same length, switching from one to the other might be done in as little time as one shift. Until experience has be attained, switehing will inevitably require time to optimally tune the machine for the experiments

- experiments on the East side probably would not be operatonal at turn-on to save money

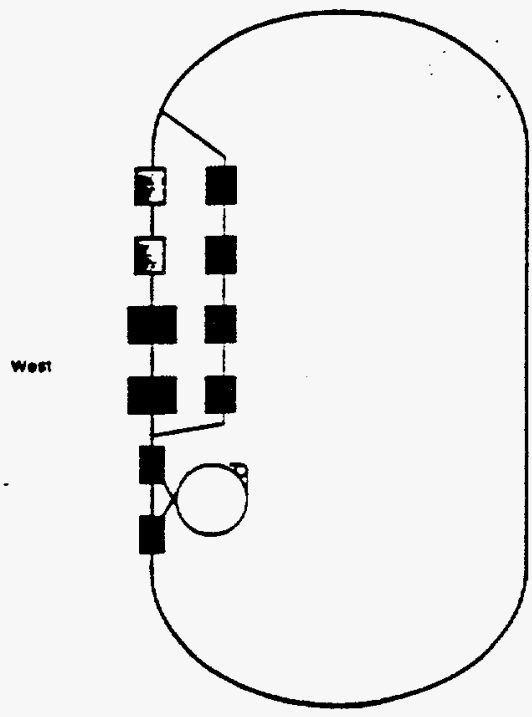

Fig. 17 The experimental layout with a West bypass. In this picture, all experiments would be built in piace.
Construction of a bypass on the West Side is more complicated because of injection into the main ring. Injection requires two straight sections. We assume that the bypass contains four possible IRs, and an equal number in the main leg as shown in Fig. 17. In this scheme there would be minimal facilities on the East side. All of the experiments would be relatively close to the main laboratory area and facilities. Some of the advantages of a bypass on the West side are

- siting constraints are less. Since only one side will be developed, the location of the ring is probably easier. Tilting the ring to put the West side closer to the surface is easier. Finding the appropriate geological conditions at one site is more likely than two.

- assuming that the initial complement of experiments can be accommodared in four IRs, the construction of experiments and commissioning of the machine could be completely decoupled. Experiments could be assembled, in place, in the bypass while the machine is first operated. Of course, the machine elements in the bypass would have to be installed to get beams to the experiments, but initial (and probably lengthy) operation of the machine would be independent of the experiments. From an experimental point of view this is not completely desirable, since completing the bypass could take a long time after machine turn-on. The benefits to experiments after construction of the bypass and its successful operation are more clear. Initially this would also allow beam to be sent to experiments for short periods of time (days) for debugging. Experiment construction could also be profitably staged in time, ie. take data with a partial detector and then switch the beam to the other leg while completing assembly.

- useful underground space is maximized if assembly halls are eliminated

- utility distribution to the East side is substantially reduced, a cost savings

- major support facilities (the East campus) would be eliminated

The disadvantages of a bypass on the West side are

o the circumference of the machine is substantially increased, by about $8 \%$ over the design in the CDR

o the bypass tunnel is needed. The total increase is therefore about 23\%.

- more magnets are required

o initial operation of experiments, if they are in the bypass, could be substantially delayed uniess the bypass construction and magnet installation is in phase with the completion of the main machine.

Either bypass option would allow more flexibility in staging the experimental program. As an example consider bypassing the East cluster. At tum-on of the machine the initial experimental complement might look like Fig. 18a, assuming that all detectors are built in-place. After an initial period of operation, the bypass has been completed, and the beams are switched to experiments in the bypass as in Fig. 18b. Again after a substantial period of machine operation. new experiments or upgrades have been constructed in the original leg of the machine and the beams are switched back as shown in Fig. 18c. This scenario and the choice of experiments is, of course, arbitrary; many other possibilities exist.

Assuming that either of the bypass options is technically feasible and will produce a working machine, the decision to bypass or not to bypass must be made on examination of funding requirements, up to and beyond the commissioning period of the machine and the desirability of increased flexibility in the experimental program. 


\section{Appendix C}

\section{C1. Experience at LEP}

About $3000 \mathrm{~m}^{2}$ of preassembly space was given to each of the four LEP experiments. The example of ALEPH, which required substantially more, will be illustrated below:

1. Heavy Hall Space (crane capacity 80 tons; hook height about $13 \mathrm{~m}$ ) - Used for preassembly of the full magnet yoke and coil to check mechanical fitting, testing superconducting coil, and field mapping.

Number of components:

24 barrel steel pieces, 75 tons each

12 endcap steel pieces, 75 tons each

1 coil, about 70 tons.

The space assigned for this use was $600 \mathrm{~m}^{2}$.

2. Medium Hall Space (crane capacity required around 20 tons; hook height 8 to $10 \mathrm{~m}$ ) Used for preassembly of the mobile electronic huts; large model studies ( scale 1:1); preparation of Iarocci chambers (for this operation, the magnet pieces are transported into the hall on a trailer one by one, and stay on the trailer so as not to require a heavy crane); and fabrication of the outer field cage for the TPC (diameter about $4.5 \mathrm{~m}$ ). The space used for these operations was about $1600 \mathrm{~m}^{2}$.

3. Light Hall Space ( crane capacity about 10 tons) - Assembly of the TPC and tests of TPC with lasers, cosmic rays, etc. for about one year. Because of the tests, one of the mobile electronics huts has been assembled close to the TPC to receive the final electronics and cabling. The space was about $800 \mathrm{~m}^{2}$.

4. Test Beam Space - Typically 2 or 3 calorimeter modules, vertex chamber prototypes, etc. are located in a test beam area dedicated to ALEPH. Space assigned was $200 \mathrm{~m}^{2}$.

5. Components made in other labs - In the case of ALEPH, the electromagnetic calorimeters are made at Saclay and Rutherford. They will arrive at CERN some months before final installation. They will have to be stored in an "active storage" area where gas mixtures can be circulated in the chambers. This may require up to $700 \mathrm{~m}^{2}$.

6. Hall Space at the pit head - At typical LEP areas, the experimental equipment shafts are covered by halls of about $1000 \mathrm{~m}^{2}$ ( $17 \mathrm{~m}$ by $60 \mathrm{~m}$, equipped with 80 ton cranes). Used for:

- Unloading and preparing components before lowering them into the shaft

- Limited preassembly operations

- Maintenance of components

- Mechanical shop with a few medium sized machine tools 
- Housing of main control computer in an air conditioned space

It should be noted that almost one third of the floor surface cannot be used for assembly work because of the shaft penetration and the truck entrance. The heavy crane covers only about $11 \mathrm{~m}$ of the $17 \mathrm{~m}$ span.

7. Grand Total-All spaces: $4900 \mathrm{~m}^{2}$.

\section{C2. Experience at CDF}

CDF is located in a surface facility at Fermilab. It does not have the problem of lowering all components down a long shaft as do the LEP experiments; however, similar preassembly spaces were found to be needed to support the assembly of the detector at the experimental area.

1. Heavy Hall Space - Space was used at Argonne National Lab to assemble one of the large calorimeter arches as a mechanical test prior to instrumenting the calorimeters. This was done at the experimental area of the ZGS. A 50 ton crane with a hook height of about $10 \mathrm{~m}$ was used to stack up the arch. There were no cranes with sufficient hook height at Fermilab and the experimental area was not yet ready. This was felt to be necessary in order to test the mechanical design and to measure the actual deflections of the arch as a check on the finite element calculations. Since we only assembled one arch, the actual space needed was small $\left(200 \mathrm{~m}^{2}\right)$.

2. Medium Hall Space (crane capacity of 20 tons; hook height of $6 \mathrm{~m}$ ): This space was located in Industrial Building 4 at Fermilab across the street from CDF and was used as the calorimeter assembly factory. The primary need here was for floor space. The calorimeter modules were set up on the floor and assembly operations were scheduled to work on each module. At the peak of production, as many as twelve modules were on the floor at one time. The total factory space was about $1200 \mathrm{~m}^{2}$. The space has now been turned over to the D0 Collaboration to set up their calorimeter factory. The largest space requirement occurred as the factory was finishing production. Additional storage was needed for the completed modules awaiting the trip to the calibration beam. An additional $400 \mathrm{~m}^{2}$ was needed just for this storage, giving a total need of medium hall space of $1600 \mathrm{~m}^{2}$, the same as ALEPH.

3. Light Hall Space ( crane capacity less than 10 tons) - This was used for the assembly of the central drift chambers, the Vertex TPC, and the endcap electromagnetic calorimeters. Only the calorimeters needed a crane. The two drift chambers were assembled in rooms without cranes although one has been installed in the central drift chamber room so that it can now be used as a service facility for large proportional chambers. The total space required for these operations was about $300 \mathrm{~m}^{2}$.

4. Test Beam Space: Initially two separate test beams were dedicated to CDF, one for the scintillator calorimeters which was used to calibrate every module, and one for 
the gas calorimeters. Now after the detector is complete, the test beam areas have been combined at one location and a subset of each type of calorimeter is located there for further calibration checks and geometry studies. The space used was about $200 \mathrm{~m}^{2}$.

5. Components made in other labs: Many of the lighter detector components were made off the Fermilab site. Generally the components were held at the originating institution until close to the time for use in the assembly of the detector when they were shipped to Fermilab. Some were shipped directly to the experimental area for installation, others to the test beam, and still others to Industrial Building 4 after the calorimeter factory was dismantled. Space was made for these components either by recycling other space or by closely coordinating delivery with installation.

6. Hall Space at the Experimental Area: Although CDF is at a surface location, the detector was assembled in a pit approximately $10 \mathrm{~m}$ deep. Surface facilities were necessary to act as a receiving area to support the work in the pit. The main uses were for unloading components before lowering them into the pit, limited preassembly operations, and mechanical shops. These facilities take up about $900 \mathrm{~m}^{2}$. The assembly pit itself took another $700 \mathrm{~m}^{2}$ for a total building of $1600 \mathrm{~m}^{2}$. The entire facility was served by a single bridge crane with a 50 ton hook and a 10 ton auxiliary hook.

7. Grand Total - All spaces: $3900 \mathrm{~m}^{2}$.

8. Office Space: CDF has approximately 210 collaborators. Of these, about 80 are located at Fermilab. In addition to these, there are a further 50 technical support personnel permanently assigned to CDF. With 17 institutions there is an additional need for transient desks for the other collaborators who commute, 34 desks are assigned to this use. The grand total of desks is 164 and if the canonical $10 \mathrm{~m}^{2}$ of floor space is assigned to each, there is a need for $1640 \mathrm{~m}^{2}$ of office space. 


\section{Appendix D - Radiation Levels in the Collision Hall}

\section{D1. Assumptions}

We follow the radiation criteria discussed in SSC-SR-1026 (SSC Environmental Radiation Shielding): an average annual dose of $10 \mathrm{mrem}$. The sources of radiation in the experimental areas are:

- Accidental Beam loss $4 \times 10^{14}$ protons at $20 \mathrm{TeV}$. : Assumed to happen at most once per year and that the entire beam is dumped at a point (worst case) anywhere along the beam path in the hall;

- Hadronic interactions $2 \times 10^{16}$ at $40 \mathrm{TeV}$ per year at the center of the detector. The number assumes $4 \times 10^{14}$ protons per bunch and a luminosity of $10^{34} \mathrm{~cm}^{-2} \mathrm{~s}^{-1}$ at a low- $\beta$ interaction region.

The calculation converting proton interactions to radiation does are made using the formula* :

$$
H=6.9 \times 10^{-13} E 0.8 \frac{\mathrm{e}^{-(R-a) / \lambda}}{R^{2}}
$$

where $E$ is the proton energy, $\mathrm{R}$ is the radius from the center of the tunnel, $a$ is the radius of the tunnel, and $\lambda$ is an effective absorption length; $R-a$ is then the absorber thickness. Additional shielding from the tunnel wall and the magnets, etc. is not taken into account.

For evaluating shielding by soil, $\lambda$ can be calculated:

$$
\lambda=\frac{117 \mathrm{gm} \mathrm{cm}^{-2}}{\rho}
$$

Typical soil densities are in the range of $\geq 1.8-2.4 \mathrm{gm} \mathrm{cm}^{-3}$, yielding absorption lengths in the range of from 65 to $49 \mathrm{~cm}$. For other materials: concrete is treated as a 'soil' with a $\rho=2.5 \mathrm{gm} \mathrm{cm}^{-3}(\lambda \sim 47 \mathrm{~cm})$; iron, $\lambda=17 \mathrm{~cm}$; and, uranium, $\lambda=11 \mathrm{~cm}$.

\section{D.2 Hadronic Interactions}

The radiation does from proton-proton interactions at the intersection point is calculated assuming the parameters of the Model Detector. In the central part of the detector, the intersection point is surrounded by dense material: the 'precision calorimeter' is taken to be seven absorption lengths deep, the iron flux return/'hadron catcher' calorimeter is five absorption lengths, and the iron 'muon filter' is more than 15 absorption lengths, for

* Ref. to G. Stevenson in SSC-SR-1026. 
a total of greater than 27 absorption lengths. Since the proton-proton interaction described here can only take place at the intersection point, the radiation produced by the $2 \times 10^{16}$ proton interactions/year at $40 \mathrm{TeV}$ is well shielded by the detector material. In the absence of a detector, the interaction region could be shielded at the required level with about $8.5 \mathrm{~m}$ of concrete close to the beam pipe (within $25 \mathrm{~cm}$ ). Alternatively, the shielding could be external to the hall. If we assume that the hall is a cylinder of radius $12 \mathrm{~m}$ and use soil as the shielding, a thickness of roughly $8.75 \mathrm{~m}$ of soil (density $\rho=$ $2.24 \mathrm{gm} \mathrm{cm}^{-3}$ ) is required at the closest point.

\section{D3. Beam Loss in the Collision Hall}

If one assumes a beam loss of $4 \times 10^{14}$ protons at $20 \mathrm{TeV}$ at a single point, the energy deposition and produced radiation are less than the integral dose from hadronic interactions, and hence the detector shielding is sufficient for beam loss at the intersection

point (or the concrete used in the case of no detector.) However, if the beam loss were to occur at a point not shielded by the detector - such as between the central detector and the intermediate muon toroids, or between the intermediate toroid and the forward spectrometer-additional shielding is necessary. To protect against beam loss at these points, roughly $7 \mathrm{~m}$ of concrete is required. This is most economically placed as close to the beam pipe as practical but detector considerations may dictate other locations.

A schematic drawing of the Model Detector outline and shielding is shown in Fig. D1.

\section{D4. Radiation From the Beam Collimators}

The energy flux due to secondary and scattered particles from collisions at the intersection region is highly collimated in the forward direction. To reduce the heat load on the quadrupoles from these processes, a tungsten collimator is placed in front of the focussing magnets. Interactions in the collimator are equivalent to $6 \times 10^{14}$ interacting protons at $20 \mathrm{TeV}$ per year. ${ }^{*} \quad$ Shielding requirements for this source are equivalent to $6.8 \mathrm{~m}$ of concrete placed $0.5 \mathrm{~m}$ from the beam line. If we then assume a worst case of total beam loss at the collimator in addition to the rate from the interaction point, the shielding needs to be increased by less than $0.5 \mathrm{~m}$.

\section{D5. Soft Neutrons - 'Skyshine'}

The region beyond the muon iron of the detector is shielded by an additional concrete 'skin' to aborb/reflect the remnant low energy neutron flux. This 'skyshine'

\footnotetext{
* D. Groom, private communication
} 
shielding is roughly one meter of concrete ${ }^{\dagger}$ which could be the outer layer of the detector or comprise a collision hall ceiling (or assembly hall floor).

\section{D6. Air Activation}

The issue of air activation has not yet been studied in detail. To avoid significant path length in air for particles from the IR, closely placed shielding is desirable. In the schematic detector/shielding design discussed above, the only areas with appreciable air space near the IR are the conical regions to the forward and backward spectrometers. Helium bags or vacuum would reduce this considerably.

$\dagger$ This is the 'canonical' thickness of skyshine shielding (T. Toohig, private communication). 